Keywords: high-level waste, peroxotitanate, irradiation, gas release, settling, desorption

Retention: Permanent

\title{
Tailoring Inorganic Sorbents for SRS Strontium and Actinide Separations: Modified Monosodium Titanate Phase III Final Report
}

K. M. L. Taylor-Pashow

D. T. Hobbs

September 2010

Savannah River National Laboratory

Savannah River Nuclear Solutions

Aiken, SC 29808

Prepared for the U.S. Department of Energy under contract number DE-AC09-08SR22470.

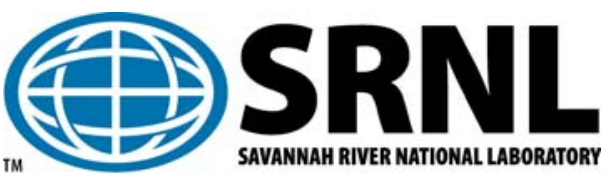




\section{DISCLAIMER}

This work was prepared under an agreement with and funded by the U.S. Government. Neither the U.S. Government or its employees, nor any of its contractors, subcontractors or their employees, makes any express or implied:

1. warranty or assumes any legal liability for the accuracy, completeness, or for the use or results of such use of any information, product, or process disclosed; or

2. representation that such use or results of such use would not infringe privately owned rights; or

3. endorsement or recommendation of any specifically identified commercial product, process, or service.

Any views and opinions of authors expressed in this work do not necessarily state or reflect those of the United States Government, or its contractors, or subcontractors.

\section{Printed in the United States of America \\ Prepared for U.S. Department of Energy}




\section{REVIEWS AND APPROVALS}

AUTHORS:

K. M. L. Taylor-Pashow, Separations and Actinide Science Program

Date

D. T. Hobbs, Separations and Actinide Science Program

Date

TECHNICAL REVIEW:

T. B. Peters, Separations and Actinide Science Program

Date

APPROVALS:

S. D. Fink, Manager

Date

Separations and Actinide Science Program

S.L. Marra, Manager

Date

Environmental \& Chemical Process Technology Research Programs 


\section{EXECUTIVE SUMMARY}

This document provides a final report of Phase III testing activities for the development of modified monosodium titanate (mMST), which exhibits improved strontium and actinide removal characteristics compared to the baseline MST material. The activities included characterization of the crystalline phases present at varying temperatures, solids settling characteristics, quantification of the peroxide content; evaluation of the post-synthesis gas release under different conditions; the extent of desorption of ${ }^{85} \mathrm{Sr}, \mathrm{Np}$, and $\mathrm{Pu}$ under washing conditions; and the effects of age and radiation on the performance of the mMST. Key findings and conclusions include the following.

The peroxide content of several mMST samples was determined using iodometric titration. The peroxide content was found to decrease with age or upon extended exposure to elevated temperature. A loss of peroxide was also measured after exposure of the material to an alkaline salt solution similar in composition to the simulated waste solution.

To determine if the loss of peroxide with age affects the performance of the material, $\mathrm{Sr}$ and actinide removal tests were conducted with samples of varying age. The oldest sample (4 years and 8 months) did show lower $\mathrm{Sr}$ and $\mathrm{Pu}$ removal performance. When compared to the youngest sample tested (1 month), the oldest sample retained only $15 \%$ of the DF for Pu. Previous testing with this sample indicated no decrease in Pu removal performance up to an age of 30 months. No loss in Np removal performance was observed for any of the aged samples, and no uptake of uranium occurred at the typical sorbent loading of $0.2 \mathrm{~g} / \mathrm{L}$. Additional testing with a uranium only simulant and higher mMST loading $(3.0 \mathrm{~g} / \mathrm{L})$ indicated a $10 \%$ increase of uranium uptake for a sample aged 3 years and 8 months when compared to the results of the same sample measured at an age of 1 year and 5 months.

Performance testing with both baseline-MST and mMST that had been irradiated in a gamma source to a total dose of $3.95 \times 10^{6} \mathrm{R}$, indicated little to no affect on the performance of the material to remove $\mathrm{Sr}$ and actinides.

Previous testing established that mMST releases oxygen gas during the synthesis, and continues to off-gas during storage post synthesis. The post-synthesis gas release rate was measured under several conditions, including varying the $\mathrm{pH}$ of the wash water and at elevated temperature $\left(49^{\circ} \mathrm{C}\right.$, typical of bounding summertime storage without air conditioning). Results indicated that a high $\mathrm{pH}$ (basic) wash reduced the initial gas release rate, but after 2 days the release rates from all different $\mathrm{pH}$ washed samples were not statistically different. The gas release rate at $49{ }^{\circ} \mathrm{C}$, a temperature at which the material may be exposed to during shipping and storage, was consistently about 2.5 times higher than the rate at room temperature. All gas release results indicated that vented containers would be necessary for shipping and storage of large quantities of material.

Suspension of sorbate-loaded solids into diluted solutions representing intermediate and final stages of washing for 24-hours revealed no evidence of desorption of $\mathrm{Sr}, \mathrm{Pu}$ or $\mathrm{Np}$ from the mMST solids.

Based on the results of the Phase III testing as well as that from earlier studies (Phases I and II), SRNL researchers recommend adopting the use of the mMST material for the removal of strontium and actinides from the SRS HLW supernatant liquids in the Actinide Removal Process and Salt Waste Processing Facility. Given the decrease in $\mathrm{Sr}$ and $\mathrm{Pu}$ removal performance for the 
mMST having an age of 4 years and 8 months, we recommend that mMST be used within 30 months of production. Furthermore we recommend that DOE provide funding to conduct pilotscale testing of the mixing and settling characteristics of the mMST and impact, if any, on the generation of hydrogen during processing in the Defense Waste Processing Facility (DWPF). 


\section{TABLE OF CONTENTS}

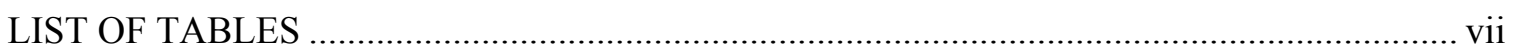

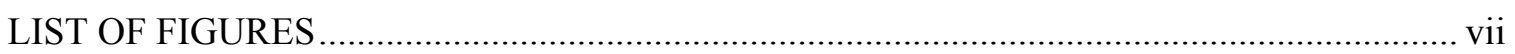

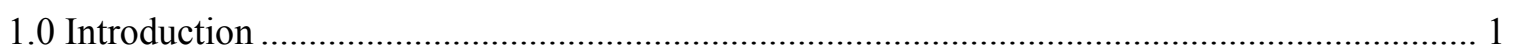

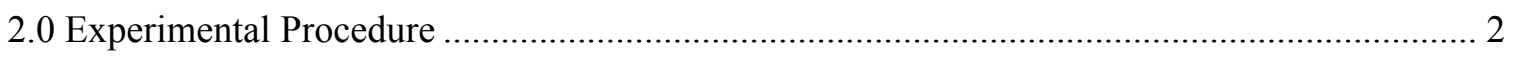

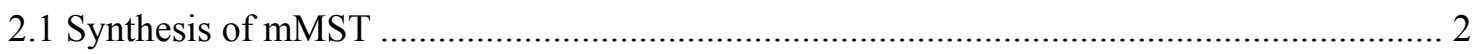

2.2 High Temperature X-Ray Diffraction Analyses (HTXRD) .............................................. 2

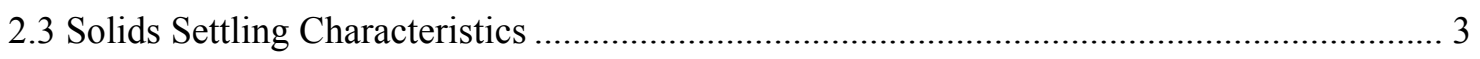

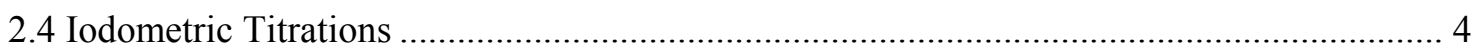

2.5 Effect of Alkaline Solution on Peroxide Content ................................................................ 4

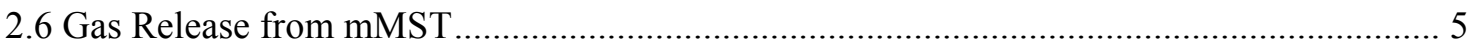

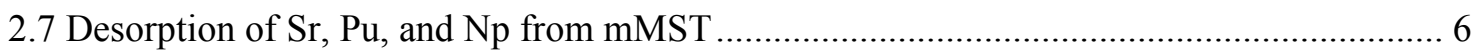

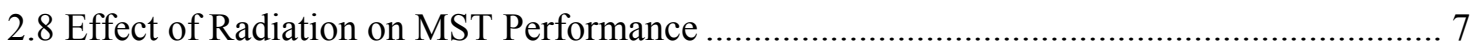

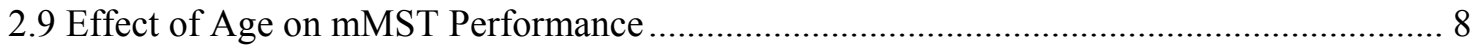

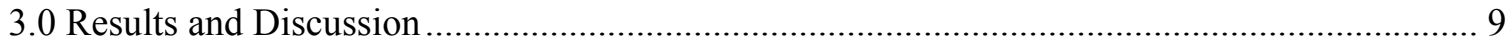

3.1 High Temperature X-Ray Diffraction Analyses (HTXRD) ${ }^{14}$........................................... 9

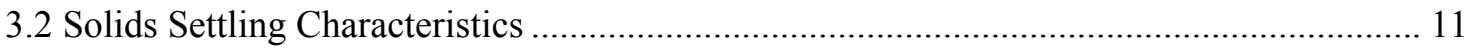

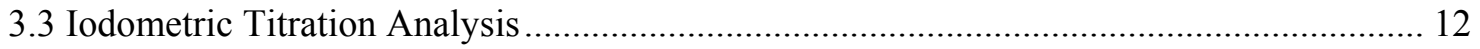

3.4 Gas Release

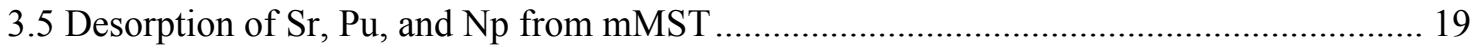

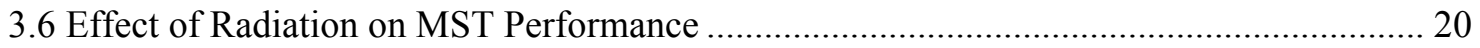

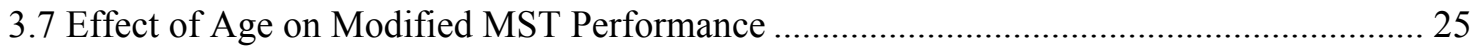

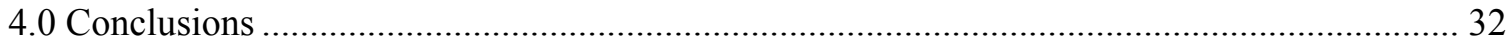

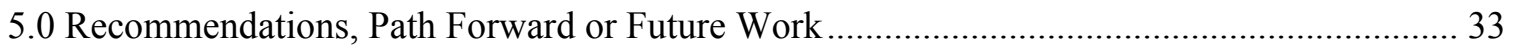

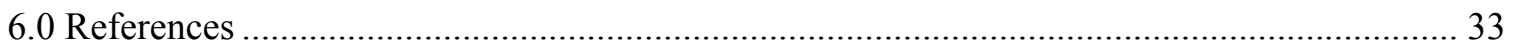

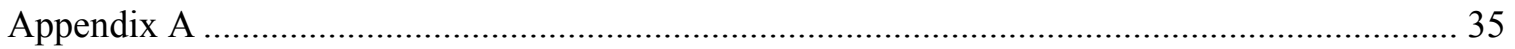




\section{LIST OF TABLES}

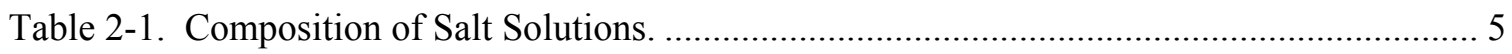

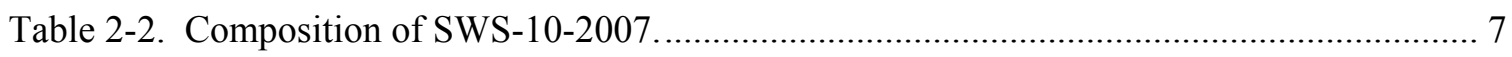

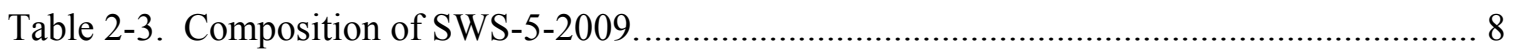

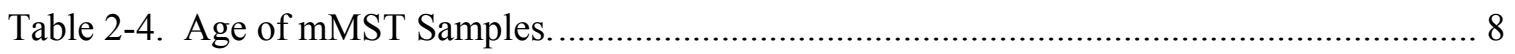

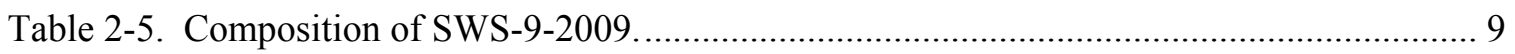

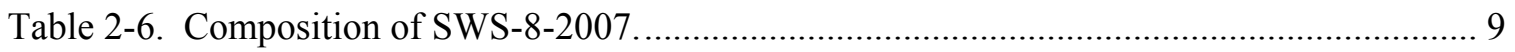

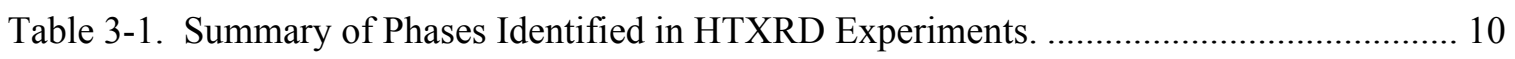

Table 3-2. Results of Settled Density Measurements for mMST............................................ 11

Table 3-3. mMST Samples, Age and Peroxide Content.......................................................... 13

Table 3-4. Summary of titration results from samples with varying $\mathrm{H}_{2} \mathrm{O}_{2}$ :Ti ratios.................... 14

Table 3-5. Peroxide:Ti Ratios for mMST Optima Batch 06-QAB-0139. .................................. 15

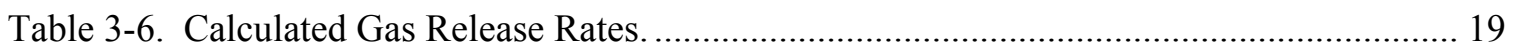

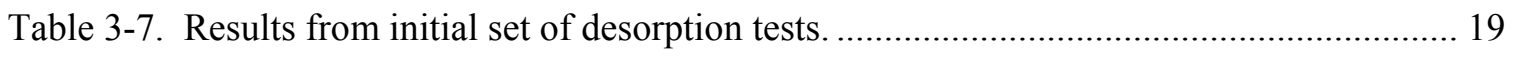

Table 3-8. Results from additional desorption tests with more dilute solutions. ........................ 20

Table 3-9. Summary of DFs. Uncertainty column represents one sigma uncertainty................ 25

Table 3-10. Pu DF Over Time for mMST Sample LS-2 .......................................................... 29

\section{LIST OF FIGURES}

Figure 1. Photograph of gas release apparatus - round bottom flask design. .............................. 6

Figure 2. Photograph of gas release apparatus - cylindrical plastic tube design. ........................ 6

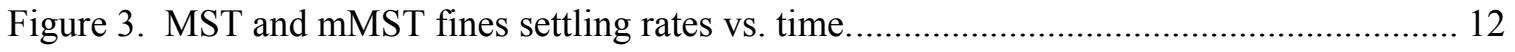

Figure 4. Peroxide content of mMST samples vs. age

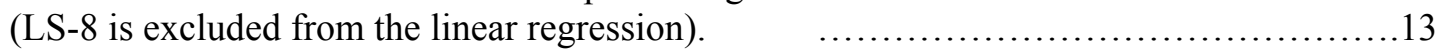

Figure 5. Peroxide:Ti molar ratio in product vs. peroxide:Ti molar ratio in synthesis. ............... 14

Figure 6. Gas release rate (log scale) versus elapsed time for mMST in round bottom flask apparatus (LS-9, blue) and cylindrical plastic tube apparatus (LS-5, red) ............................ 16

Figure 7. Gas release rate (log scale) versus elapsed time for $\mathrm{pH} 4$ washed mMST (LS-6)....... 17 
Figure 8. Gas release rate (log scale) versus elapsed time for $\mathrm{pH} 10$ washed mMST (LS-7)..... 17

Figure 9. Gas release rate (log scale) versus elapsed time for mMST (LS-8) at $49{ }^{\circ} \mathrm{C} \ldots \ldots \ldots \ldots . . . . . . .18$

Figure 10. Comparison of gas release rates from LS-5, LS-6, LS-7, LS-8, and LS-9................. 18

Figure 11. Sr concentration vs. contact time, log scale. Error bars indicate 1 sigma uncertainty.

Figure 12. U concentration vs. contact time. Error bars indicate 1 sigma uncertainty................ 22

Figure 13. Np concentration vs. contact time. Error bars indicate 1 sigma uncertainty.............. 23

Figure 14. Pu concentration vs. contact time, log scale. Error bars indicate 1 sigma uncertainty.

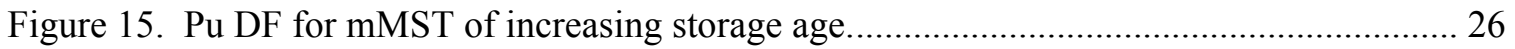

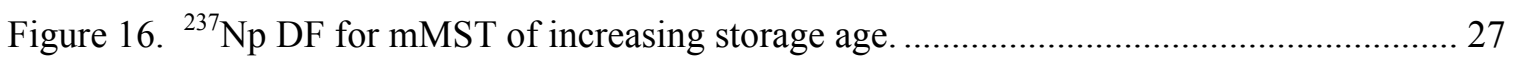

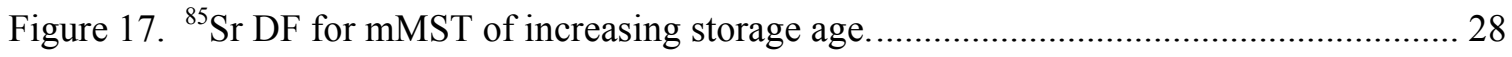

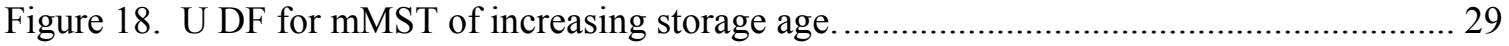

Figure 19. Pu DF for LS-2 as a function of elapsed time since preparation............................... 30

Figure 20. Uranium decontamination factors for MST (Optima 00-QAB-417) measured in

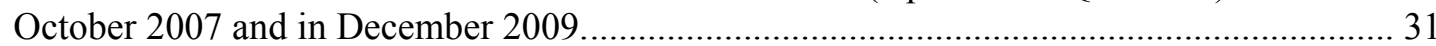

Figure 21. Uranium decontamination factors for mMST (Optima 06-QAB-0139) measured in

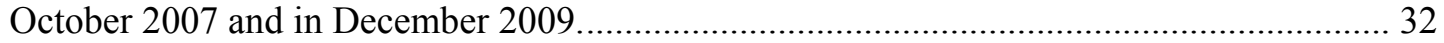

Figure A-1. Height of clear solution at top of settling test versus elapsed time for mMST and

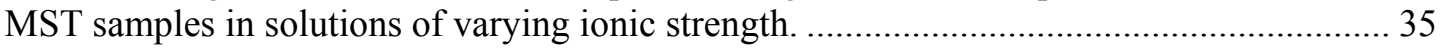

Figure A-2. Sr DF vs. contact time, calculated from gamma scan results. Error bars indicate 1

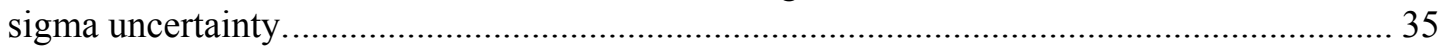

Figure A-3. U DF vs. contact time, calculated from ICP-MS results. Error bars indicate 1 sigma

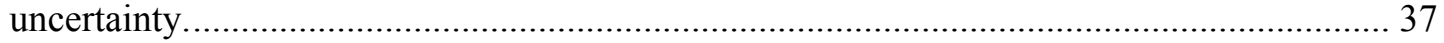

Figure A-4. Np DF vs. contact time, calculated from ICP-MS results. Error bars indicate 1 sigma

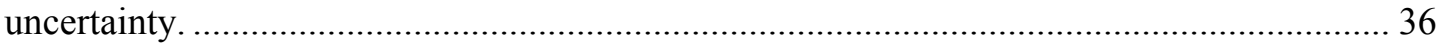

Figure A-5. Pu DF vs. contact time, calculated from PuTTA results. Error bars indicate 1 sigma uncertainty.

Figure A-6. Pu concentration versus contact time for mMST samples of increasing storage age.

Figure A-7. ${ }^{237} \mathrm{~Np}$ concentration versus contact time for mMST samples of increasing storage age.

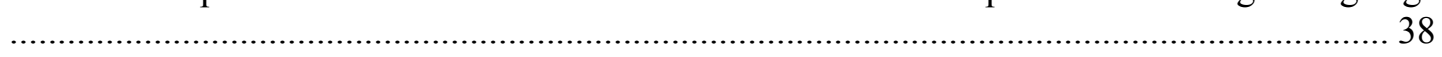

Figure A-8. ${ }^{85} \mathrm{Sr}$ activity versus contact time for mMST samples of increasing storage age. All values for LS-8 (0.19 y) and LS-9 (0.09 y) were below the method detection limit.............. 38 
Figure A-9. U concentration versus contact time for mMST samples of increasing storage age. 39

Figure A-10. Uranium concentration versus contact time for mMST and MST measured in December 2009 and October 2007.

\section{LIST OF ABBREVIATIONS}

$\begin{array}{ll}\text { ARP } & \text { Actinide Removal Project } \\ \text { DOE } & \text { Department of Energy } \\ \text { DF } & \text { decontamination factor } \\ \text { DWPF } & \text { Defense Waste Processing Facility } \\ \text { HDPE } & \text { high density polyethylene } \\ \text { HLW } & \text { High Level Waste } \\ \text { ICP-MS } & \text { inductively coupled plasma - mass spectroscopy } \\ \text { ITP } & \text { In-Tank Precipitation } \\ \text { MST } & \text { monosodium titanate } \\ \text { mMST } & \text { modified monosodium titanate } \\ \text { PuTTA } & \text { plutonium thenoyltrifluoroacetone scintillation } \\ \text { PVDF } & \text { polyvinylidene fluoride } \\ \text { SMP } & \text { Submersible Mixer Pump } \\ \text { SNL } & \text { Sandia National Lab } \\ \text { SRS } & \text { Savannah River Site } \\ \text { SRNL } & \text { Savannah River National Laboratory } \\ \text { SWPF } & \text { Salt Waste Processing Facility } \\ \text { TTP } & \text { Telescoping Transfer Pump }\end{array}$




\subsection{Introduction}

MST is an inorganic sorbent material that exhibits high selectivity for strontium and actinide elements in the presence of strongly alkaline and high sodium containing salt solutions. ${ }^{1,2}$ The Savannah River Site (SRS) selected this material for strontium and plutonium removal from highlevel waste solutions in the early 1980s as part of the In-Tank Precipitation (ITP) process. ${ }^{3}$ In 2001, the Department of Energy (DOE) selected MST for the strontium/actinide separation step within the Salt Waste Processing Facility (SWPF). ${ }^{4}$ Subsequently, Salt Processing Program Engineering selected MST for use in the Actinide Removal Process (ARP) to treat waste solutions low in cesium activity in a treatment facility located in Building 512-S. ${ }^{5}$

Original development of MST at Sandia National Laboratory (SNL) produced a dried powder. Unpublished studies conducted by L. L. Kilpatrick and D. T. Hobbs during the 1980s indicated that air drying of the MST at elevated temperature $\left(>100{ }^{\circ} \mathrm{C}\right)$ adversely impacted strontium removal performance. Principally due to the poorer sorption characteristics of MST dried at elevated temperature, procurement of MST at SRS for the ITP process specified that the vendor prepare and isolate the material without drying and deliver the MST as an aqueous solution containing $10-20 \mathrm{wt} \%$ MST solids. ${ }^{6}$

The proposed SWPF and existing ARP facilities have significantly different reactor configurations and process cycle times than the abandoned ITP operation. In particular, contact times between the MST and the alkaline waste solutions in the SWPF and ARP will be less than 12 hours versus approximately 2 weeks in the ITP process. Increased waste characterization data indicates that alpha removal characteristics (and principally plutonium removal) represent a greater challenge than that for ${ }^{90} \mathrm{Sr}$ removal. Based on recent testing at Savannah River National Laboratory (SRNL), the performance of MST to efficiently and rapidly remove alpha-emitting radionuclides serves as the limiting factor in operational throughput. Even higher alpha activities are projected for the SWPF and ARP operations as a result of initiatives to accelerate the disposal of HLW at SRS. Due to the limited solubility of titanium in HLW borosilicate glass, there are limits on the amount of MST that can be used in SWPF and ARP facilities. ${ }^{7}$ Consequently, the need exists for an improved $\mathrm{Sr} /$ alpha removal material that exhibits increased actinide capacity and removal kinetics.

In 2003 the DOE Office of Cleanup Technologies (EM-31) funded a project to develop improved sorbent materials for strontium/actinide separations at SRS. ${ }^{8}$ This work identified a methodology for modifying the synthesis of MST to produce materials that exhibited significantly improved performance for strontium and actinide removal. Improved performance included both increased effective capacity and sorption kinetics. Preliminary evaluation of the use of the modified MST materials for the treatment of SRS high-level waste (HLW) in the ARP facility suggested that the throughput could be increased by as much as a factor of three. With these promising results, the DOE Office of Cleanup Technologies funded SRNL to continue development of the modified MST materials under a Phase II project. Phase II testing demonstrated the scale up of the synthesis of mMST to a vendor prepared pilot scale batch $(15 \mathrm{~kg})$ along with demonstration of the strontium and actinide removal characteristics with actual tank waste supernate and measurement of filtration characteristics. ${ }^{9,10}$ Additional funding allowed for continuation of the development of mMST under a Phase III project. Phase III testing included evaluation of the performance of mMST under varying conditions, evaluation of the desorption of sorbates under washing conditions, evaluation of the post-synthesis gas release, determination of the crystalline phases present in the material at varying temperatures, determination of the solids settling characteristics, 
and characterization of the peroxide content. Initial results from Phase III testing were documented in an earlier report. ${ }^{11}$ This report provides a summary of the tasks completed in FY09 and FY10.

\subsection{Experimental Procedure}

\subsection{Synthesis of mMST}

The baseline MST used in these studies was prepared using a sol-gel process developed at the Savannah River National Laboratory (SRNL) and supplied by Optima Chemical Group LLC (Douglas, GA, Lot \#00-QAB-417) as a $15 \mathrm{wt} \%$ suspension in water containing $0.10-0.15 \mathrm{M}$ $\mathrm{NaOH}$ and $100-150 \mathrm{mg} \mathrm{L}^{-1} \mathrm{NaNO}_{2}{ }^{12}$ Modified monosodium titanate (mMST) used in these studies was prepared by the post-synthesis treatment of MST with hydrogen peroxide. The details of this procedure have been previously published. ${ }^{13}$ Bench-scale quantities of the mMST were prepared using 25 grams of the Optima-supplied MST. Optima Chemical Group LLC (Douglas, GA) also produced a pilot-scale quantity (15 kg) of mMST, Lot \#06-QAB-0139, as a $15 \mathrm{wt} \%$ suspension in water using the same conditions as used for the bench-scale preparations.

Six small scale batches of mMST were also synthesized with varying hydrogen peroxide:Ti molar ratios, $0.25: 1,0.5: 1,1: 1,2: 1,3: 1,4: 1$ for characterization of peroxide content. Earlier development of mMST lead to the choice of $3: 1$ as the optimal $\mathrm{H}_{2} \mathrm{O}_{2}:$ Ti molar ratio, and this ratio was used for the synthesis of the commercial scale batch of mMST (Optima 06-QAB-0139), and other larger scale lab prepared samples (LS series). The mMST samples were synthesized by adding the appropriate amount of a $30 \mathrm{wt} \%$ solution of hydrogen peroxide dropwise to approximately $10 \mathrm{~g}$ of a $15 \mathrm{wt} \%$ suspension of baseline MST (Optima 00-QAB-417). The MST had been previously isolated and washed, and the washed MST was then redispersed in water. The $\mathrm{pH}$ of the MST suspension was adjusted to 7 before the addition of peroxide. After the peroxide addition was complete, the slurries were stirred at room temperature for 24 hours. The products were then isolated by centrifuging (4400 rpm for $15 \mathrm{~min}$.) and were washed 6 times with distilled water. After the final wash, the mMST samples were redispersed in water, and the $\mathrm{pH}$ of each suspension was adjusted to 4 with $1 \mathrm{M}$ nitric acid. The suspensions were diluted to a final mass of approximately $10 \mathrm{~g}$, and the weight percentages of solids were determined.

\subsection{High Temperature X-Ray Diffraction Analyses (HTXRD)}

The X-ray diffraction data (XRD) were collected on a theta-theta PANalytical X'Pert Pro X-ray diffractometer using an Anton Paar HTK 1200 high temperature attachment. ${ }^{14}$ Instead of fixing the sample on a resistively heated platinum strip, the sample cup was placed in a uniformly heated sample chamber in the camera. A type $\mathrm{S}$ thermocouple was inserted into the chamber near the sample cup to monitor the sample temperature. This configuration eliminates most of the sample temperature gradients observed in ribbon style high temperature attachments. The alumina sample cup has a well that is $0.4 \mathrm{~mm}$ deep. The instrument was scanned over a $5-70^{\circ} 2 \theta$ range with a $0.0167^{\circ}$ step size and a dwell time of $99.695 \mathrm{~s} / 2.122^{\circ}(2 \theta)$ for a total measurement time of $\sim 25$ minutes. The large dwell time with short analysis time was achieved using the $\mathrm{X}^{\prime}$ Celerator ${ }^{\mathrm{TM}}$ detector that has a $2.122^{\circ}(2 \theta)$ active length and operates as if there were an array of over a hundred detectors working simultaneously. High temperature x-ray diffraction scans were performed at seven temperatures: $25,75,125,250,300,600$, and $800{ }^{\circ} \mathrm{C}$. All the HTXRD scans were performed under an ultra-pure $(>99.999 \%)$ helium purge. After the powder sample had cooled to room temperature, the powder residue was ground into a fine powder and analyzed using a conventional XRD arrangement. A detailed compilation of all the instrument parameters is included in Table 1. Compound search-match identification was performed with Jade ${ }^{\mathrm{TM}}$ 
software (Version 9) from Materials Data Inc. using the latest inorganic PDF4 ${ }^{\mathrm{TM}}$ powder diffraction database from the International Centre for Diffraction Data (ICDD).

A temperature calibration curve was generated for the helium atmosphere to correct for any temperature gradients in the high temperature attachment and any thermal lag between the measured and set-point temperatures. The phase transition temperatures and melting points for several recommended compounds routinely referenced by the X-ray diffraction community were used to construct calibration curves for He. ${ }^{15,16}$ The observed temperatures were $\sim 4-30{ }^{\circ} \mathrm{C}$ low in helium with the smallest $\Delta \mathrm{T}$ at low temperatures. All the temperature data were corrected.

Two samples of both baseline and modified MST were analyzed. The first two samples were the commercially prepared materials as received (Optima 00-QAB-417 and Optima 06-QAB-0139). The second two samples were samples of these commercially prepared batches that had been $\mathrm{pH}$ adjusted. The baseline MST is received as a $\mathrm{pH} 10$ slurry and the mMST is received as a $\mathrm{pH} 4$ slurry. For the HTXRD experiments samples of MST were adjusted to $\mathrm{pH} 4$ and samples of mMST were adjusted to $\mathrm{pH} 10$, so that comparisons could be made between the two materials at the same $\mathrm{pH}$ values. All samples were dried prior to analysis.

\subsection{Solids Settling Characteristics}

Two tests were completed to examine the settling characteristics of mMST in simulated salt solutions, with sodium concentrations of $0.5,4.6,5.6$, and $6.6 \mathrm{M}$. The first test involved determination of the settled solids density. For this experiment, aliquots of mMST (Optima 06QAB-0139) were added to $15-\mathrm{mL}$ centrifuge tubes. The solids were washed once with the appropriate salt solution (5 mL), either SWS-11-2008 (5.6 M Na) or SWS-12-2008-2 (0.5 M Na), and were re-isolated by centrifugation at $3000 \mathrm{rpm}$. After decanting the solution, $10-\mathrm{mL}$ aliquots of the salt solutions were added to the washed solids. The contents were then gently mixed to suspend all the solids. Each suspension was then centrifuged at either $6.3 \mathrm{x} g$ or $1400 \mathrm{xg}$ for 10 minutes. The volume of the settled solids was then measured. Without disturbing the settled solid plug in the bottom of the centrifuge tube, the tube was returned to the centrifuge, and was centrifuged for an additional 5 minutes at the appropriate speed. The tubes were removed and the volume of settled solids was again measured. This process was repeated until no additional change in the settled solids volume was observed.

Table 2-1. Composition of Salt Solutions Used for Settling Tests.

\begin{tabular}{||c|c|c|c||}
\hline Component & Units & SWS-11-2008 & SWS-12-2008-2 \\
\hline $\mathrm{NaNO}_{3}$ & $M$ & 2.60 & 0.232 \\
\hline $\mathrm{NaOH}$ & $M$ & 1.33 & 0.118 \\
\hline $\mathrm{Na}_{2} \mathrm{SO}_{4}$ & $M$ & 0.521 & 0.046 \\
\hline $\mathrm{NaAl}_{4}(\mathrm{OH})_{4}$ & $M$ & 0.429 & 0.038 \\
\hline $\mathrm{NaNO}_{2}$ & $M$ & 0.134 & 0.012 \\
\hline $\mathrm{Na}_{2} \mathrm{CO}_{3}$ & $M$ & 0.026 & 0.002 \\
\hline Total Na & $M$ & 5.6 & 0.50 \\
\hline
\end{tabular}

The second set of tests examined the solid settling rate as a function of time in three salt solutions with $\mathrm{Na}$ concentrations of 4.6, 5.6, and $6.6 \mathrm{M}$. For these experiments aliquots of mMST and MST were placed in graduated cylinders along with $90 \mathrm{~mL}$ of the appropriate salt solutions, giving final mMST and MST concentrations of $0.53 \mathrm{~g} / \mathrm{L}$. This concentration of solids was selected to be consistent with earlier settling rate studies performed with MST. ${ }^{17}$ Each cylinder 
was capped, and shaken to disperse the solids. The graduated cylinders were then placed on the bench top, and the level of the liquid-solid interface was monitored as a function of time. During the tests two interfaces were observed, one between the cloudy slurry and the clear supernate at the top which is indicative of the smallest, slowest settling particles (fines), and one between the concentrated slurry and cloudy slurry located at the bottom of the graduated cylinder. This bottom interface is indicative of the largest fastest settling particles.

\subsection{Iodometric Titrations}

Iodometric titrations were performed using several mMST samples. The general procedure for the titrations involved first performing the reaction between sodium iodide and peroxide to form iodine, which was then titrated with sodium thiosulfate using starch as an indicator. See reactions 1 and 2 below. An aliquot of a known weight percent suspension of mMST was placed in a $25-\mathrm{mL}$ volumetric flask. The amount of suspension added corresponded to between 0.3 and $0.4 \mathrm{~g}$ of mMST. The suspension was then diluted to an approximate volume of $15-20 \mathrm{~mL}$ with distilled water. Next, $0.42 \mathrm{~mL}$ of $18 \mathrm{M}$ sulfuric acid was added to the suspension, and the sample was then diluted to the 25-mL mark with additional distilled water. This suspension was then transferred to a glass vessel containing a stir bar, and $25 \mathrm{~mL}$ of a $0.27 \mathrm{M}$ solution of sodium iodide was added. This reaction was then stirred at room temperature for a minimum of 17 hours. Aliquots of the reaction mixture were then removed and titrated with a $0.1 \mathrm{M}$ solution of sodium thiosulfate, using starch as an indicator. All titrations were performed in triplicate.

$$
\begin{array}{r}
\mathrm{H}_{2} \mathrm{O}_{2}+2 \mathrm{I}^{-}+2 \mathrm{H}^{+} \rightarrow \mathrm{I}_{2}+2 \mathrm{H}_{2} \mathrm{O} \\
2 \mathrm{Na}_{2} \mathrm{~S}_{2} \mathrm{O}_{3}+\mathrm{I}_{2} \rightarrow \mathrm{Na}_{2} \mathrm{~S}_{4} \mathrm{O}_{6}+2 \mathrm{NaI}
\end{array}
$$

Control experiments were also performed without any material, i.e. just sulfuric acid and sodium iodide, and also with baseline MST, which contains no peroxide. No measurable amount of $\mathrm{I}_{2}$ was formed in the blank control experiment; however, the baseline MST did cause the formation of iodine from $\mathrm{NaI}$ under the reaction conditions. Experiments were also performed using the supernatant from mMST and MST slurries, and also dried samples of MST. The results from the supernatant titrations indicated no formation of $\mathrm{I}_{2}$ from the mMST supernatant, confirming there was no free hydroxide in the supernatant. Reaction of the MST supernatant did lead to the formation of $I_{2}$, while the dried sample of MST did not. The formation of $I_{2}$ in the MST supernatant experiment is due to the presence of $\mathrm{NaNO}_{2}$ added to the commercially prepared MST as a corrosion inhibitor. See reaction 3.

$$
2 \mathrm{HNO}_{2}+2 \mathrm{H}^{+}+2 \mathrm{I}^{-} \rightarrow \mathrm{I}_{2}+2 \mathrm{NO}+2 \mathrm{H}_{2} \mathrm{O}
$$

\subsection{Effect of Alkaline Solution on Peroxide Content}

A series of experiments were also performed to determine how much of the peroxide was lost upon exposure to alkaline salt solutions, such as the simulated waste solutions used for performance testing. For these experiments, aliquots of mMST suspension (Optima Batch 06QAB-0139), corresponding to $0.10 \mathrm{~g}$ of mMST solid, were added to $500 \mathrm{~mL}$ volumes of several salt solutions. The mixtures were then stirred at room temperature for 24 hours. The mMST solids were isolated by filtration through a $0.2-\mu \mathrm{m}$ membrane, and were washed three times with distilled water. The washed solids were then transferred to a $10-\mathrm{mL}$ volumetric flask. The solids were redispersed in water, $0.42 \mathrm{~mL}$ of $18 \mathrm{M}$ sulfuric acid was added, and the mixture was diluted to a final volume of $10 \mathrm{~mL}$. This suspension was then transferred to a glass vessel containing a stir bar, and $10 \mathrm{~mL}$ of a $0.27 \mathrm{M}$ solution of sodium iodide was added. This reaction was then stirred at room temperature for a minimum of 17 hours. Then 6-mL aliquots of the reaction 
mixture were removed and titrated with a $0.1 \mathrm{M}$ solution of sodium thiosulfate, using starch as an indicator. All titrations were performed in triplicate. The three solutions tested included SWS-1-2010, a non-radioactive salt solution containing only sodium, SWS-1-2008, a nonradioactive salt solution containing $\mathrm{Sr}$, and a control experiment using distilled water. The compositions of the salt solutions are presented in Table 2-1.

Table 2-2. Composition of Salt Solutions Used Peroxide Content Testing.

\begin{tabular}{||c|c|c|c||}
\hline Component & Units & SWS-1-2010 & SWS-1-2008 \\
\hline $\mathrm{NaNO}_{3}$ & M & 2.60 & 2.60 \\
\hline $\mathrm{NaOH}_{\mathrm{Na}} \mathrm{SO}_{4}$ & $M$ & 1.33 & 1.33 \\
\hline $\mathrm{NaAl}_{4}(\mathrm{OH})_{4}$ & $M$ & 0.581 & 0.521 \\
\hline $\mathrm{NaNO}_{2}$ & $M$ & 0 & 0.429 \\
\hline $\mathrm{Na}_{2} \mathrm{CO}_{3}$ & $M$ & 0.149 & 0.134 \\
\hline Total Na & $M$ & 0.029 & 0.026 \\
\hline Total Sr & $\mathrm{mg} \mathrm{L}^{-1}$ & 5.6 & 5.6 \\
\hline
\end{tabular}

\subsection{Gas Release from mMST}

The mMST material releases oxygen during the synthesis, and continues to offgas after the synthesis at a rapidly diminishing rate until below a measurable rate after 4 months. Several experiments were performed to measure the gas release rate under different conditions. For each experiment a $25-\mathrm{g}$ batch of mMST was synthesized, and after the work-up was immediately transferred to the gas release apparatus to begin measurements. The gas release design consisted of either a round bottom flask equipped with a magnetic stir bar (Figure 1), or a cylindrical plastic tube (Figure 2), connected to a U-tube containing water and a gas-tight syringe. As gas is released, the water in the U-tube is displaced. The volume of displaced water was then measured periodically by pulling the released gas into the gas-tight syringe, which returns the water level to the original position in the U-tube. After recording the volume, the system was vented to the atmosphere and then closed again. Time intervals were recorded between each set of measurements.

Two experiments were performed to test the effect of an acidic or alkaline wash on the gas release rate. For the acidic and alkaline wash experiments, new 25-g batches of mMST (LS-6,7) were synthesized using the standard method; however, during the work-up the material was washed with either a $\mathrm{pH} 4$ or $\mathrm{pH} 10$ solution, rather than distilled water. At the end of the workup the $\mathrm{pH}$ of the suspension was also adjusted to either 4 or 10 . The freshly prepared, washed batch of mMST was then transferred to the gas release apparatus. The cylindrical tube apparatus (Figure 2) was used for the acid washed sample (LS-6), while the round bottom flask apparatus (Figure 1) was used for the alkaline washed sample (LS-7). An additional experiment was also performed using the standard synthesis and washing with distilled water (LS-9) in the round bottom flask apparatus.

Because the material may be exposed to temperatures as high as $120^{\circ} \mathrm{F}\left(49^{\circ} \mathrm{C}\right)$ during shipping in the summer months, gas release measurements were also taken at this elevated temperature. For this experiment the vessel holding the suspension (see Figure 1) was submerged in a temperature controlled water-bath, which was held at a constant temperature of $49{ }^{\circ} \mathrm{C}$. A new 25-g batch of material (LS-8) was synthesized immediately before measurements began. 


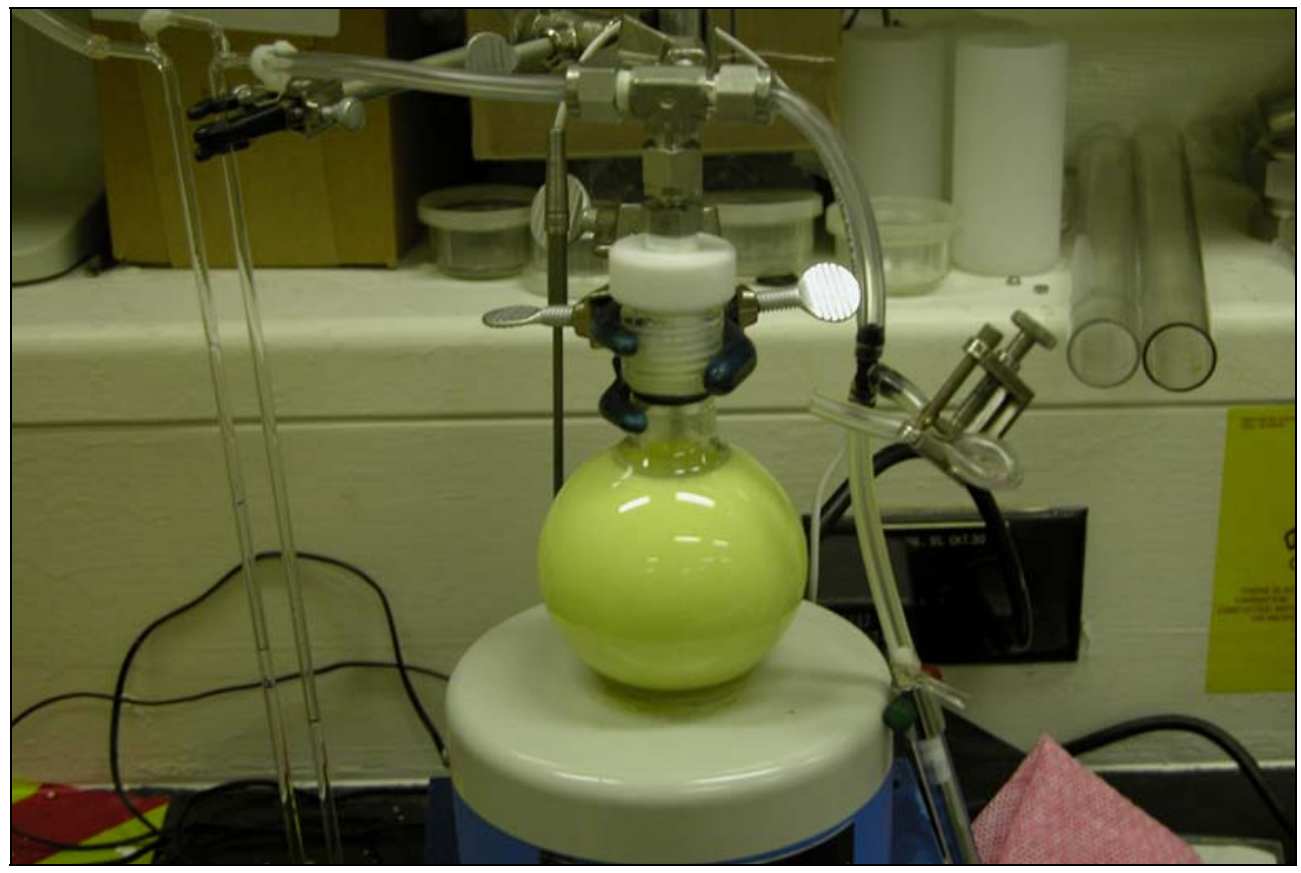

Figure 1. Photograph of gas release apparatus - round bottom flask design.
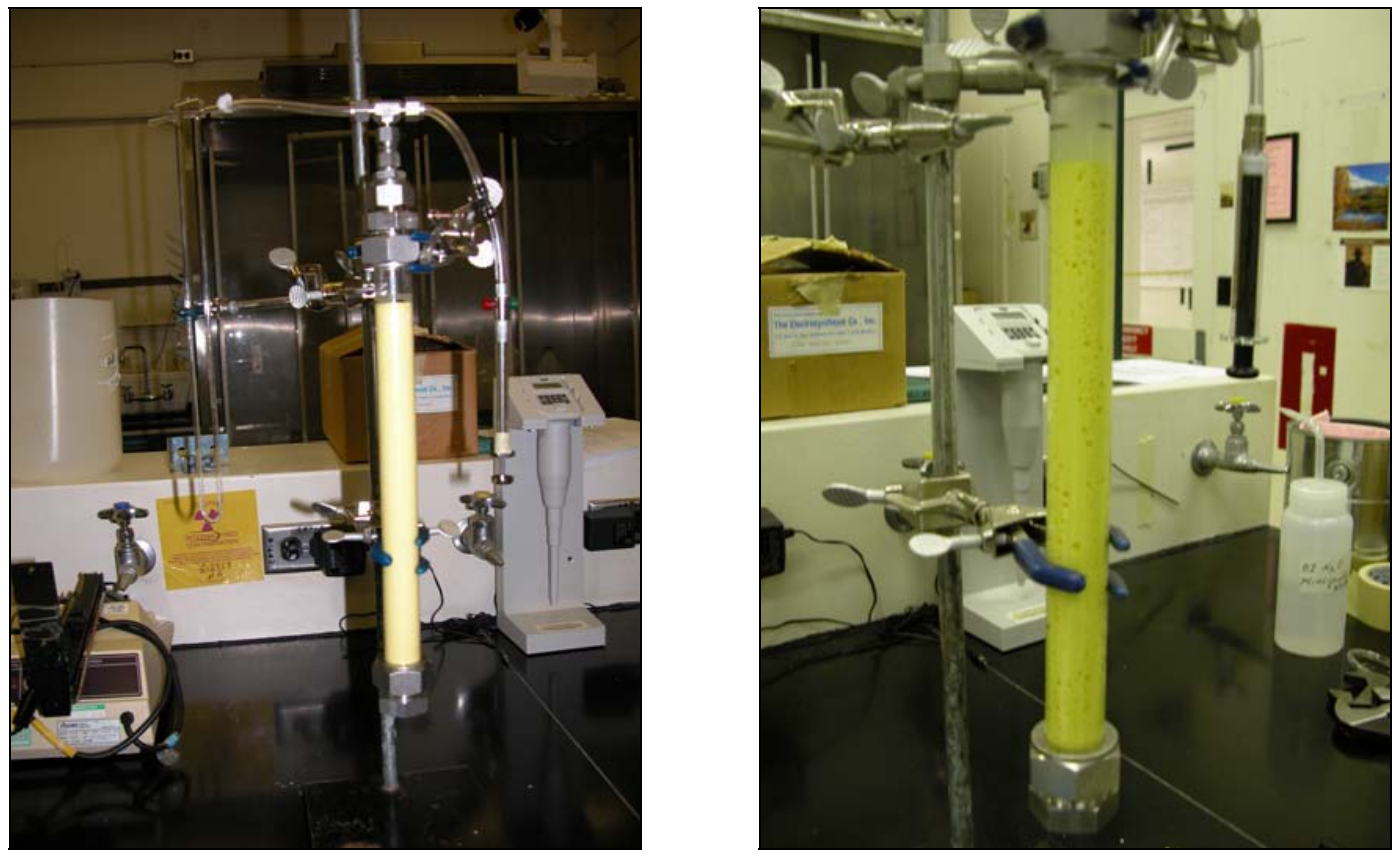

Figure 2. Photograph of gas release apparatus - cylindrical plastic tube design.

\subsection{Desorption of $\mathrm{Sr}, \mathrm{Pu}$, and $\mathrm{Np}$ from mMST}

A series of desorption experiments were performed to determine if any of the strontium or actinides that are loaded onto the mMST solids during the contact period will desorb during the washing sequence performed before sending the mMST to the DWPF for vitrification. The mMST samples were first loaded by contacting $0.2 \mathrm{~g}$ of mMST (Optima Batch 06-QAB-0139) with 1.0 L of simulated salt solution (SWS-10-2007) having the composition shown in Table 2-2. 
Three samples were loaded in this fashion using contact times of 504, 672, and 720 hours. The mMST solids were then isolated and placed into clean centrifuge tubes. The decontaminated salt solutions from each test were then diluted with ultrapure water to provide three dilutions having target Na concentrations of 2.8, 1.0, and $0.5 \mathrm{M}$. These concentrations represent dilution factors of $2,5.6$ and 11.2, and represent the intermediate and final stages of the washing sequence. Then $4 \mathrm{~mL}$ of these diluted salt solutions were added to the isolated mMST samples, which still contain some entrained undiluted decontaminated salt solution. These samples were then mixed in a water bath/shaker at $25{ }^{\circ} \mathrm{C}$ for 24 hours. The solids were then separated from the diluted salt solutions by centrifugation. The salt solutions were filtered through $0.1 \mu \mathrm{m}$ PVDF filters, and were submitted for analysis of $\mathrm{Cs}, \mathrm{Sr}, \mathrm{U}, \mathrm{Np}$, and $\mathrm{Pu}$ content using ICP-MS, gamma scan, and PuTTA analyses.

Results from the initial tests indicated that the dilutions did not reach the conditions expected in the final wash stage (i.e. [Na] of $0.5 \mathrm{M}$ ), due to higher than anticipated residual interstitial supernate. The amount of residual interstitial supernate was determined by the measured sodium concentration after adding the diluted salt solution back to the solids. Additional desorption experiments were performed with more dilute samples of the decontaminated salt solution. The samples of decontaminated salt solution were diluted to dilution factors of 10.9, 20.7, and 47.7. An $8.5-\mathrm{mL}$ aliquot of each diluted solution was added to the $0.2 \mathrm{~g}$ of the isolated mMST solids which had been previously loaded with sorbates. The samples were then mixed in a water bath/shaker at $25^{\circ} \mathrm{C}$ for 24 hours. The solids were then separated from the diluted salt solutions by centrifugation. The salt solutions were filtered through $0.1 \mu \mathrm{m}$ PVDF filters, and were submitted for analysis of $\mathrm{Cs}, \mathrm{Sr}, \mathrm{U}, \mathrm{Np}$, and $\mathrm{Pu}$ content using ICP-MS, gamma scan, and PuTTA analyses.

Table 2-3. Composition of SWS-10-2007.

\begin{tabular}{|c|c|c|}
\hline Component & Target Concentration & Measured Concentration \\
\hline $\mathrm{NaNO}_{3}$ & $2.60 \mathrm{M}$ & $2.42 \pm 0.24 \mathrm{M}$ \\
\hline $\mathrm{NaOH}$ & $1.33 \mathrm{M}$ & $1.36 \pm 0.14 \mathrm{M}$ \\
\hline $\mathrm{Na}_{2} \mathrm{SO}_{4}$ & $0.521 \mathrm{M}$ & $0.562 \pm 0.056 \mathrm{M}$ \\
\hline $\mathrm{NaAl}(\mathrm{OH})_{4}$ & $0.429 \mathrm{M}$ & $0.419 \pm 0.042 \mathrm{M}$ \\
\hline $\mathrm{NaNO}_{2}$ & $0.134 \mathrm{M}$ & $0.141 \pm 0.014 \mathrm{M}$ \\
\hline $\mathrm{NaCO}_{3}$ & $0.0260 \mathrm{M}$ & $0.0266 \pm 0.0027$ \\
\hline Total Na & $5.6 \mathrm{M}$ & $5.52 \pm 0.72 \mathrm{M}$ \\
\hline Total Sr & $0.6 \mathrm{mg} / \mathrm{L}$ & $0.318 \pm 0.106 \mathrm{mg} / \mathrm{L}$ \\
\hline${ }^{85} \mathrm{Sr}$ & $\geq 30,000 \mathrm{dpm} / \mathrm{mL}$ & $189,000 \mathrm{dmp} / \mathrm{mL}$ \\
\hline Total Pu & $0.2 \mathrm{mg} / \mathrm{L}$ & $0.235 \pm 0.007 \mathrm{mg} / \mathrm{L}$ \\
\hline${ }^{237} \mathrm{~Np}$ & $0.5 \mathrm{mg} / \mathrm{L}$ & $0.450 \pm 0.098 \mathrm{mg} / \mathrm{L}$ \\
\hline Total U & $10 \mathrm{mg} / \mathrm{L}$ & $11.3 \pm 0.38 \mathrm{mg} / \mathrm{L}$ \\
\hline${ }^{137} \mathrm{Cs}$ & $\geq 30,000 \mathrm{dpm} / \mathrm{mL}$ & $86,900 \pm 577 \mathrm{dpm} / \mathrm{mL}$ \\
\hline
\end{tabular}

\subsection{Effect of Radiation on MST Performance}

To determine if irradiation of the MST or modified MST (mMST) would have an effect on the sorption of strontium and actinides, the materials were irradiated in a gamma source, and the performance was tested. The total dose the materials received was $3.95 \times 10^{6} \mathrm{R}$, which corresponds to the dose the material may receive after the accumulation of 50 batches in the actinide removal process (ARP). This value also bounds the total dose the material may receive in the salt waste processing facility (SWPF). Even though higher Cs concentrations and therefore higher activities are expected in SWPF, the maximum number of batches that may be accumulated will be much lower than in ARP (7 vs. 50). The materials were irradiated in two 
different media, the as received aqueous suspension and in a non-radioactive simulated salt solution (SWS-11-2008).

Samples of MST (Optima Batch 00-QAB-417) and mMST (Optima Batch 06-QAB-0139) were transferred into the salt solution by first centrifuging to isolate the solids, and then dispersing the solids in the salt solution. These samples, along with samples of the as received suspension, were then irradiated for 697 minutes in a gamma source with a dose rate of $3.4 \times 10^{5} \mathrm{R} / \mathrm{h}$.

Performance tests were carried out using a simulated waste solution (SWS-5-2009), having the composition shown in Table 2-3. The experiments were carried out in a waterbath-shaker at $25^{\circ} \mathrm{C}$, with an agitation speed of $175 \mathrm{rpm}$. All MST experiments were performed with a sorbent loading of $0.4 \mathrm{~g} / \mathrm{L}$, and the mMST experiments were performed at a loading of $0.2 \mathrm{~g} / \mathrm{L}$. Samples were taken after 6,12, and 24 hours of contact, and were analyzed for $\mathrm{Sr}, \mathrm{U}, \mathrm{Np}$, and $\mathrm{Pu}$ content using ICP-MS, gamma scan, and PuTTA analyses.

Table 2-4. Composition of SWS-5-2009.

\begin{tabular}{|c|c|c|}
\hline Component & Target Concentration & Measured Concentration \\
\hline $\mathrm{NaNO}_{3}$ & $2.60 \mathrm{M}$ & $2.13 \pm 0.21 \mathrm{M}$ \\
\hline $\mathrm{NaOH}$ & $1.33 \mathrm{M}$ & $1.37 \pm 0.14 \mathrm{M}$ \\
\hline $\mathrm{Na}_{2} \mathrm{SO}_{4}$ & $0.521 \mathrm{M}$ & $0.483 \pm 0.048 \mathrm{M}$ \\
\hline $\mathrm{NaAl}(\mathrm{OH})_{4}$ & $0.429 \mathrm{M}$ & $0.484 \pm 0.048 \mathrm{M}$ \\
\hline $\mathrm{NaNO}_{2}$ & $0.134 \mathrm{M}$ & $0.133 \pm 0.013 \mathrm{M}$ \\
\hline $\mathrm{NaCO}_{3}$ & $0.0260 \mathrm{M}$ & $0.0298 \pm 0.0030$ \\
\hline Total Na & $5.6 \mathrm{M}$ & $5.05 \pm 0.01 \mathrm{M}$ \\
\hline Total Sr & $0.6 \mathrm{mg} / \mathrm{L}$ & $0.521 \pm 0.052 \mathrm{mg} / \mathrm{L}$ \\
\hline${ }^{85} \mathrm{Sr}$ & $\geq 30,000 \mathrm{dpm} / \mathrm{mL}$ & $189,000 \mathrm{dmp} / \mathrm{mL}$ \\
\hline Total Pu & $0.2 \mathrm{mg} / \mathrm{L}$ & $0.216 \pm 0.019 \mathrm{mg} / \mathrm{L}$ \\
\hline${ }^{237} \mathrm{~Np}$ & $0.5 \mathrm{mg} / \mathrm{L}$ & $0.392 \pm 0.92 \mathrm{mg} / \mathrm{L}$ \\
\hline Total U & $10 \mathrm{mg} / \mathrm{L}$ & $10.7 \pm 0.13 \mathrm{mg} / \mathrm{L}$ \\
\hline${ }^{137} \mathrm{Cs}$ & $\geq 30,000 \mathrm{dpm} / \mathrm{mL}$ & $102,000 \pm 1910 \mathrm{dpm} / \mathrm{mL}$ \\
\hline
\end{tabular}

\subsection{Effect of Age on mMST Performance}

Iodometric titration analyses indicated that the peroxide content of modified MST samples decreases linearly with age. Strontium and actinide sorption tests were performed with several lab prepared batches of mMST of varying age (see Table 2-4). Performance tests were carried out with a simulated waste solution (SWS-9-2009) having the composition shown in Table 2-5. This simulant $(60 \mathrm{~mL})$ was placed in $125-\mathrm{mL}$ HDPE bottles. After equilibrating at $25{ }^{\circ} \mathrm{C}$, overnight, aliquots of mMST were added, giving final mMST concentrations of $0.2 \mathrm{~g} / \mathrm{L}$. The experiments were carried out in a waterbath/shaker at $25^{\circ} \mathrm{C}$, with an agitation speed of $175 \mathrm{rpm}$. Samples were taken after 6,12, and 24 hours of contact, and were filtered through a $0.1 \mu \mathrm{m}$ PVDF filter. The samples were then acidified before being submitted for analysis of $\mathrm{Sr}, \mathrm{U}, \mathrm{Np}$, and $\mathrm{Pu}$ content using ICP-MS, gamma scan, and PuTTA analyses.

Table 2-5. Age of mMST Samples.

\begin{tabular}{||c|c|}
\hline Sample & Age at Time of Testing \\
\hline LS-2 & $4.70 \mathrm{y}$ \\
\hline LS-7 & $0.30 \mathrm{y}$ \\
\hline LS-8 & $0.19 \mathrm{y}$ \\
\hline LS-9 & $0.09 \mathrm{y}$ \\
\hline
\end{tabular}


*Sample LS-8 was used in the gas release experiment at elevated temperature; therefore, this sample was held at $49^{\circ} \mathrm{C}$ for one month. Iodometric titration analysis indicates the peroxide content for this sample is lower than predicted based on age.

Table 2-6. Composition of SWS-9-2009.

\begin{tabular}{||c|c|c||}
\hline Component & Target Concentration & Measured Concentration \\
\hline $\mathbf{N a N O}_{3}$ & $2.60 \mathrm{M}$ & $2.35 \pm 0.18 \mathrm{M}$ \\
\hline $\mathbf{N a O H}$ & $1.33 \mathrm{M}$ & $1.27 \pm 0.13 \mathrm{M}$ \\
\hline $\mathbf{N a}_{2} \mathbf{S O}_{4}$ & $0.521 \mathrm{M}$ & $0.531 \pm 0.040 \mathrm{M}$ \\
\hline $\left.\mathbf{N a A l}_{\mathbf{O}} \mathbf{O H}\right)_{4}$ & $0.429 \mathrm{M}$ & $0.389 \pm 0.039 \mathrm{M}$ \\
\hline $\mathbf{N a N O}_{2}$ & $0.134 \mathrm{M}$ & $0.127 \pm 0.010 \mathrm{M}$ \\
\hline $\mathbf{N a C O}_{3}$ & $0.0260 \mathrm{M}$ & $0.0302 \pm 0.0030$ \\
\hline Total Na & $5.6 \mathrm{M}$ & $5.05 \pm 0.01 \mathrm{M}$ \\
\hline Total Sr & $0.6 \mathrm{mg} / \mathrm{L}$ & $0.676 \pm 0.026 \mathrm{mg} / \mathrm{L}$ \\
\hline${ }^{85} \mathbf{S r}$ & $\geq 10,000 \mathrm{dpm} / \mathrm{mL}$ & $12,000 \mathrm{dmp} / \mathrm{mL}$ \\
\hline Total Pu & $0.2 \mathrm{mg} / \mathrm{L}$ & $0.17 \pm 0.033 \mathrm{mg} / \mathrm{L}$ \\
\hline${ }^{237} \mathbf{N p}$ & $0.5 \mathrm{mg} / \mathrm{L}$ & $0.463 \pm 0.026 \mathrm{mg} / \mathrm{L}$ \\
\hline Total U & $10 \mathrm{mg} / \mathrm{L}$ & $10.1 \pm 0.36 \mathrm{mg} / \mathrm{L}$ \\
\hline${ }^{137} \mathbf{C s}$ & $\geq 30,000 \mathrm{dpm} / \mathrm{mL}$ & $123,000 \pm 6130 \mathrm{dpm} / \mathrm{mL}$ \\
\hline
\end{tabular}

Previous testing indicated that the mMST does not adsorb appreciable uranium, as opposed to MST, which does. A performance test was designed using a "uranium-only" simulant to examine if the loss of peroxide with age causes the mMST to begin sorbing uranium. Performance tests were carried out with simulated waste solution (SWS-8-2007) having the composition shown in Table 2-6. Personnel added $60 \mathrm{~mL}$ of this simulant to $125-\mathrm{mL}$ HDPE bottles. After equilibrating at $25^{\circ} \mathrm{C}$, overnight, aliquots of MST (Optima Batch 00-QAB-417) and mMST (Optima Batch 06QAB-0139) were added, giving final MST concentrations of $3.0 \mathrm{~g} / \mathrm{L}$. The experiments were carried out in a waterbath/shaker at $25^{\circ} \mathrm{C}$, with an agitation speed of $175 \mathrm{rpm}$. Samples were taken after 4 and 12 hours of contact, and were filtered through a $0.1 \mu \mathrm{m}$ PVDF filter. The samples were then acidified before being submitted for analysis of $U$ content using ICP-MS.

Table 2-7. Composition of SWS-8-2007.

\begin{tabular}{|c|c|c|c|c||}
\hline \multirow{2}{*}{ Component } & \multirow{2}{*}{$\begin{array}{c}\text { Target } \\
\text { Concentration }\end{array}$} & \multicolumn{2}{|c|}{ Measured Concentration } & \multirow{2}{*}{ Units } \\
\cline { 3 - 4 } & 2.60 & 3.11 & $\mathbf{1} \sigma$ Uncertainty & \\
\hline $\mathrm{NaNO}_{3}$ & 1.33 & 1.38 & 0.31 & $\mathrm{M}$ \\
\hline $\mathrm{NaOH}$ & 0.521 & 0.606 & 0.138 & $\mathrm{M}$ \\
\hline $\mathrm{Na}_{2} \mathrm{SO}_{4}$ & 0.429 & 0.461 & 0.0409 & $\mathrm{M}$ \\
\hline $\mathrm{NaAl}^{2}(\mathrm{OH})_{4}$ & 0.134 & 0.160 & 0.032 & $\mathrm{M}$ \\
\hline $\mathrm{NaNO}_{2}$ & 0.026 & 0.0314 & 0.00471 & $\mathrm{M}$ \\
\hline $\mathrm{Na}_{2} \mathrm{CO}_{3}$ & 5.60 & 5.10 & 0.51 & $\mathrm{M}$ \\
\hline $\mathrm{Total} \mathrm{Na}^{+}$ & 10,000 & 9545 & 294 & $\mu \mathrm{g} / \mathrm{L}$ \\
\hline Uranium & \multicolumn{3}{|l}{} \\
\hline \hline
\end{tabular}

\subsection{Results and Discussion}

\subsection{High Temperature X-Ray Diffraction Analyses (HTXRD) ${ }^{14}$}

A summary of the phases identified in these high temperature XRD experiments can be found in Table 3-1. Both the baseline and modified MST samples are amorphous materials, but several crystalline phases were observed as the materials were heated from 25 to $800{ }^{\circ} \mathrm{C}$. For the 
baseline MST material poorly crystalline sodium titanium oxide hydrate $\left(\mathrm{Na}_{2} \mathrm{Ti}_{2} \mathrm{O}_{4}(\mathrm{OH})_{2}\right)$ was the only phase detected in both the as-received and $\mathrm{pH}$ adjusted samples from 25 to $300{ }^{\circ} \mathrm{C}$. As the powders were heated, the unit cell for this titanate phase contracted along the a-axis in the direction of the (200) plane. The contraction continued until the phase disappeared above $300{ }^{\circ} \mathrm{C}$. In the $600{ }^{\circ} \mathrm{C}$ scan, differences between the as-received and $\mathrm{pH}$ adjusted samples began to emerge. A metastable phase, $\mathrm{Na}_{0.8} \mathrm{Ti}_{4} \mathrm{O}_{8}$, (only found at $600{ }^{\circ} \mathrm{C}$ ) and $\mathrm{Na}_{2} \mathrm{Ti}_{6} \mathrm{O}_{13}$ or $\mathrm{Na}_{2} \mathrm{O} 6 \mathrm{TiO}_{2}$ (stable to $800^{\circ} \mathrm{C}$ ) appear in both samples. However, in the $\mathrm{pH}$ adjusted sample the two titanium dioxide polymorphs, anatase and rutile, were also identified at $600{ }^{\circ} \mathrm{C}$. The anatase completely transformed to rutile somewhere between $600-800{ }^{\circ} \mathrm{C}$. At $800{ }^{\circ} \mathrm{C}$ an additional sodium titanate, $\mathrm{Na}_{2} \mathrm{Ti}_{3} \mathrm{O}_{7}$ or $\mathrm{Na}_{2} \mathrm{O} 3 \mathrm{TiO}_{2}$, appears only in the as-received sample. The room temperature XRD analysis of the HTXRD residues found the same phases that were present at $800{ }^{\circ} \mathrm{C}$ in the high temperature scans.

Table 3-1. Summary of Phases Identified in HTXRD Experiments.

\begin{tabular}{|c|c|c|}
\hline \multicolumn{3}{|c|}{ Baseline MST As Received } \\
\hline Compound & Formula & Temperature $\left({ }^{\circ} \mathrm{C}\right)$ in $\mathrm{He}$ \\
\hline Sodium Titanium Oxide Hydrate & $\mathrm{Na}_{2} \mathrm{Ti}_{2} \mathrm{O}_{4}(\mathrm{OH})_{2}$ & $25-300$ \\
\hline Sodium Titanium Oxide & $\mathrm{Na}_{0.8} \mathrm{Ti}_{4} \mathrm{O}_{8}$ & 600 \\
\hline Sodium Titanium Oxide & $\mathrm{Na}_{2} \mathrm{Ti}_{6} \mathrm{O}_{13}$ & 600-800, residue \\
\hline Sodium Titanium Oxide & $\mathrm{Na}_{2} \mathrm{Ti}_{3} \mathrm{O}_{7}$ & 800 , residue \\
\hline \multicolumn{3}{|c|}{$\begin{array}{c}\text { Baseline MST pH Adjusted } \\
\end{array}$} \\
\hline Compound & Formula & Temperature $\left({ }^{\circ} \mathrm{C}\right)$ in $\mathrm{He}$ \\
\hline Sodium Titanium Oxide Hydrate & $\mathrm{Na}_{2} \mathrm{Ti}_{2} \mathrm{O}_{4}(\mathrm{OH})_{2}$ & $25-300$ \\
\hline Sodium Titanium Oxide & $\mathrm{Na}_{0.8} \mathrm{Ti}_{4} \mathrm{O}_{8}$ & 600 \\
\hline Anatase & $\mathrm{TiO}_{2}$ & 600 \\
\hline Sodium Titanium Oxide & $\mathrm{Na}_{2} \mathrm{Ti}_{6} \mathrm{O}_{13}$ & 600-800, residue \\
\hline Rutile & $\mathrm{TiO}_{2}$ & $600-800$, residue \\
\hline \multicolumn{3}{|c|}{ mMST As Received } \\
\hline Compound & Formula & Temperature $\left({ }^{\circ} \mathrm{C}\right)$ in $\mathrm{He}$ \\
\hline Sodium Titanium Oxide Hydrate & $\mathrm{Na}_{2} \mathrm{Ti}_{2} \mathrm{O}_{4}(\mathrm{OH})_{2}$ & $25-300(?)$ \\
\hline Anatase & $\mathrm{TiO}_{2}$ & $25-600$ \\
\hline Rutile & $\mathrm{TiO}_{2}$ & 800 , residue \\
\hline Sodium Titanium Oxide & $\mathrm{Na}_{2} \mathrm{Ti}_{6} \mathrm{O}_{13}$ & 800 , residue \\
\hline \multicolumn{3}{|c|}{ mMST pH Adjusted } \\
\hline Compound & Formula & Temperature $\left({ }^{\circ} \mathrm{C}\right)$ in $\mathrm{He}$ \\
\hline Sodium Titanium Oxide Hydrate & $\mathrm{Na}_{2} \mathrm{Ti}_{2} \mathrm{O}_{4}(\mathrm{OH})_{2}$ & $25-300(?)$ \\
\hline Anatase & $\mathrm{TiO}_{2}$ & $25-600$ \\
\hline Sodium Titanium Oxide & $\mathrm{Na}_{0.8} \mathrm{Ti}_{4} \mathrm{O}_{8}$ & 600 \\
\hline Rutile & $\mathrm{TiO}_{2}$ & 800 , residue \\
\hline Sodium Titanium Oxide & $\mathrm{Na}_{2} \mathrm{Ti}_{6} \mathrm{O}_{13}$ & 800, residue \\
\hline
\end{tabular}

The HTXRD results for the mMST decomposition were similar to those for the baseline MST with a few notable differences. Although sodium titanium oxide hydrate $\left(\mathrm{Na}_{2} \mathrm{Ti}_{2} \mathrm{O}_{4}(\mathrm{OH})_{2}\right)$ or a similar compound, such as sodium peroxotitanate, may also be present in both samples from $25^{\circ} \mathrm{C}$ to $300^{\circ} \mathrm{C}$, the main phase identified was nano-crystalline anatase. Both the as-received and $\mathrm{pH}$ adjusted samples exhibit the same unit cell contraction along the a-axis in the direction of the (200) plane as mentioned above. The main difference in the decomposition for the mMST samples occurs at $600{ }^{\circ} \mathrm{C}$, with the metastable phase, $\mathrm{Na}_{0.8} \mathrm{Ti}_{4} \mathrm{O}_{8}$, only observed in the $\mathrm{pH}$ adjusted 
sample. As in the monosodium titanate HTXRD measurements, at $800^{\circ} \mathrm{C}$ and in the HTXRD residues, rutile and $\mathrm{Na}_{2} \mathrm{Ti}_{6} \mathrm{O}_{13}$ were identified.

\subsection{Solids Settling Characteristics}

Table 3-2 contains the results of the settled density measurements for mMST in both $0.5 \mathrm{M}$ and 5.6 M Na solutions, and at centrifuge speeds of $6.3 \mathrm{xg}$ and $1400 \mathrm{xg}$. As expected, the density of the settled solids increases with increased centrifuge speed. At $1400 \mathrm{x} \mathrm{g}$, the density also increases slightly with increasing suspended solids concentrations. The effect of sodium concentration is minor, and in general does not produce a measurable difference in the density, for the sodium concentrations tested.

Table 3-2. Results of Settled Density Measurements for mMST.

\begin{tabular}{|c|c|c|c|c|}
\hline & \multicolumn{2}{|c|}{$\begin{array}{l}\text { Sodium Concentration of Settling Fluid is } \\
5.6 \mathrm{M}\end{array}$} & \multicolumn{2}{|c|}{$\begin{array}{c}\text { Sodium Concentration of Settling Fluid } \\
\text { is } 0.5 \mathrm{M}\end{array}$} \\
\hline $\begin{array}{c}\text { Suspended } \\
\text { Solids Conc. } \\
(\mathrm{g} / \mathrm{mL})\end{array}$ & $\begin{array}{l}\text { Ave. Settled Solids } \\
\text { Conc. (g/mL) at } 6.3 \\
\times \mathrm{x} \mathrm{g}\end{array}$ & $\begin{array}{l}\text { St. Dev. of Settled } \\
\text { Solids Conc. } \\
\text { (g/mL) at } 6.3 \times \text { x }\end{array}$ & $\begin{array}{l}\text { Ave. Settled Solids } \\
\text { Conc. (g/mL) at } 6.3 \\
\times \mathrm{x} \mathrm{g}\end{array}$ & $\begin{array}{l}\text { St. Dev. of Settled } \\
\text { Solids Conc. } \\
\text { (g/mL) at } 6.3 \times \mathrm{g}\end{array}$ \\
\hline 0.03 & 0.188 & 0.0073 & 0.212 & 0.0150 \\
\hline 0.09 & 0.201 & 0.0018 & 0.214 & 0.0051 \\
\hline 0.15 & 0.197 & 0.0000 & 0.197 & 0.0000 \\
\hline & \multicolumn{2}{|c|}{$\begin{array}{l}\text { Sodium Concentration of Settling Fluid is } \\
5.6 \mathrm{M}\end{array}$} & \multicolumn{2}{|c|}{$\begin{array}{c}\text { Sodium Concentration of Settling Fluid } \\
\text { is } 0.5 \mathrm{M}\end{array}$} \\
\hline $\begin{array}{c}\text { Suspended } \\
\text { Solids Conc. } \\
(\mathrm{g} / \mathrm{mL})\end{array}$ & $\begin{array}{c}\text { Ave. Settled Solids } \\
\text { Conc. }(\mathrm{g} / \mathrm{mL}) \text { at } \\
1400 \times \mathrm{g}\end{array}$ & $\begin{array}{l}\text { St. Dev. of Settled } \\
\text { Solids Conc. } \\
\text { (g/mL) at } 1400 \times \mathrm{g}\end{array}$ & $\begin{array}{c}\text { Ave. Settled Solids } \\
\text { Conc. }(\mathrm{g} / \mathrm{mL}) \text { at } \\
1400 \times \mathrm{g}\end{array}$ & $\begin{array}{l}\text { St. Dev. of Settled } \\
\text { Solids Conc. } \\
\text { (g/mL) at } 1400 \times \mathrm{g}\end{array}$ \\
\hline 0.03 & 0.300 & 0.0196 & 0.318 & 0.0039 \\
\hline 0.09 & 0.338 & 0.0036 & 0.342 & 0.0020 \\
\hline 0.15 & 0.365 & 0.0118 & 0.348 & 0.0052 \\
\hline
\end{tabular}

Results from the gravity settling tests for MST and mMST in salt solutions with varying sodium concentrations $(4.6,5.6$, and $6.6 \mathrm{M})$ are shown in Figure 3. The rates were determined by measuring the height of the clear supernate at the top of the graduated cylinder over time. As can be seen from the graph, the mMST settling rate is much slower than the MST settling rate, indicating the mMST contains a larger fraction of fine particles. For MST, there did not appear to be a measurable effect of the sodium concentration on the settling rate. For mMST the settling rate was slightly lower in the highest sodium concentration solution. This is the expected trend, as the viscosity of the solution increases with increasing ionic strength. The apparent increase in settling rate for mMST at times $>20$ hours is attributed to the fact that mMST adheres to the walls of the graduated cylinder to a much greater extent than MST, making the measurement of the clear supernate at the top of the cylinder difficult. When this was taken into account the height of the clear supernatant appeared to increase rapidly over a short period of time, which was likely not the case. 


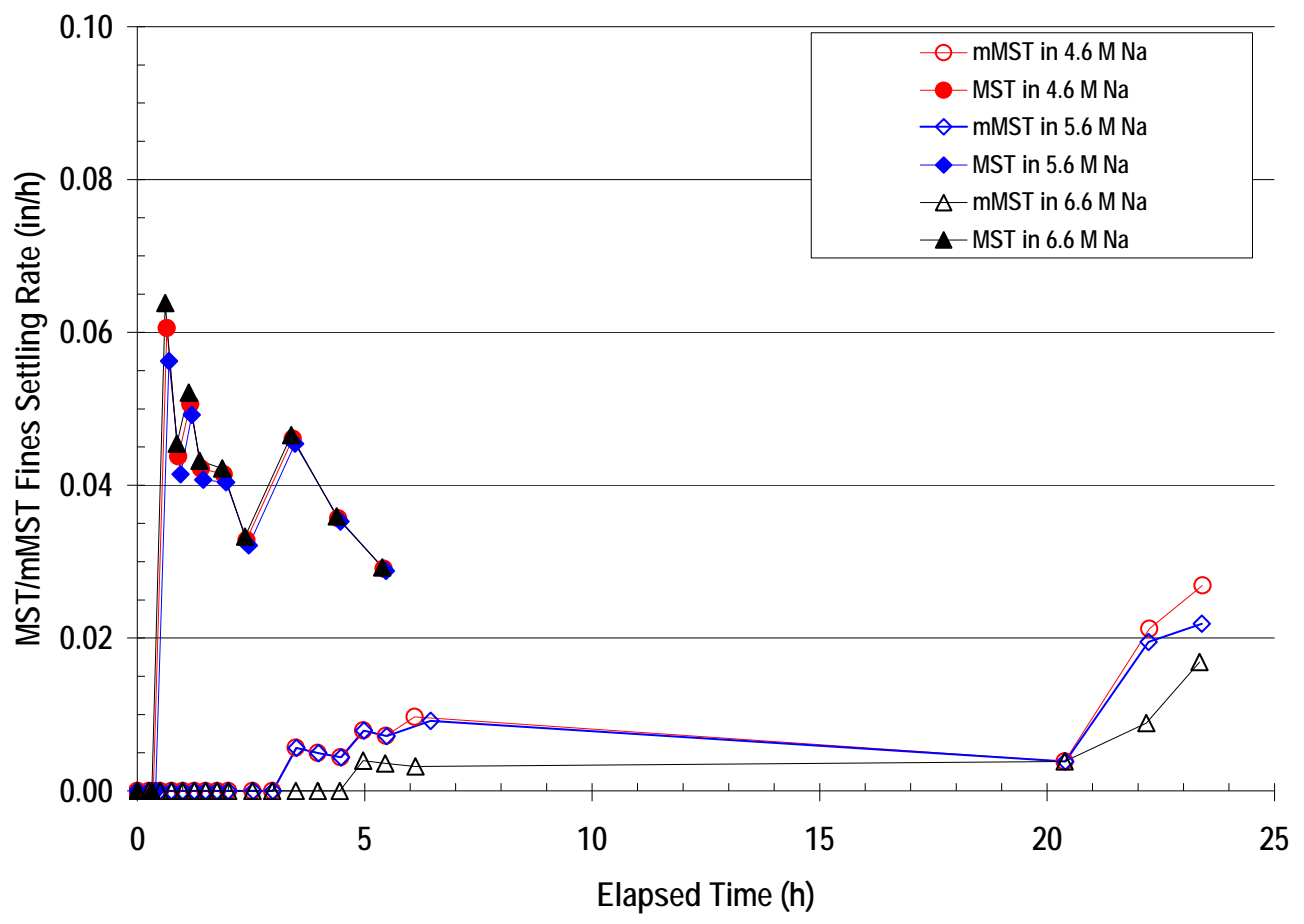

Figure 3. MST and mMST fines settling rates vs. time.

\subsection{Iodometric Titration Analysis}

Several batches of mMST of different ages, prepared both in our lab and by the vendor, were analyzed using the iodometric titration method. The amount of peroxide in the samples was found to decrease linearly with the age of the sample (Table 3-3, Figure 4). There was one exception to this trend, Sample LS-8. This lab prepared sample had been held at $49{ }^{\circ} \mathrm{C}$ for one month (for gas release measurements), whereas the other samples had not been exposed to elevated temperatures. Sample LS-8 contained approximately one-half the amount of peroxide of a slightly older sample, LS-7. 
Table 3-3. mMST Samples, Age and Peroxide Content

\begin{tabular}{|c|c|c|c|c|}
\hline Sample & Age (y) & $\begin{array}{c}\text { Peroxide/Ti Molar } \\
\text { Ratio }\end{array}$ & St. Dev. & Sample Notes \\
\hline LS-1 & 4.72 & 0.142 & 0.0017 & Lab Prepared \\
\hline$\overline{L S-2}$ & 4.61 & 0.140 & 0.0026 & Lab Prepared \\
\hline LS-3 & 4.70 & 0.131 & 0.0066 & Lab Prepared \\
\hline LS-4A & 4.37 & 0.173 & 0.0011 & Lab Prepared \\
\hline LS-4B & 4.37 & 0.171 & 0.0034 & $\begin{array}{l}\text { Left on filter for } 4 \text { days during } \\
\text { work-up }\end{array}$ \\
\hline LS-5 & 3.16 & 0.208 & 0.0017 & Lab Prepared \\
\hline 06-QAB-0139 & 3.56 & 0.202 & 0.0018 & Vendor Prepared \\
\hline LS-6 & 1.33 & 0.263 & 0.0006 & $\begin{array}{l}\text { Acid wash during synthesis work- } \\
\text { up }\end{array}$ \\
\hline LS-7 & 0.27 & 0.333 & 0.0093 & $\begin{array}{l}\text { Alkaline wash during synthesis } \\
\text { work-up }\end{array}$ \\
\hline LS-8 & 0.16 & 0.206 & 0.0011 & Held at $49^{\circ} \mathrm{C}$ for 30 days \\
\hline LS-10 & 0.22 & 0.328 & 0.0061 & Lab Prepared \\
\hline 3:1 Small Batch & 0.02 & 0.327 & 0.0030 & Small scale batch \\
\hline
\end{tabular}

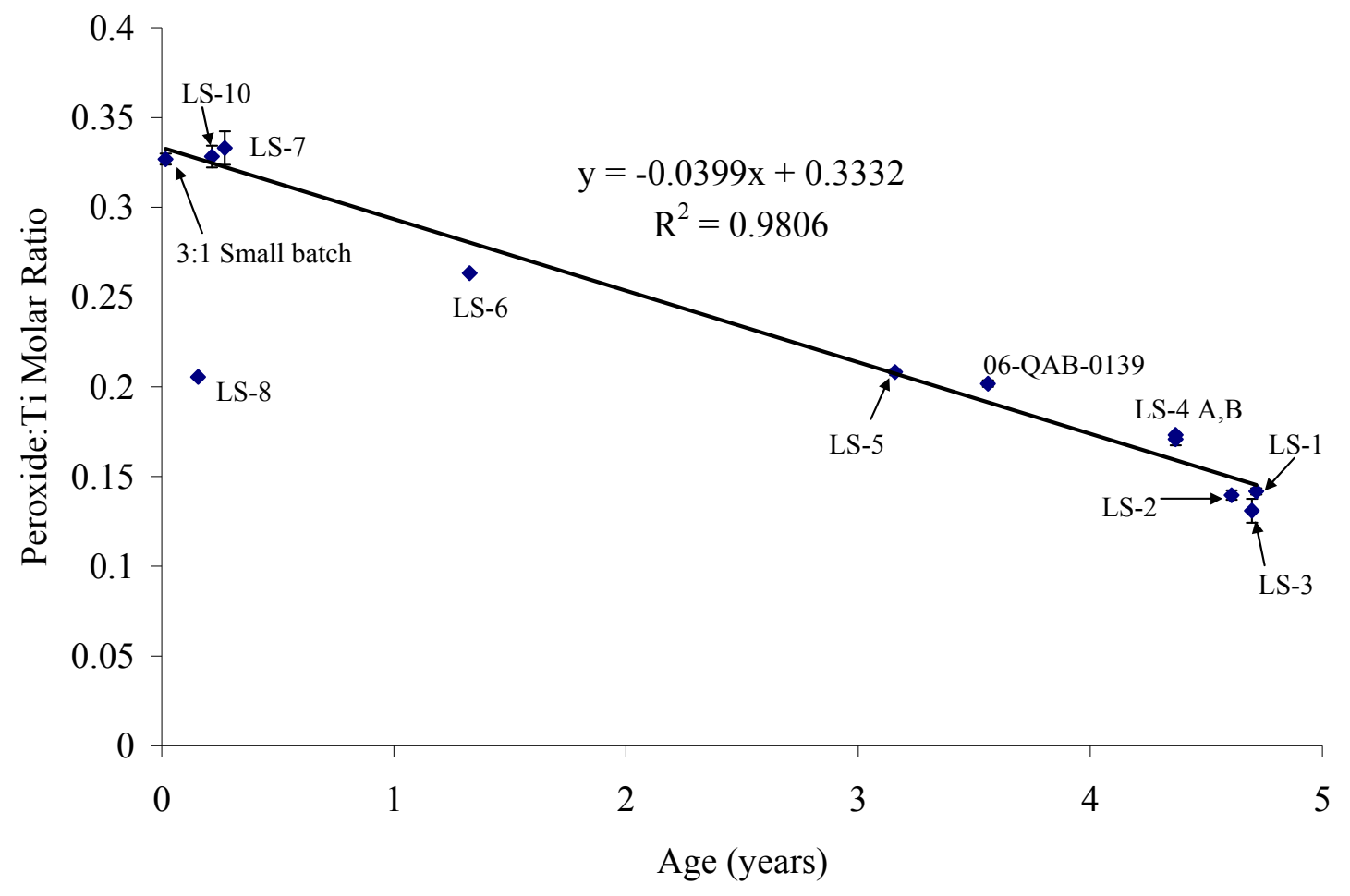

Figure 4. Peroxide content of mMST samples vs. age (LS-8 is excluded from the linear regression).

Results from the titration of mMST samples synthesized using different $\mathrm{H}_{2} \mathrm{O}_{2}$ :Ti molar ratios showed a logarithmic trend between the amount of peroxide added during the synthesis and the amount of peroxide present in the product (Table 3-4, Figure 5). 
Table 3-4. Summary of titration results from samples with varying $\mathrm{H}_{2} \mathrm{O}_{2}$ :Ti molar ratios.

\begin{tabular}{|c|c|c|}
\hline $\begin{array}{c}\mathbf{H}_{2} \mathbf{O}_{2}: \text { Ti molar ratio in } \\
\text { synthesis }\end{array}$ & $\begin{array}{c}\text { Peroxide/Ti molar ratio in } \\
\text { product }\end{array}$ & $\begin{array}{c}\text { St. Dev. } \mathbf{H}_{2} \mathbf{O}_{2} / \text { Ti molar ratio in } \\
\text { product }\end{array}$ \\
\hline $0.25: 1$ & 0.148 & 0.0024 \\
\hline $0.5: 1$ & 0.186 & 0.0011 \\
\hline $1: 1$ & 0.244 & 0.0079 \\
\hline $2: 1$ & 0.299 & 0.0026 \\
\hline $3: 1$ & 0.327 & 0.0030 \\
\hline $4: 1$ & 0.346 & 0.0035 \\
\hline
\end{tabular}

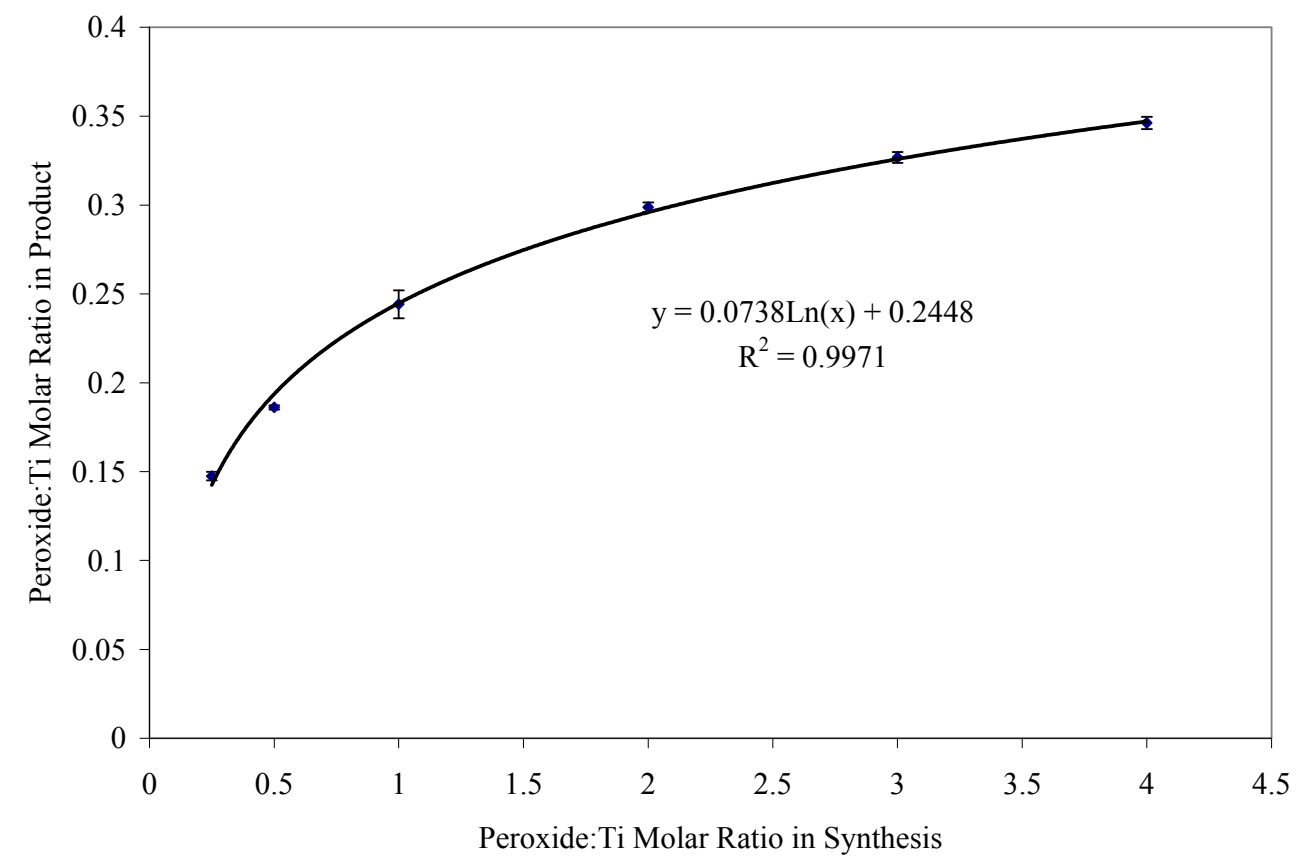

Figure 5. Peroxide:Ti molar ratio in product vs. peroxide:Ti molar ratio in synthesis.

Results from the effect of salt solution experiments showed a significant decrease in peroxide content after 24-h exposure to the two salt solutions. The experiment using only distilled water showed a peroxide content within error of the previous results for this sample (Optima Batch 06QAB-0139). This control experiment was designed to account for any loss of material during the soaking and recovery process, since the initial weight added to the salt solutions was used to determine the peroxide:Ti molar ratio. The peroxide:Ti molar ratios for these samples are presented in Table 3-5. The salt solution containing only sodium (SWS-1-2010) resulted in the largest reduction of peroxide content, to only about $42 \%$ of the control value. The Sr containing salt solution (SWS-1-2008) resulted in a slightly higher peroxide content, 58\% of the control value. 
Table 3-5. Peroxide:Ti Molar Ratios for mMST Optima Batch 06-QAB-0139.

\begin{tabular}{||c|c|c|c||}
\hline \hline mMST Sample & Salt Solution & $\begin{array}{c}\text { Peroxide/Ti molar } \\
\text { ratio }\end{array}$ & \% of Control Value \\
\hline 06-QAB-0139 & None & $0.202 \pm 0.0018$ & $\mathrm{n} / \mathrm{a}^{*}$ \\
\hline 06-QAB-0139 & Control - Water & $0.211 \pm 0.0086$ & 100 \\
\hline 06-QAB-0139 & SWS-1-2010 & $0.089 \pm 0.0034$ & 42.2 \\
\hline 06-QAB-0139 & SWS-1-2008 & $0.123 \pm 0.0034$ & 58.3 \\
\hline
\end{tabular}

*This is the previously measured value (copied from Table 3-2).

\subsection{Gas Release}

Figure 6 provides a plot of the measured gas release rate $(\mathrm{mL} / \mathrm{min})$ versus elapsed time (days) for the freshly prepared batch of modified MST under the standard conditions (LS-9) in the new round bottom flask apparatus. Results from previous testing of mMST synthesized using the standard procedure in the cylindrical tube apparatus (LS-5) are also shown for comparison. Initially the release rate measured approximately $0.47 \mathrm{~mL} / \mathrm{min}$ and decreased by an order of magnitude in less than one day. The release rate dropped an additional order of magnitude, to $0.0052 \mathrm{~mL} / \mathrm{min}$, after approximately 5 days. One month after the preparation of the modified MST, the gas release rate had dropped to $0.0017 \mathrm{~mL} / \mathrm{min}$. Using this value, the gas release rate per gram of mMST slurry containing $15 \mathrm{wt} \%$ solids was calculated to be approximately $1.15 \mathrm{E}-05$ $\mathrm{mL} \cdot \mathrm{min}^{-1} \cdot \mathrm{g}^{-1}$. Using a value of $1.10 \mathrm{~g} \cdot \mathrm{mL}^{-1}$ for the density of $15 \mathrm{wt} \%$ slurry of modified MST, the release rate on a slurry volume basis is approximately $18.2 \mathrm{~mL} \cdot$ day $^{-1} \cdot \mathrm{L}^{-1}$.

Figure 7 provides a plot of the measured gas release rate $(\mathrm{mL} / \mathrm{min})$ versus elapsed time (days) for the freshly prepared batch of modified MST that included an acidic wash during the work-up (LS-6). Initially the release rate measured approximately $0.0913 \mathrm{~mL} / \mathrm{min}$ and decreased by an order of magnitude after approximately 3 days. One month after the preparation of the modified MST, the gas release rate had dropped to $0.00039 \mathrm{~mL} / \mathrm{min}$. Using this value, the gas release rate per gram of mMST slurry containing $15 \mathrm{wt} \%$ solids was calculated to be approximately $2.6 \mathrm{E}-06$ $\mathrm{mL} \cdot \mathrm{min}^{-1} \cdot \mathrm{g}^{-1}$. Using a value of $1.10 \mathrm{~g} \cdot \mathrm{mL}^{-1}$ for the density of $15 \mathrm{wt} \%$ slurry of modified MST, the release rate on a slurry volume basis is approximately $4.0 \mathrm{~mL} \cdot$ day $^{-1} \cdot \mathrm{L}^{-1}$.

Figure 8 provides a plot of the measured gas release rate $(\mathrm{mL} / \mathrm{min})$ versus elapsed time (days) for the freshly prepared batch of modified MST that included an alkaline wash during the work-up (LS-7). Initially the release rate measured approximately $0.024 \mathrm{~mL} / \mathrm{min}$ and decreased by an order of magnitude after approximately 6 days. One month after the preparation of the modified MST, the gas release rate had dropped to $0.00113 \mathrm{~mL} / \mathrm{min}$. Using this value, the gas release rate per gram of mMST slurry containing $15 \mathrm{wt} \%$ solids was calculated to be approximately $7.5 \mathrm{E}-06$ $\mathrm{mL} \cdot \mathrm{min}^{-1} \cdot \mathrm{g}^{-1}$. Using a value of $1.10 \mathrm{~g} \cdot \mathrm{mL}^{-1}$ for the density of $15 \mathrm{wt} \%$ slurry of modified MST, the release rate on a slurry volume basis is approximately $11.9 \mathrm{~mL} \cdot$ day $^{-1} \cdot \mathrm{L}^{-1}$.

Figure 9 provides a plot of the measured gas release rate $(\mathrm{mL} / \mathrm{min})$ versus elapsed time (days) for a freshly prepared batch of modified MST at a temperature of $49^{\circ} \mathrm{C}$ (LS-8). Initially the release rate measured approximately $0.525 \mathrm{~mL} / \mathrm{min}$ and decreased by an order of magnitude in less than one day. The release rate dropped an additional order of magnitude, to $0.0052 \mathrm{~mL} / \mathrm{min}$, after approximately 13 days. One month after the preparation of the modified MST, the gas release rate had dropped to $0.00268 \mathrm{~mL} / \mathrm{min}$. Using this value, the gas release rate per gram of $\mathrm{mMST}$ slurry containing $15 \mathrm{wt} \%$ solids was calculated to be approximately $1.79 \mathrm{E}-05 \mathrm{~mL} \cdot \mathrm{min}^{-1} \cdot \mathrm{g}^{-1}$. Using a value of $1.10 \mathrm{~g} \cdot \mathrm{mL}^{-1}$ for the density of $15 \mathrm{wt} \%$ slurry of modified MST, the release rate on a slurry volume basis is approximately $28.3 \mathrm{~mL} \cdot$ day $^{-1} \cdot \mathrm{L}^{-1}$. 
Figure 10 compares the gas release rate of all five batches of mMST. The initial gas release rate for LS-7 is lower than LS-9 indicating some effect from the alkaline wash; however, at the later time points the gas release rate for LS-7 becomes more similar to LS-9. Using the formula for the trend lines, the gas release from LS-9 will drop below the release rate for LS-7 after approximately 50 days (See Table 3-4). The gas release rate at elevated temperature (LS-8) is consistently higher than the measured rates at room temperature, and calculations using the trend lines, predict this will remain true. At one year after the synthesis, the calculated rate at $49{ }^{\circ} \mathrm{C}$ is still approximately twice the release rate at room temperature (Table 3-6).

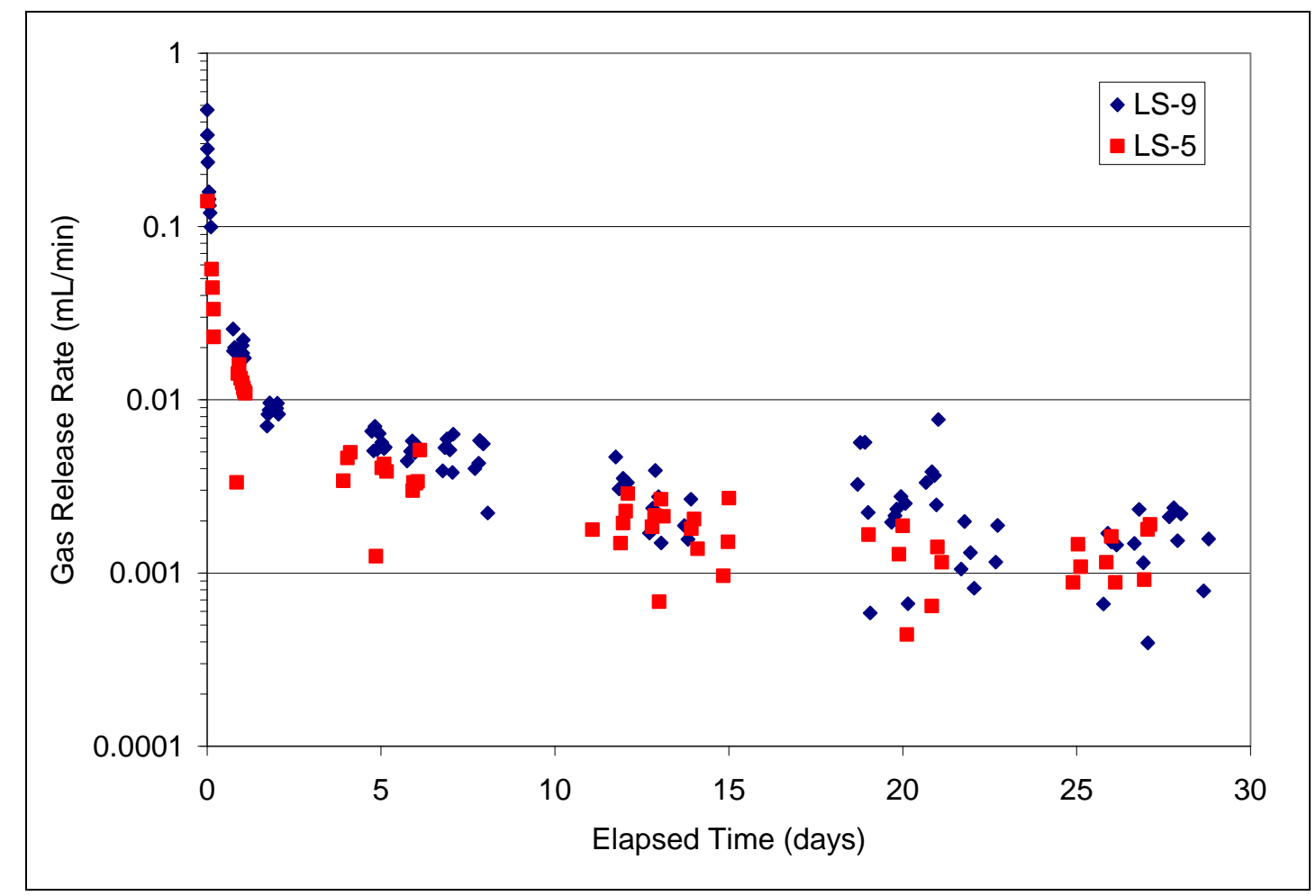

Figure 6. Gas release rate (log scale) versus elapsed time for mMST in round bottom flask apparatus (LS-9, blue) and cylindrical plastic tube apparatus (LS-5, red). 


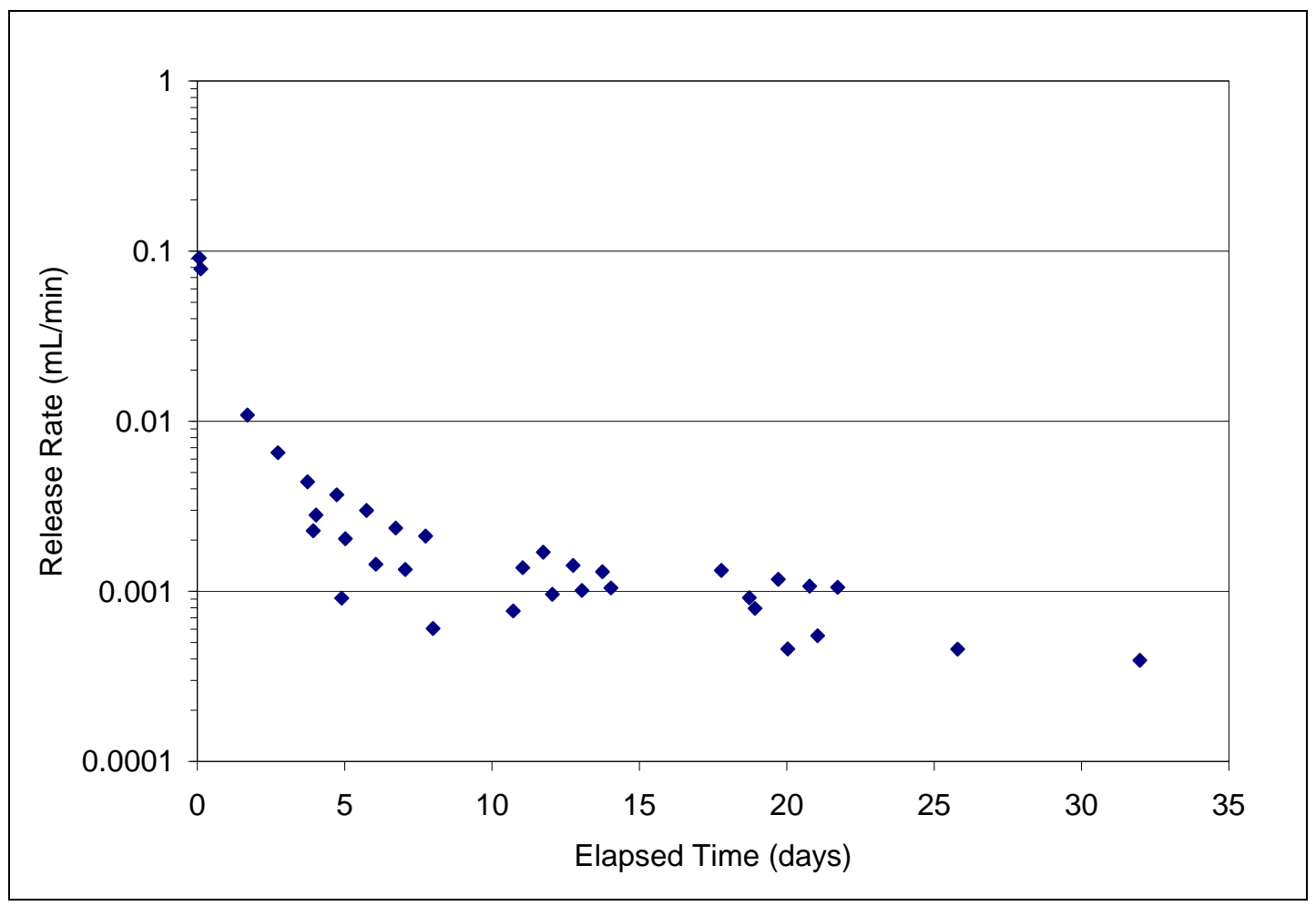

Figure 7. Gas release rate (log scale) versus elapsed time for $\mathrm{pH} 4$ washed mMST (LS-6).

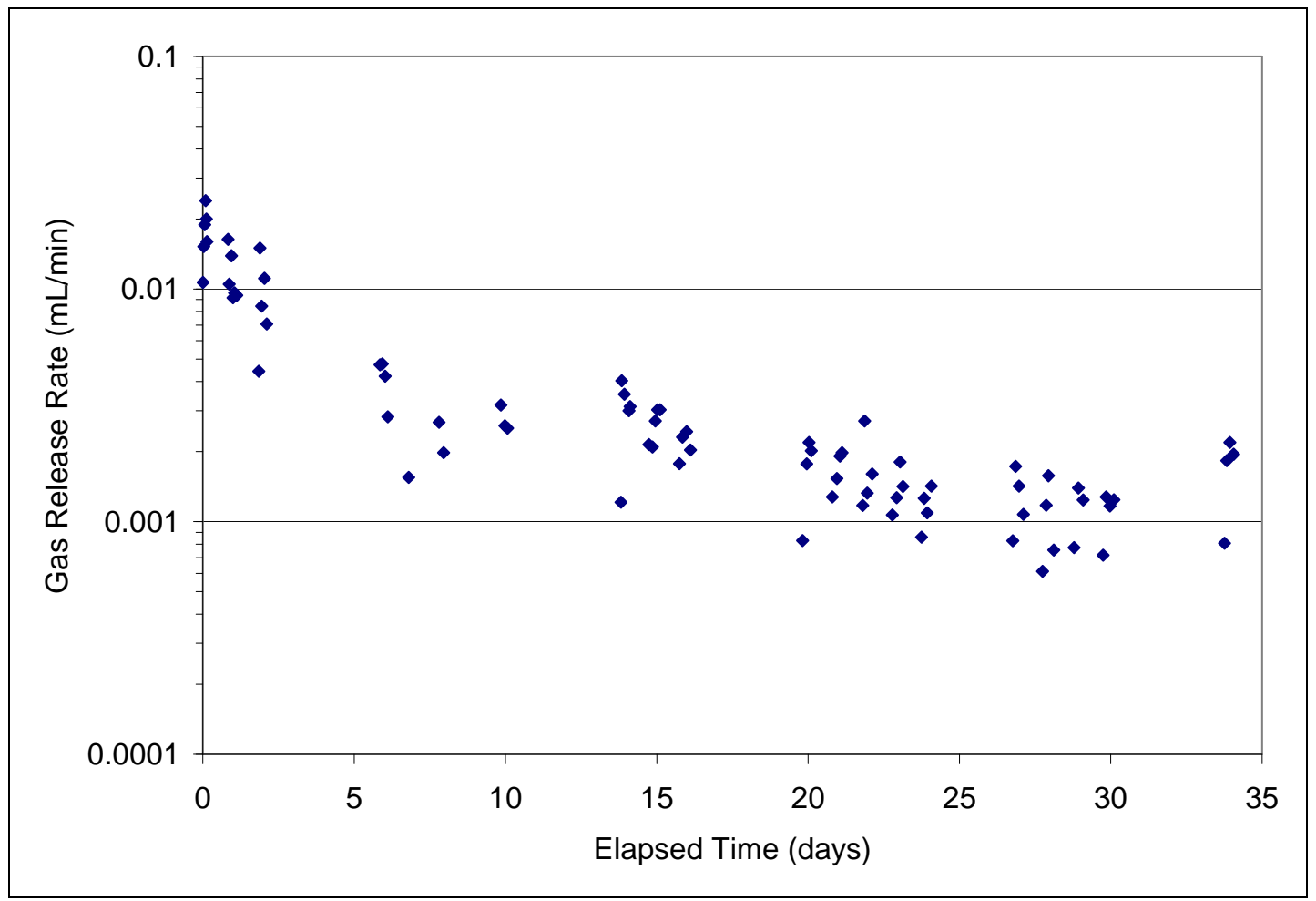

Figure 8. Gas release rate (log scale) versus elapsed time for pH 10 washed mMST (LS-7). 


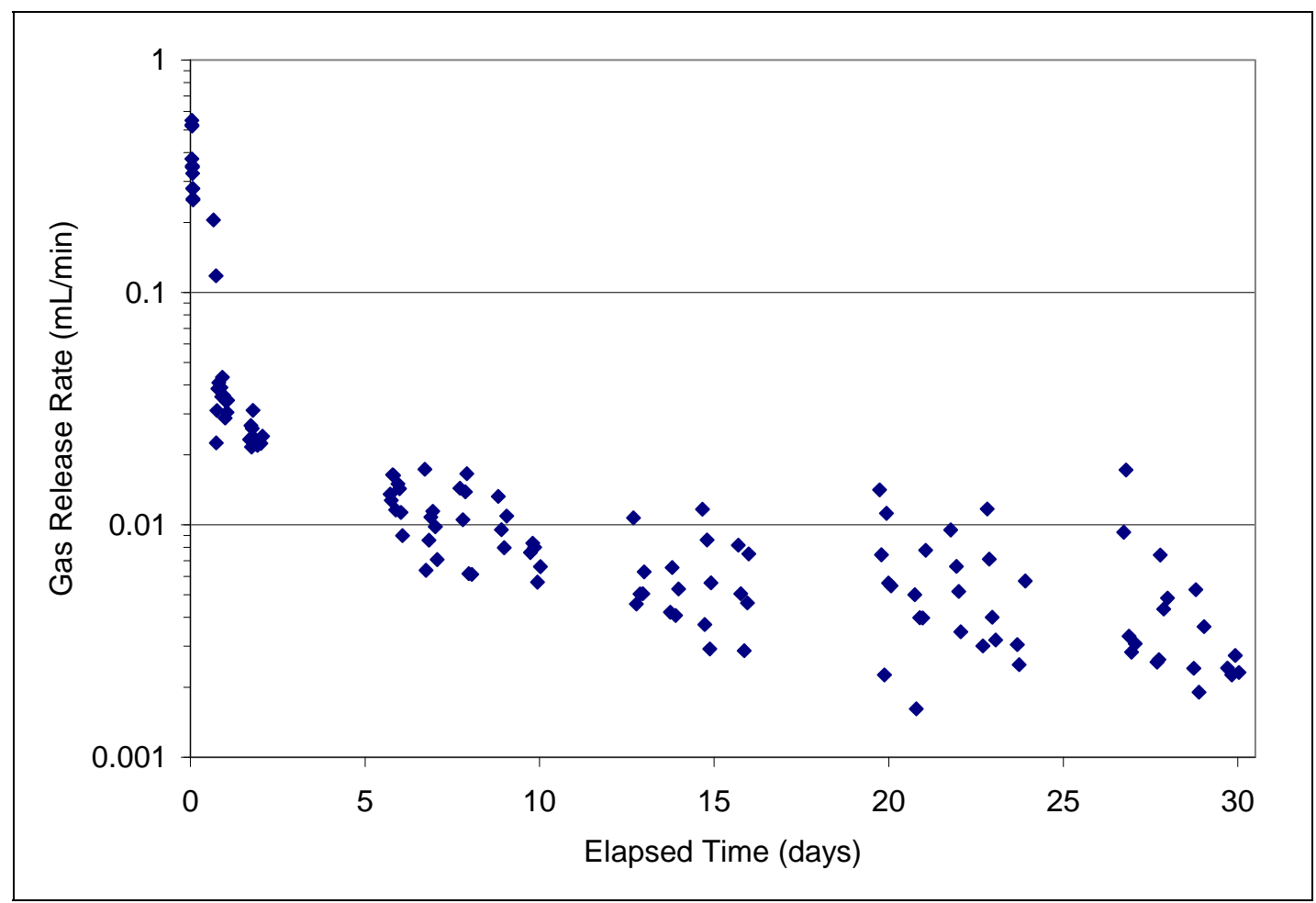

Figure 9. Gas release rate (log scale) versus elapsed time for mMST (LS-8) at $49^{\circ} \mathrm{C}$.

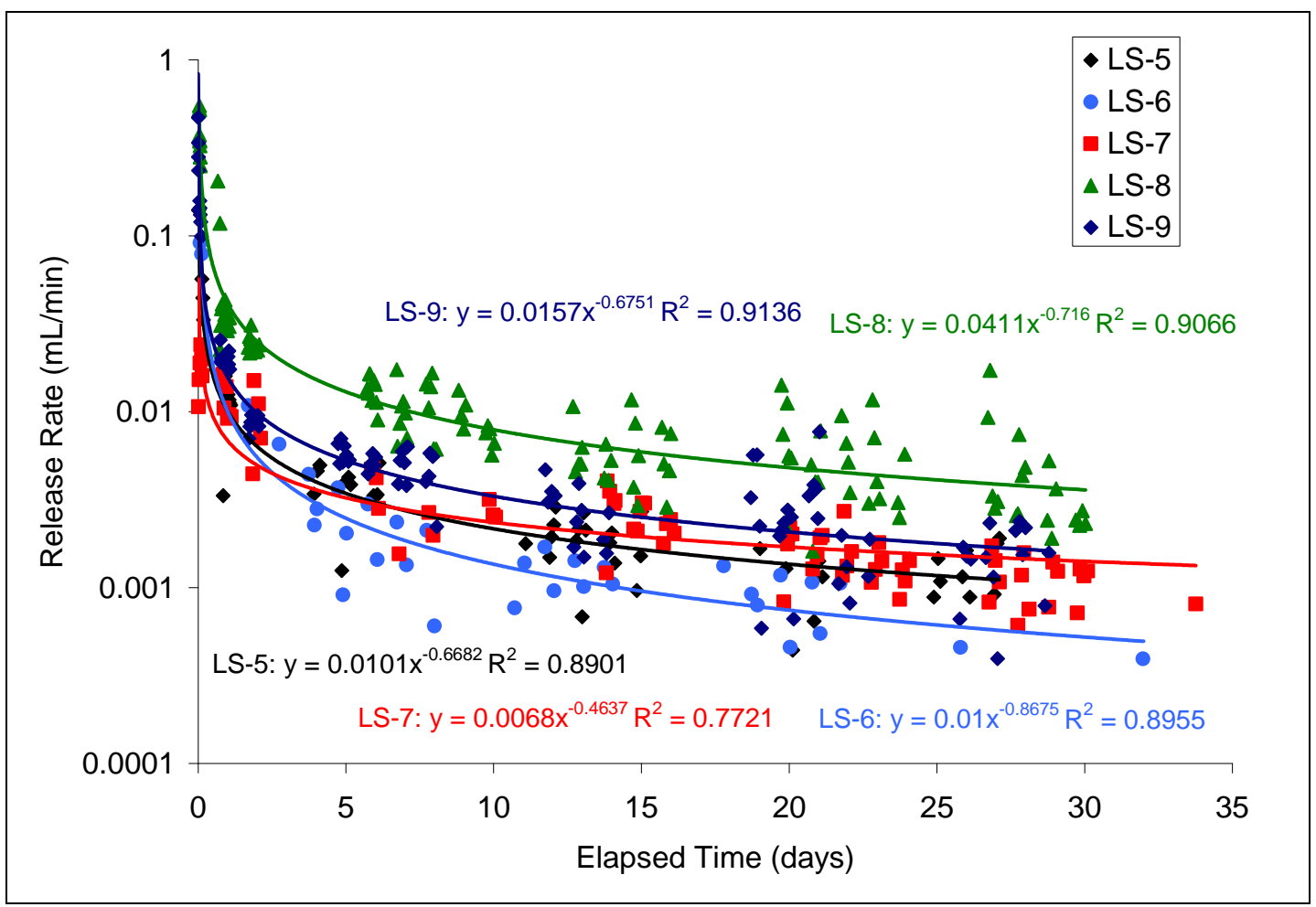

Figure 10. Comparison of gas release rates from LS-5, LS-6, LS-7, LS-8, and LS-9. 
Table 3-6. Calculated Gas Release Rates.

\begin{tabular}{|c|c|c|c||}
\hline Batch ID & $\mathbf{a}$ & $\mathbf{b}$ & $\mathbf{r}^{2}$ \\
\hline LS-5 & 0.0101 & -0.6682 & 0.8901 \\
\hline LS-6 & 0.0100 & -0.8675 & 0.8955 \\
\hline LS-7 & 0.0068 & -0.4637 & 0.7712 \\
\hline LS-8 & 0.0411 & -0.716 & 0.8773 \\
\hline LS-9 & 0.0157 & -0.6751 & 0.9136 \\
\hline
\end{tabular}

\begin{tabular}{|c|c|c|c|c|c||}
\hline \multirow{2}{*}{$\begin{array}{c}\text { Elapsed } \\
\text { Time } \\
\text { (days) }\end{array}$} & \multicolumn{5}{|c||}{ Calculated Gas Release Rate (mL min $^{-1}$ ) } \\
\cline { 2 - 6 } & LS-5 & LS-6 & LS-7 & LS-8 & LS-9 \\
\hline 1 & $1.01 \mathrm{E}-02$ & $1.00 \mathrm{E}-02$ & $6.80 \mathrm{E}-03$ & $4.12 \mathrm{E}-02$ & $1.57 \mathrm{E}-02$ \\
\hline 2 & $6.33 \mathrm{E}-03$ & $5.49 \mathrm{E}-03$ & $4.94 \mathrm{E}-03$ & $2.51 \mathrm{E}-02$ & $9.83 \mathrm{E}-03$ \\
\hline 10 & $2.16 \mathrm{E}-03$ & $1.36 \mathrm{E}-03$ & $2.35 \mathrm{E}-03$ & $7.94 \mathrm{E}-03$ & $3.32 \mathrm{E}-03$ \\
\hline 30 & $1.04 \mathrm{E}-03$ & $5.24 \mathrm{E}-04$ & $1.42 \mathrm{E}-03$ & $3.62 \mathrm{E}-03$ & $1.58 \mathrm{E}-03$ \\
\hline 60 & $6.53 \mathrm{E}-03$ & $2.87 \mathrm{E}-04$ & $1.03 \mathrm{E}-03$ & $2.21 \mathrm{E}-03$ & $9.90 \mathrm{E}-04$ \\
\hline 90 & $4.98 \mathrm{E}-04$ & $2.02 \mathrm{E}-04$ & $8.55 \mathrm{E}-04$ & $1.65 \mathrm{E}-03$ & $7.53 \mathrm{E}-04$ \\
\hline 120 & $4.11 \mathrm{E}-04$ & $1.57 \mathrm{E}-04$ & $7.49 \mathrm{E}-04$ & $1.34 \mathrm{E}-03$ & $6.20 \mathrm{E}-04$ \\
\hline 365 & $1.95 \mathrm{E}-04$ & $6.00 \mathrm{E}-05$ & $4.49 \mathrm{E}-04$ & $6.07 \mathrm{E}-04$ & $2.92 \mathrm{E}-04$ \\
\hline
\end{tabular}

\subsection{Desorption of $\mathrm{Sr}, \mathrm{Pu}$, and $\mathrm{Np}$ from mMST}

Results from the initial set of desorption experiments showed no measurable desorption of sorbates. Table 3-7 compares the calculated concentration of each sorbate based upon the mixture of the diluted decontaminated salt solution and the residual interstitial liquid with the measured concentration of each sorbate after the desorption test period of 24 hours. Desorption would be evidenced by a higher measured than calculated concentration. There is some evidence of additional sorption of sorbates, including $\mathrm{Pu}, \mathrm{Np}-237$, and $\mathrm{U}$, as evidenced of the measured solution concentrations being well below the calculated values. This is likely due to the much higher sorbent concentration in these experiments (28-34 g/L) compared to the initial loading condition $(0.4 \mathrm{~g} / \mathrm{L})$.

Table 3-7. Results from initial set of desorption tests.

\begin{tabular}{||c|c|c|c|c|c|c|c||}
\hline \multicolumn{2}{|c|}{ [Na] of soln (M) } & \multicolumn{2}{c|}{$\mathbf{3 . 7}$} & \multicolumn{2}{c|}{$\mathbf{2 . 7}$} & \multicolumn{2}{c|}{$\mathbf{2 . 8}$} \\
\hline Analyte & Unit & Calc. $^{*}$ & Measured & Calc.* & Measured & Calc. ${ }^{*}$ & Measured \\
\hline $\mathrm{Cs}-137$ & $\mathrm{dpm} / \mathrm{mL}$ & $5.62 \mathrm{E}+04$ & $5.62 \mathrm{E}+04$ & $3.86 \mathrm{E}+04$ & $3.86 \mathrm{E}+04$ & $4.10 \mathrm{E}+04$ & $4.10 \mathrm{E}+04$ \\
\hline $\mathrm{Sr}-85$ & $\mathrm{dpm} / \mathrm{mL}$ & $5.35 \mathrm{E}+01$ & $<3.65 \mathrm{E}+01$ & $3.88 \mathrm{E}+01$ & $3.78 \mathrm{E}+01$ & $4.92 \mathrm{E}+01$ & $5.13 \mathrm{E}+01$ \\
\hline $\mathrm{Pu}$ & $\mu \mathrm{g} / \mathrm{L}$ & $1.30 \mathrm{E}+00$ & $5.33 \mathrm{E}-01$ & $1.10 \mathrm{E}+00$ & $2.76 \mathrm{E}-01$ & $8.78 \mathrm{E}-01$ & $1.57 \mathrm{E}-01$ \\
\hline $\mathrm{Np}-237$ & $\mu \mathrm{g} / \mathrm{L}$ & $1.04 \mathrm{E}+02$ & $6.26 \mathrm{E}+01$ & $6.30 \mathrm{E}+01$ & $3.56 \mathrm{E}+01$ & $7.41 \mathrm{E}+01$ & $4.61 \mathrm{E}+01$ \\
\hline $\mathrm{U}$ & $\mu \mathrm{g} / \mathrm{L}$ & $5.26 \mathrm{E}+03$ & $1.73 \mathrm{E}+03$ & $3.81 \mathrm{E}+03$ & $1.31 \mathrm{E}+03$ & $4.33 \mathrm{E}+03$ & $1.31 \mathrm{E}+03$ \\
\hline
\end{tabular}

*Calculated values are based on the measured volume of diluted decontaminated salt solution and estimated volume of interstitial final filtrate without any desorption. 
Since the initial tests did not reach the Na concentration expected in the final stages of washing, additional tests were conducted by further diluting the decontaminated salt solution to reduce the $\mathrm{Na}$ concentration to a level of approximately $0.5 \mathrm{M}$, the expected $\mathrm{Na}$ concentration at the end of the washing cycle. Again, Table 3-8 compares the calculated and measured sorbate concentrations in the solution. The calculated and measured concentrations for $\mathrm{Sr}-85, \mathrm{Pu}$ and $\mathrm{U}$ for all three diluted solutions are very similar and indicate no measurable desorption at the more dilute sodium concentrations representing the final stages of washing. For Np-237 the measured and calculated concentrations were similar for the two diluted solutions having $\mathrm{Na}$ concentrations of $0.39 \mathrm{M}$ and $0.56 \mathrm{M}$, respectively. The $\mathrm{Np}-237$ concentration in the $0.88 \mathrm{M}$ Na concentration solution measured $57.6 \mu \mathrm{g} / \mathrm{L}$ compared to the calculated concentration of $16.8 \mu \mathrm{g} / \mathrm{L}$. This result may indicate that a small amount of $\mathrm{Np}-237$ desorbed at this solution concentration. However, no measurable desorption occurred in either of the two solutions which were more dilute than the $0.88 \mathrm{M} \mathrm{Na}$ solution. One would expect desorption, if any, to increase in the more diluted sodium solutions. Since that is not the case with Np-237 (or any of the other sorbates), we suspect that the $\mathrm{Np}-237$ concentration in the $0.88 \mathrm{M} \mathrm{Na}$ solution may be due to experimental error.

Table 3-8. Results from additional desorption tests with more dilute solutions.

\begin{tabular}{||c|c|c|c|c|c|c|c||}
\hline \hline \multicolumn{2}{|c|}{ [Na] of soln (M) } & \multicolumn{2}{c|}{$\mathbf{0 . 8 8}$} & \multicolumn{2}{c|}{$\mathbf{0 . 3 9}$} & \multicolumn{2}{c||}{$\mathbf{0 . 5 6}$} \\
\hline Analyte & Unit & Calc. $^{*}$ & Measured & Calc. $^{*}$ & Measured & Calc.* & Measured \\
\hline $\mathrm{Cs}-137$ & $\mathrm{dpm} / \mathrm{mL}$ & $1.30 \mathrm{E}+04$ & $1.23 \mathrm{E}+04$ & $5.61 \mathrm{E}+03$ & $4.76 \mathrm{E}+03$ & $8.19 \mathrm{E}+03$ & $7.46 \mathrm{E}+03$ \\
\hline $\mathrm{Sr}-85$ & $\mathrm{dpm} / \mathrm{mL}$ & $1.29 \mathrm{E}+01$ & $1.11 \mathrm{E}+01$ & $1.13 \mathrm{E}+01$ & $1.02 \mathrm{E}+01$ & $1.89 \mathrm{E}+01$ & $1.33 \mathrm{E}+01$ \\
\hline $\mathrm{Pu}$ & $\mu \mathrm{g} / \mathrm{L}$ & $1.42 \mathrm{E}-01$ & $<5.82 \mathrm{E}-01$ & $7.53 \mathrm{E}-02$ & $<8.12 \mathrm{E}-02$ & $<7.47 \mathrm{E}-02$ & $<1.76 \mathrm{E}-01$ \\
\hline $\mathrm{Np}-237$ & $\mu \mathrm{g} / \mathrm{L}$ & $1.68 \mathrm{E}+01$ & $5.76 \mathrm{E}+01$ & $<8.20 \mathrm{E}+00$ & $<5.00 \mathrm{E}+00$ & $<9.54 \mathrm{E}+00$ & $<5.00 \mathrm{E}+00$ \\
\hline $\mathrm{U}$ & $\mu \mathrm{g} / \mathrm{L}$ & $9.60 \mathrm{E}+02$ & $1.04 \mathrm{E}+03$ & $3.12 \mathrm{E}+02$ & $7.58 \mathrm{E}+01$ & $5.40 \mathrm{E}+02$ & $9.90 \mathrm{E}+01$ \\
\hline
\end{tabular}

*Calculated values are based on the measured volume of diluted decontaminated salt solution and estimated volume of interstitial final filtrate without any desorption.

\subsection{Effect of Radiation on MST Performance}

Figures 11-14 show the strontium and actinide concentrations as a function of time. Similar removal kinetics are seen for the irradiated samples when compared to the unirradiated controls. The decontamination factors are summarized in Table 3-9, and the plots of DF versus time are provided in the Appendix. There is no general trend for the effect of radiation on the material performance. For the majority of the samples, the DF values for the irradiated samples are within 2 sigma uncertainty of the unirradiated samples, with a few exceptions. In two cases the DF values are slightly higher for the irradiated samples when compared to the unirradiated samples. For Sr, the 24-h DF value for the mMST irradiated in the as received suspension slightly higher than the 24-h DF for the unirradiated mMST. For Np, the 24-h DF value for the MST irradiated in the as received suspension is higher than the DF for the unirradiated MST. The only adverse effect of irradiation was seen for Pu, where the 6-h DF for the mMST irradiated in the SWS was slightly lower than the DF for the unirradiated MST. At later time points, 12 and 24 hours, the DF values come within the 2 sigma uncertainty of the unirradiated material. 


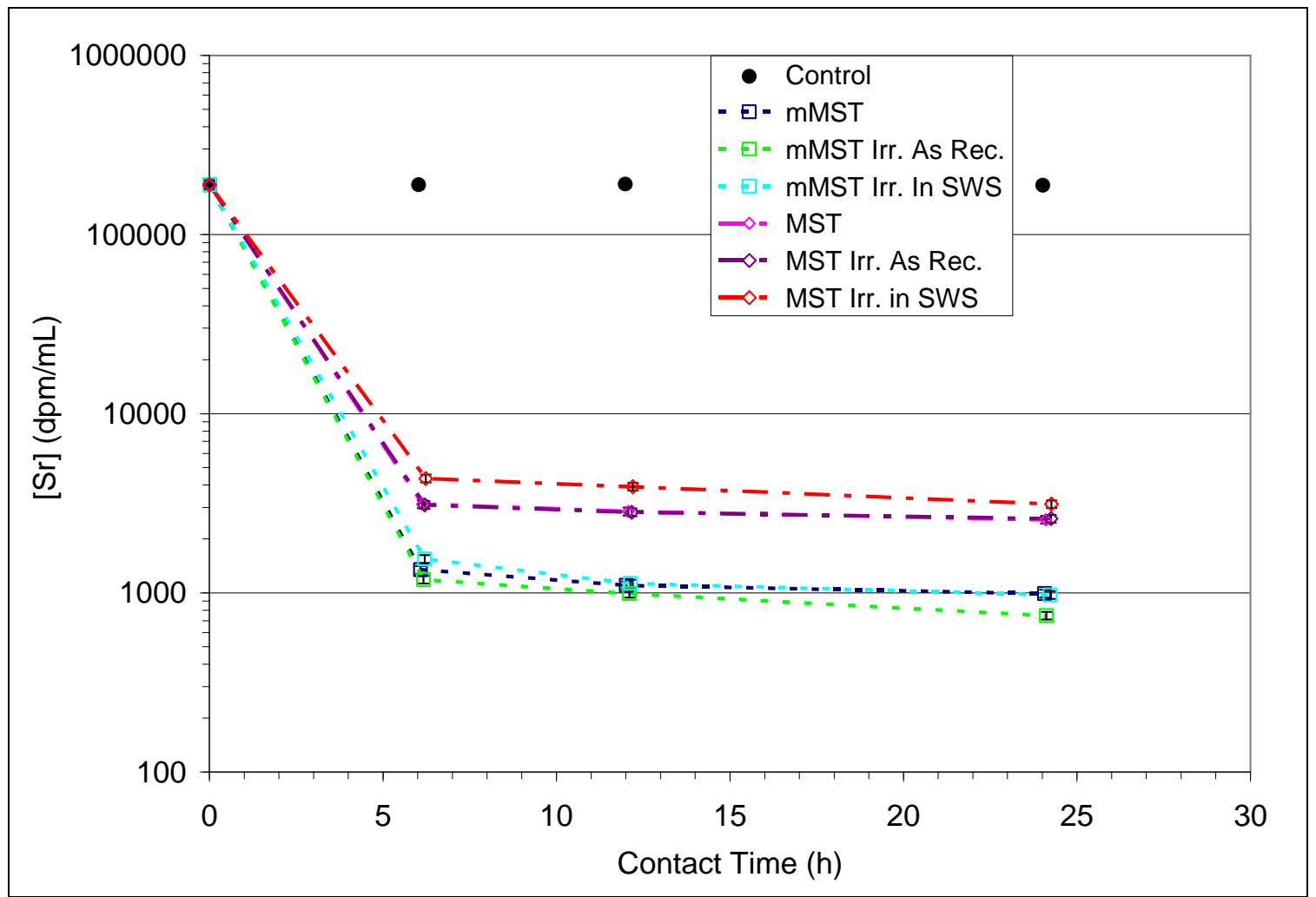

Figure 11. Sr concentration vs. contact time, log scale. Error bars indicate 1 sigma uncertainty. 


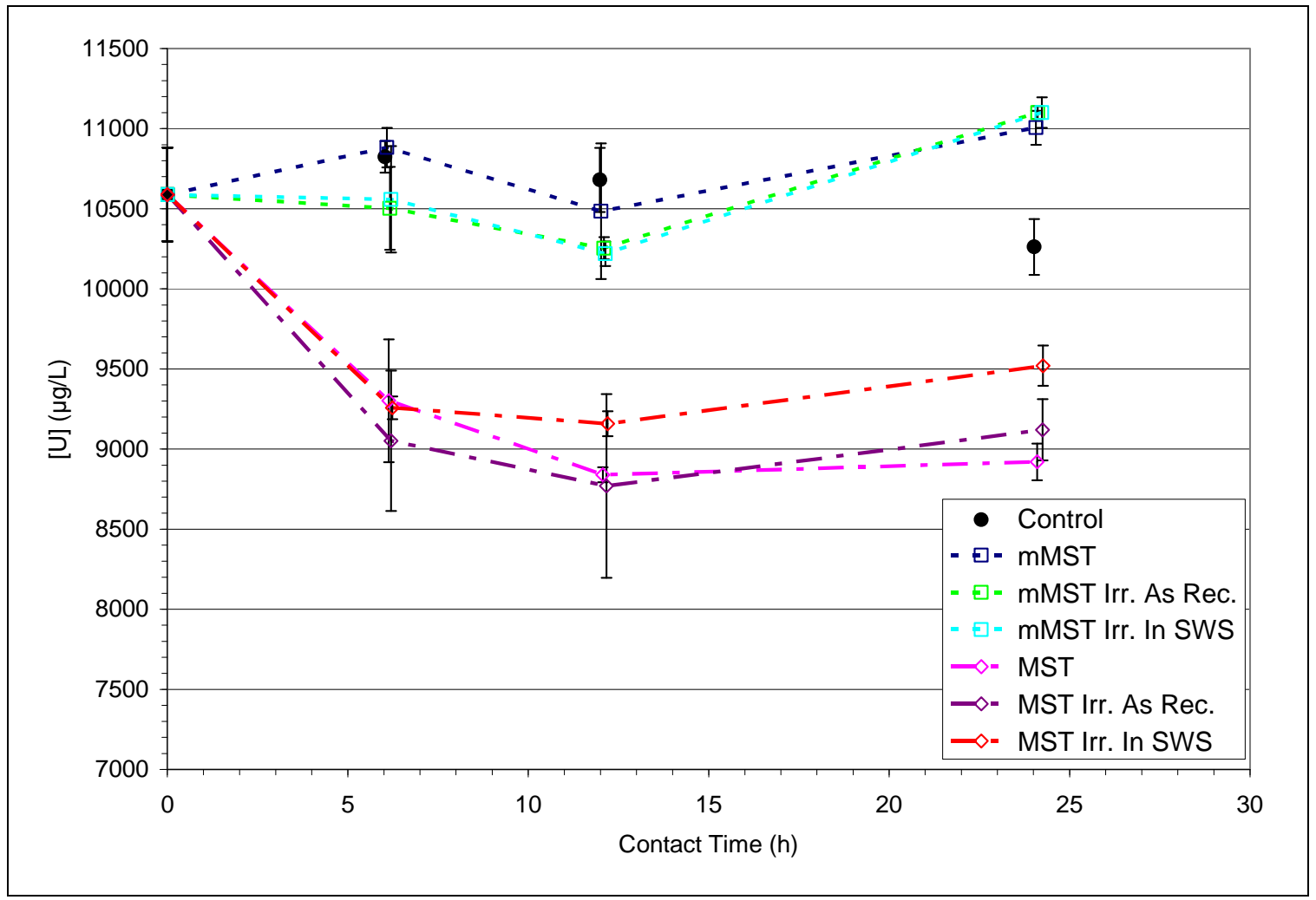

Figure 12. U concentration vs. contact time. Error bars indicate 1 sigma uncertainty. 


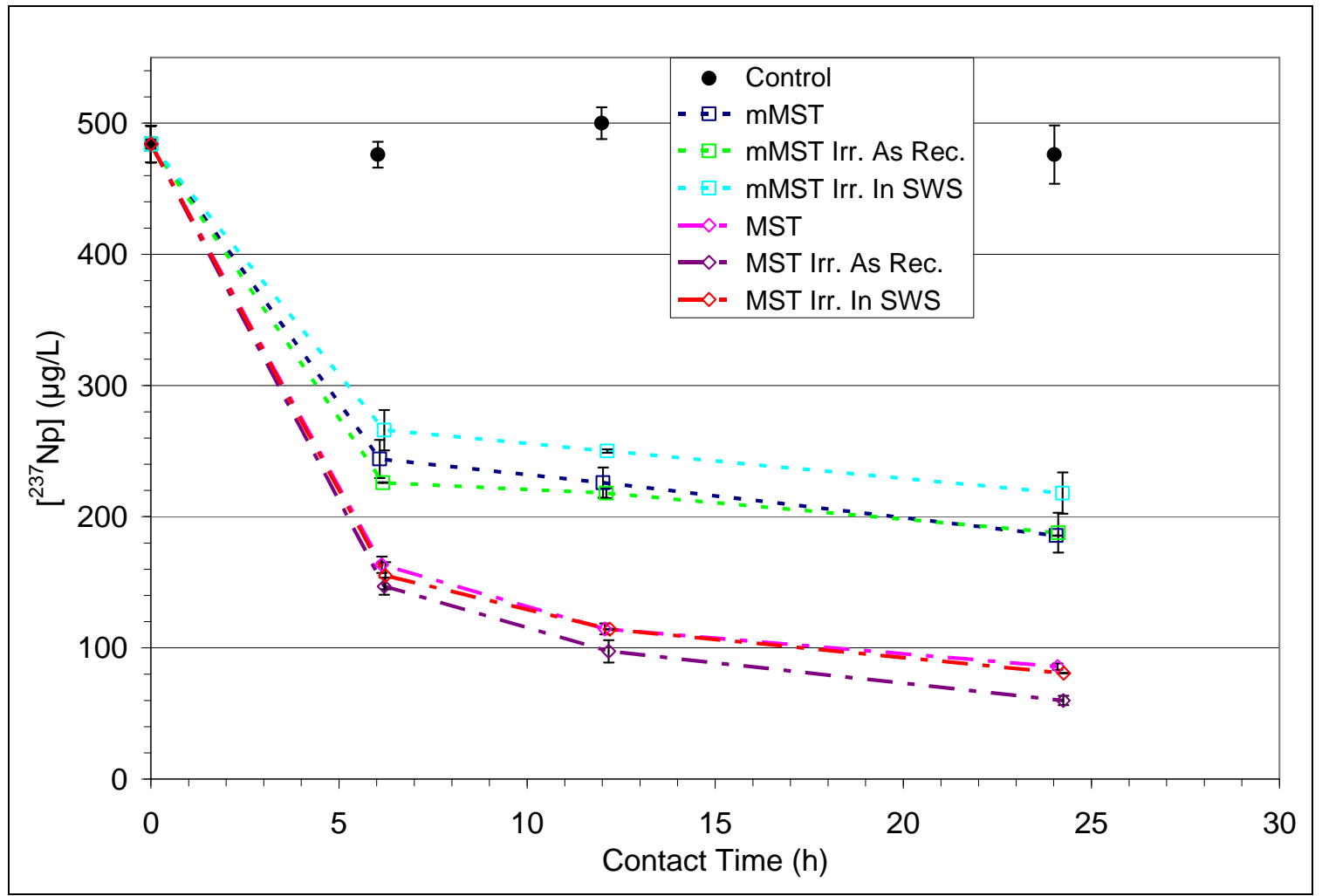

Figure 13. Np concentration vs. contact time. Error bars indicate 1 sigma uncertainty. 
SRNL-STI-2010-00383

Rev 0

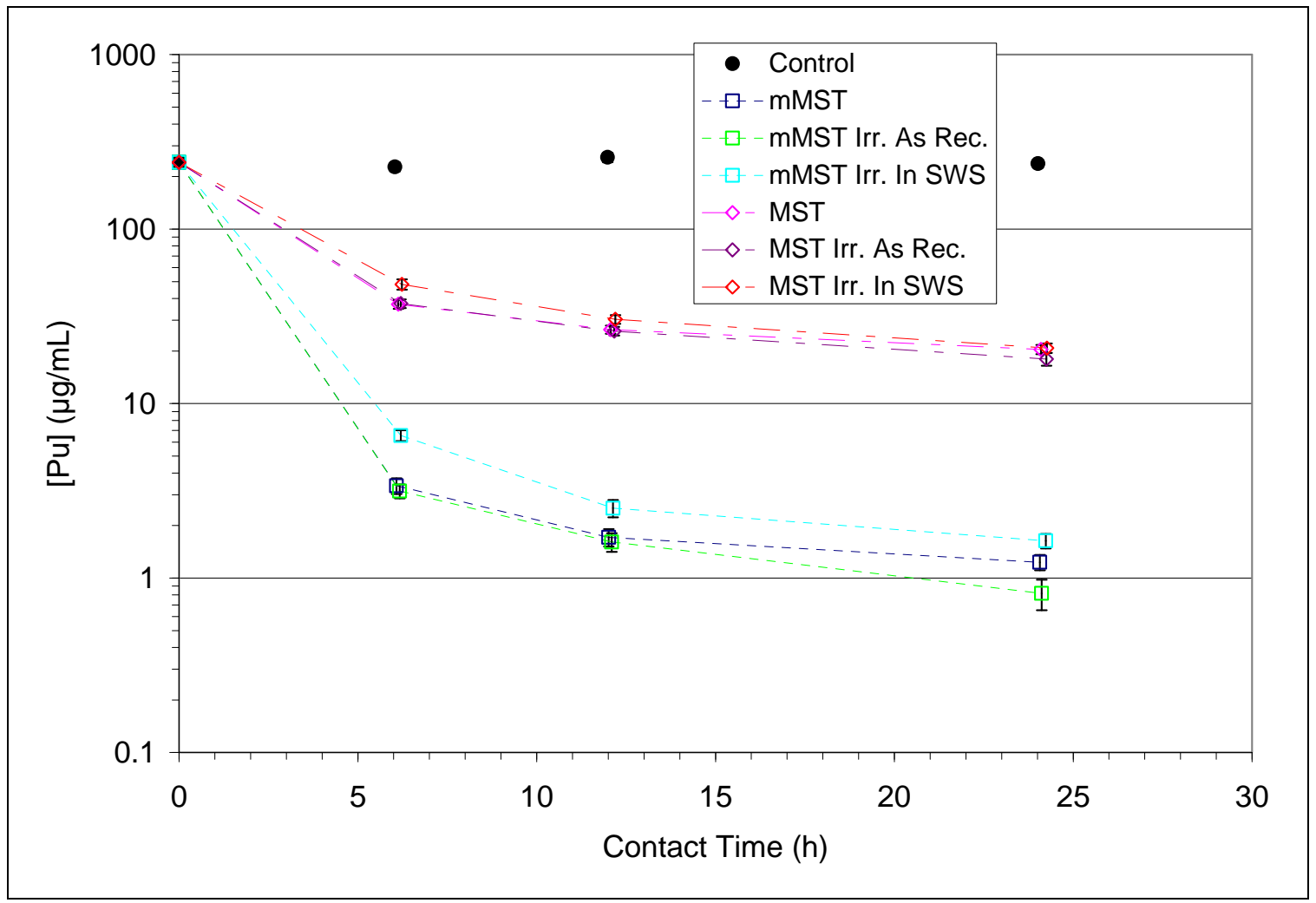

Figure 14. Pu concentration vs. contact time, log scale. Error bars indicate 1 sigma uncertainty. 
Table 3-9. Summary of DFs. Uncertainty column represents one sigma uncertainty.

\begin{tabular}{|c|c|c|c|c|c|c|c|c|c|c|c|c|}
\hline \multicolumn{13}{|c|}{ Sr DF } \\
\hline \multirow{3}{*}{$\begin{array}{l}\text { Contact } \\
\text { Time } \\
\text { (h) }\end{array}$} & \multicolumn{6}{|c|}{ mMST } & \multicolumn{6}{|c|}{ MST } \\
\hline & \multicolumn{2}{|c|}{ Unirradiated } & \multicolumn{2}{|c|}{ Irr. As Rec. } & \multicolumn{2}{|c|}{ Irr. In SWS } & \multicolumn{2}{|c|}{ Unirradiated } & \multicolumn{2}{|c|}{ Irr. As Rec. } & \multicolumn{2}{|c|}{ Irr. In SWS } \\
\hline & DF & Unc. & DF & Unc. & DF & Unc. & DF & Unc. & DF & Unc. & DF & Unc. \\
\hline 6 & 141 & 9.94 & 160 & 11.3 & 122 & 8.66 & 60.5 & 4.28 & 61.1 & 4.32 & 43.5 & 3.08 \\
\hline 12 & 173 & 12.3 & 193 & 13.6 & 169 & 12.0 & 67.0 & 4.74 & 67.7 & 4.79 & 48.8 & 3.45 \\
\hline 24 & 190 & 13.5 & 253 & 17.9 & 194 & 13.7 & 73.7 & 5.21 & 72.7 & 5.14 & 60.3 & 4.26 \\
\hline \multicolumn{13}{|c|}{ U DF } \\
\hline \multirow{3}{*}{$\begin{array}{c}\text { Contact } \\
\text { Time } \\
\text { (h) }\end{array}$} & \multicolumn{6}{|c|}{ mMST } & \multicolumn{6}{|c|}{ MST } \\
\hline & \multicolumn{2}{|c|}{ Unirradiated } & \multicolumn{2}{|c|}{ Irr. As Rec. } & \multicolumn{2}{|c|}{ Irr. In SWS } & \multicolumn{2}{|c|}{ Unirradiated } & \multicolumn{2}{|c|}{ Irr. As Rec. } & \multicolumn{2}{|c|}{ Irr. In SWS } \\
\hline & DF & Unc. & DF & Unc. & DF & Unc. & DF & Unc. & DF & Unc. & DF & Unc. \\
\hline 6 & 0.995 & 0.0144 & 1.03 & 0.0270 & 1.03 & 0.0336 & 1.16 & 0.0491 & 1.20 & 0.0589 & 1.17 & 0.0139 \\
\hline 12 & 1.02 & 0.0453 & 1.04 & 0.0208 & 1.05 & 0.0211 & 1.21 & 0.0235 & 1.22 & 0.0828 & 1.17 & 0.0240 \\
\hline 24 & 0.932 & 0.0182 & 0.924 & 0.0161 & 0.924 & 0.0176 & 1.15 & 0.0245 & 1.13 & 0.0304 & 1.08 & 0.0232 \\
\hline \multicolumn{13}{|c|}{ Np DF } \\
\hline \multirow{3}{*}{$\begin{array}{c}\text { Contact } \\
\text { Time } \\
\text { (h) }\end{array}$} & \multicolumn{6}{|c|}{ mMST } & \multicolumn{6}{|c|}{ MST } \\
\hline & \multicolumn{2}{|c|}{ Unirradiated } & \multicolumn{2}{|c|}{ Irr. As Rec. } & \multicolumn{2}{|c|}{ Irr. In SWS } & \multicolumn{2}{|c|}{ Unirradiated } & \multicolumn{2}{|c|}{ Irr. As Rec. } & Irr. & 1 SWS \\
\hline & DF & Unc. & DF & Unc. & DF & Unc. & DF & Unc. & DF & Unc. & DF & Unc. \\
\hline 6 & 1.95 & 0.123 & 2.11 & 0.0434 & 1.82 & 0.117 & 2.96 & 0.141 & 3.29 & 0.173 & 3.12 & 0.226 \\
\hline 12 & 2.21 & 0.125 & 2.29 & 0.0682 & 1.94 & 0.0562 & 4.23 & 0.197 & 4.97 & 0.459 & 4.24 & 0.121 \\
\hline 24 & 2.56 & 0.120 & 2.53 & 0.237 & 2.22 & 0.172 & 5.64 & 0.226 & 8.07 & 0.523 & 5.99 & 0.172 \\
\hline & & & & & & $1 \mathrm{DF}$ & & & & & & \\
\hline Contact & & & & IST & & & & & & $\overline{\text { ST }}$ & & \\
\hline Time & Uniri & Idiated & Irr. & s Rec. & Irr. & SWS & Unir & adiated & Irr. & s Rec. & Irr. & 1 SWS \\
\hline (h) & DF & Unc. & DF & Unc. & $\overline{D F}$ & Unc. & DF & Unc. & DF & Unc. & DF & Unc. \\
\hline 6 & 67.2 & 8.06 & 72.1 & 7.91 & 34.6 & 3.20 & 6.12 & 0.512 & 6.08 & 0.508 & 4.71 & 0.423 \\
\hline 12 & 151 & 19.7 & 160 & 21.8 & 103 & 13.3 & 9.71 & 0.789 & 9.90 & 0.837 & 8.49 & 0.722 \\
\hline 24 & 193 & 22.1 & 291 & 60.2 & 145 & 15.7 & 11.6 & 0.950 & 13.2 & 1.30 & 11.4 & 0.942 \\
\hline
\end{tabular}

\subsection{Effect of Age on Modified MST Performance}

Figures 15-18 show the decontamination factors (DFs) obtained for each of the samples of different ages (as listed in Table 2-4). LS-8 has experienced accelerated aging due to exposure to elevated temperature, which is evident in the reduced peroxide content as measured by iodometric titration. As can be seen from Figure 15, the Pu DF for the oldest sample (4.7 y, LS-2) is significantly lower than the Pu DF obtained with the other samples. Sample LS-8, which iodometric titration indicated had a reduced amount of peroxide, also shows a lower Pu DF. The $\mathrm{Pu}$ DF for samples of ages $0.30 \mathrm{y}$ (LS-7) and 0.09 y (LS-9) are within error at the 6 and 24 hour sampling times. Samples from the 12 hour sampling time fell below the method detection limit, resulting in greater than values calculated for the DFs. Figure 16 shows the DF values for ${ }^{237} \mathrm{~Np}$. In this case LS-8, which has experienced accelerated aging due to exposure to elevated temperature, shows the highest ${ }^{237} \mathrm{~Np} \mathrm{DF}$, whereas the DF for the other samples are not statistically different from each other. It is difficult to draw any conclusions regarding the ${ }^{85} \mathrm{Sr}$ removal, since many of the samples fell below the method detection limit, resulting in greater than values being obtained for the DFs. However, it does appear that the oldest sample $(4.7 \mathrm{y}$, LS-2) resulted in the least Sr removal, as the results for all time points for this sample were above the method detection limit. At the 6 hour time point, the Sr DF for LS-2 is clearly lower than that obtained for LS-8 and LS-9: however at the later time points this conclusion cannot be drawn as the value falls within error of the minimum DF values for LS-8 and LS-9. As can be seen in 
Figure 18, there appears to be no effect of age on the uranium sorption of these materials. None of the samples appear to adsorb a measurable amount of uranium. Figures showing the strontium and actinide concentrations with respect to time are provided in the Appendix.

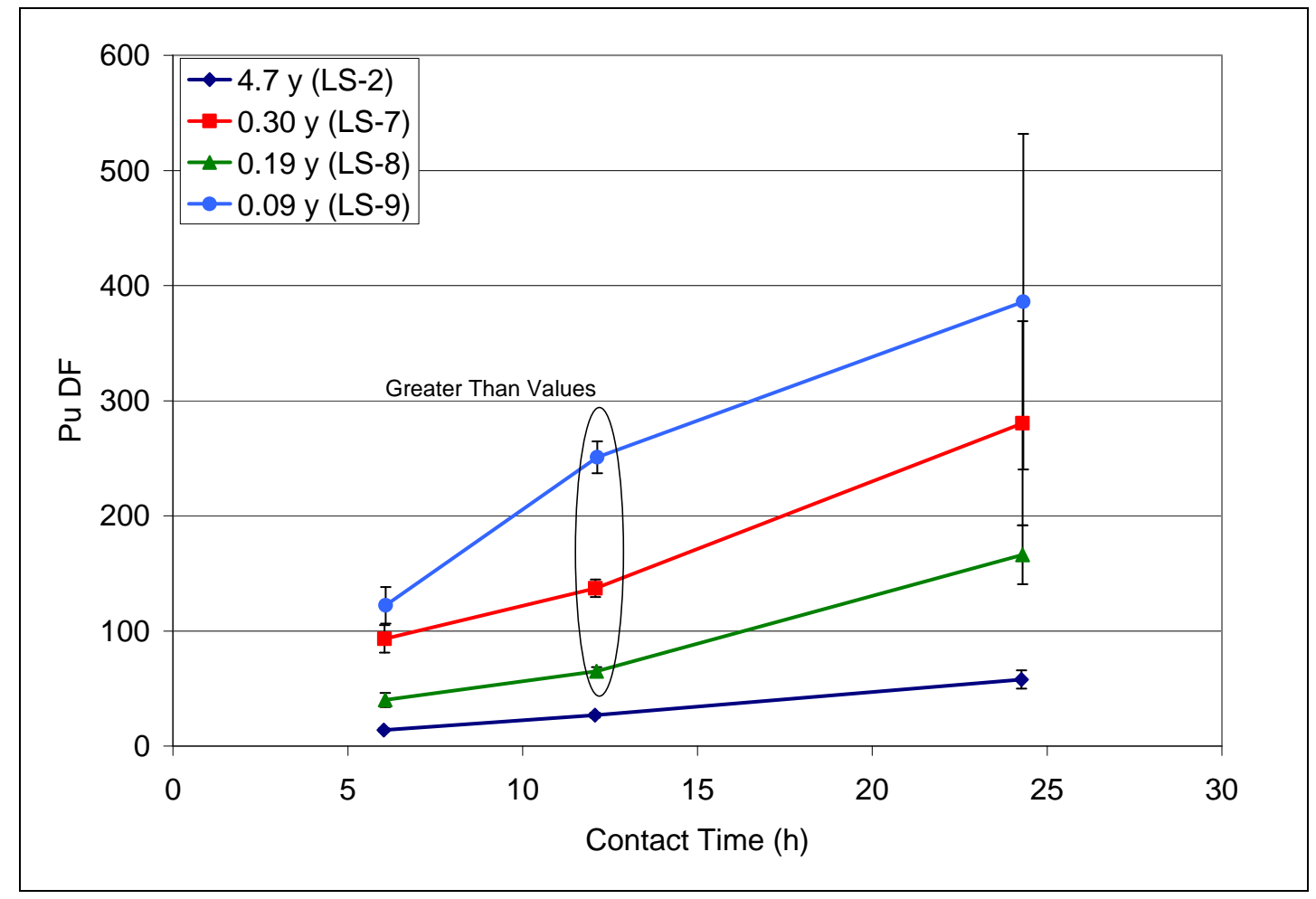

Figure 15. Pu DF for mMST of increasing storage age. 


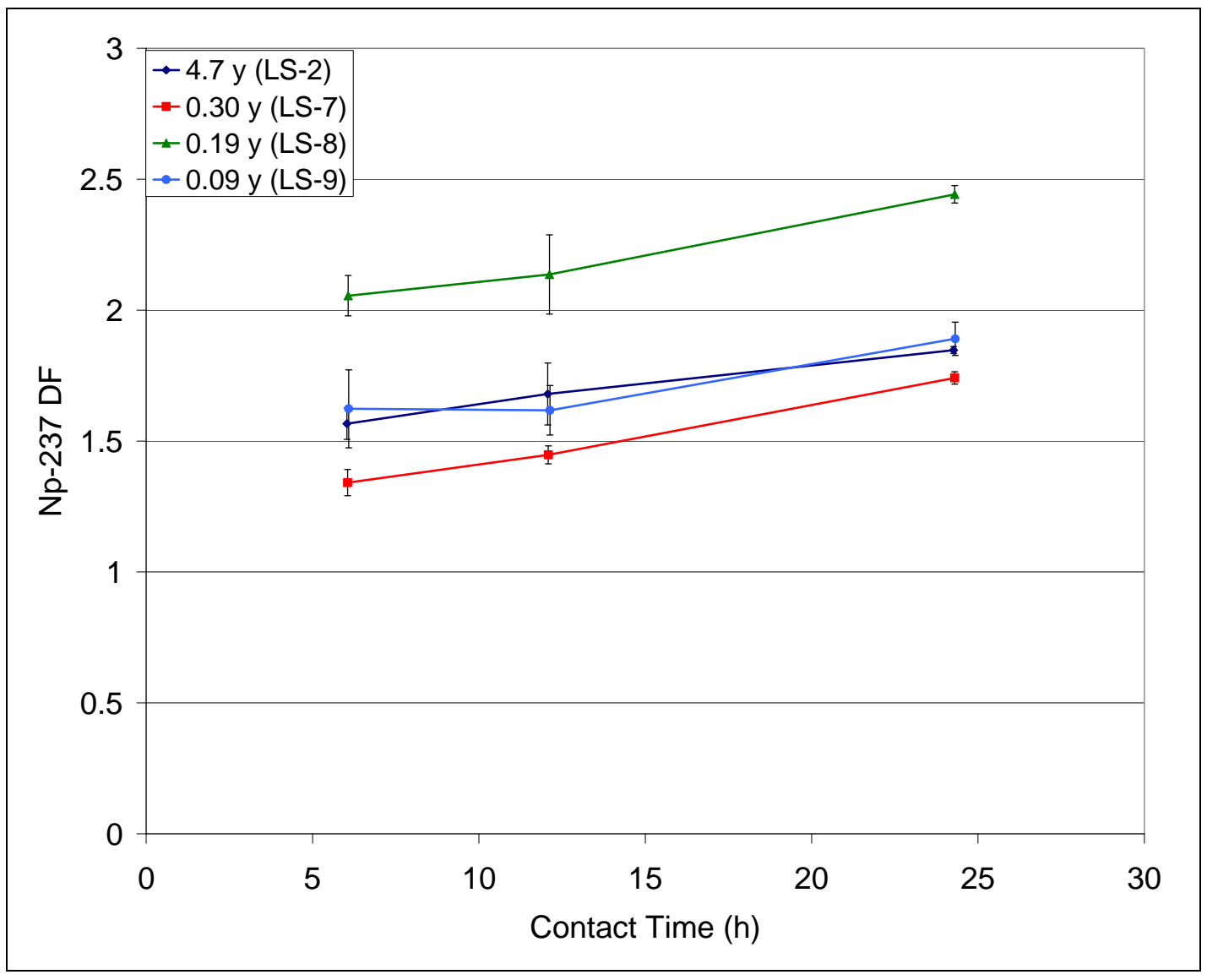

Figure 16. ${ }^{237} \mathrm{~Np} \mathrm{DF}$ for mMST of increasing storage age. 


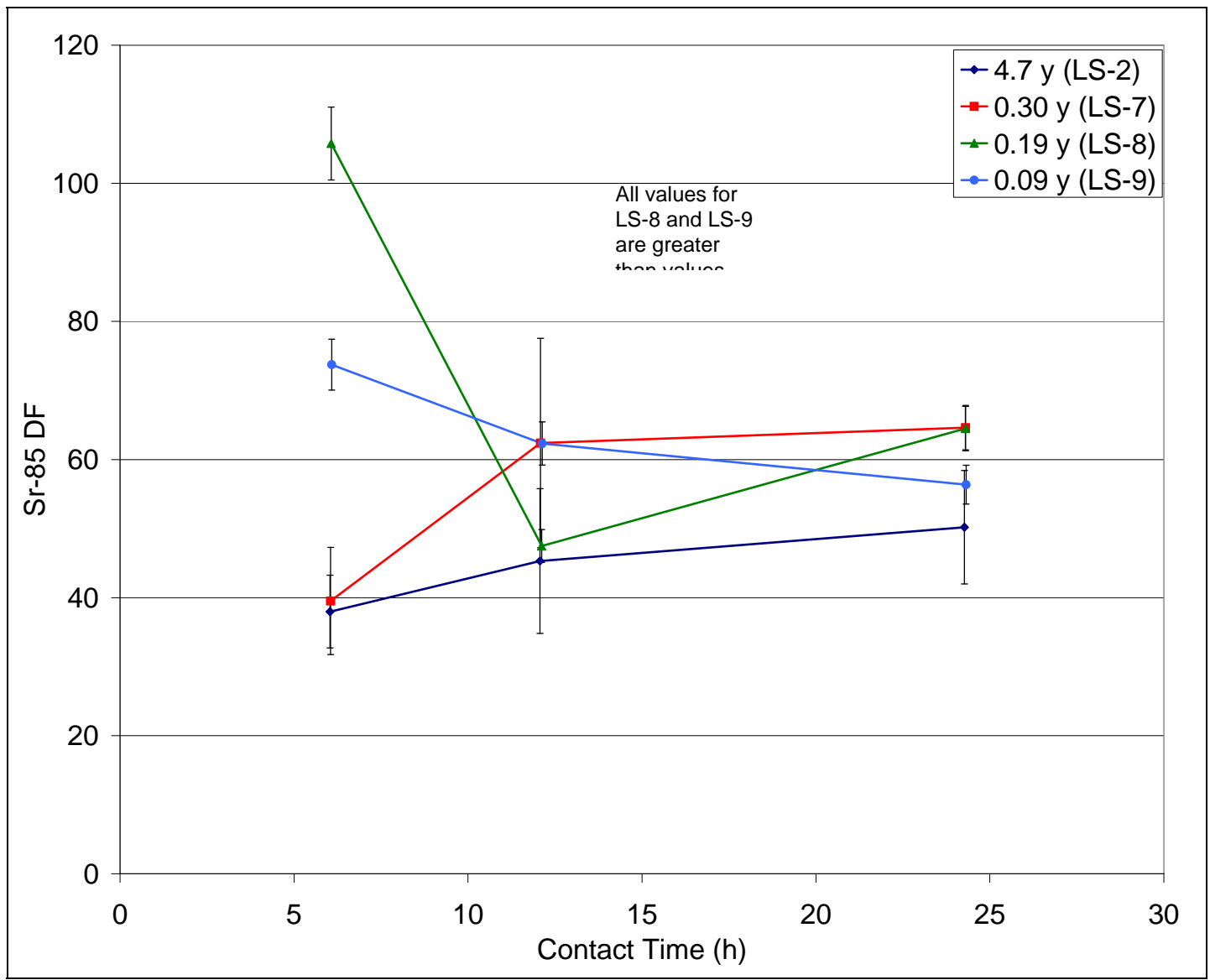

Figure 17. ${ }^{85} \mathrm{Sr}$ DF for $\mathrm{mMST}$ of increasing storage age. 


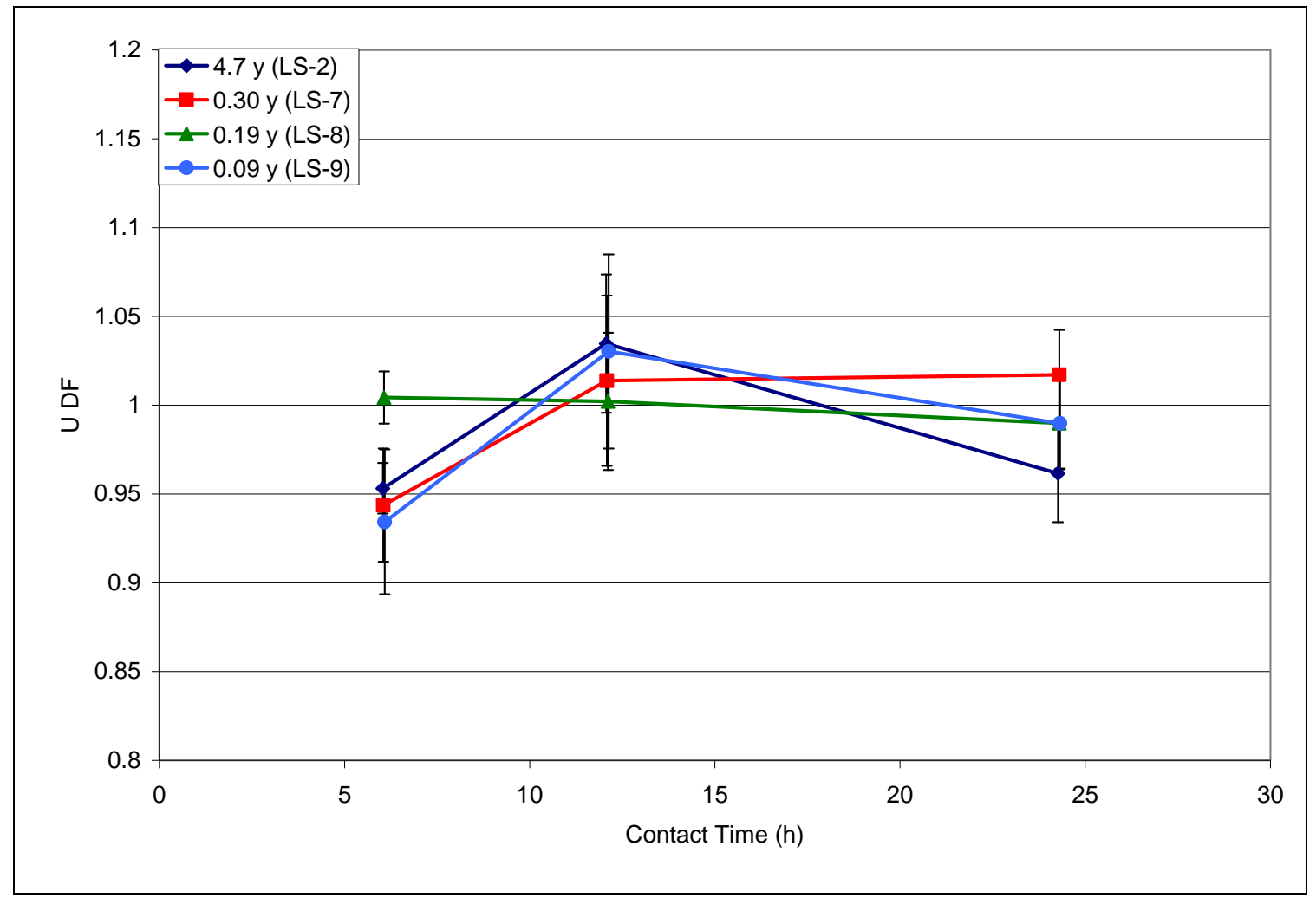

Figure 18. U DF for mMST of increasing storage age.

Earlier testing evaluated the performance of sample LS-2 over a time period of approximately 30 months with no measurable decrease in Pu DF. However, this testing at 56.4 months showed a significant decrease in Pu DF to a value only $18 \%$ of the Pu DF averaged over the earlier test dates (Table 3-10 and Figure 19).

Table 3-10. Pu DF Over Time for mMST Sample LS-2.

\begin{tabular}{|c|c|c|c|c||}
\hline Elapsed Time from & \multicolumn{4}{|c|}{ Pu DF } \\
\cline { 2 - 5 } $\begin{array}{c}\text { Prep. To Performance } \\
\text { Test (months) }\end{array}$ & 6-hour Contact Time & \multicolumn{1}{|c|}{ 12-hour Contact Time } \\
\cline { 2 - 5 } & Average & Std Dev & Average & Std Dev \\
\hline 0.44 & $9.57 \mathrm{E}+01$ & $1.76 \mathrm{E}+01$ & $1.72 \mathrm{E}+02$ & $6.16 \mathrm{E}+00$ \\
\hline 6.16 & $6.38 \mathrm{E}+01$ & $6.14 \mathrm{E}+00$ & $1.43 \mathrm{E}+02$ & $2.66 \mathrm{E}+01$ \\
\hline 11.72 & $6.82 \mathrm{E}+01$ & $1.39 \mathrm{E}+01$ & $1.24 \mathrm{E}+02$ & $9.25 \mathrm{E}+00$ \\
\hline 13.43 & $7.85 \mathrm{E}+01$ & $1.12 \mathrm{E}+01$ & $1.48 \mathrm{E}+02$ & $2.66 \mathrm{E}+01$ \\
\hline 29.91 & $9.52 \mathrm{E}+01$ & $1.17 \mathrm{E}+01$ & $1.22 \mathrm{E}+02$ & $2.09 \mathrm{E}+01$ \\
\hline 56.41 & $1.40 \mathrm{E}+01$ & $1.46 \mathrm{E}+00$ & $2.69 \mathrm{E}+01$ & $2.19 \mathrm{E}+00$ \\
\hline
\end{tabular}




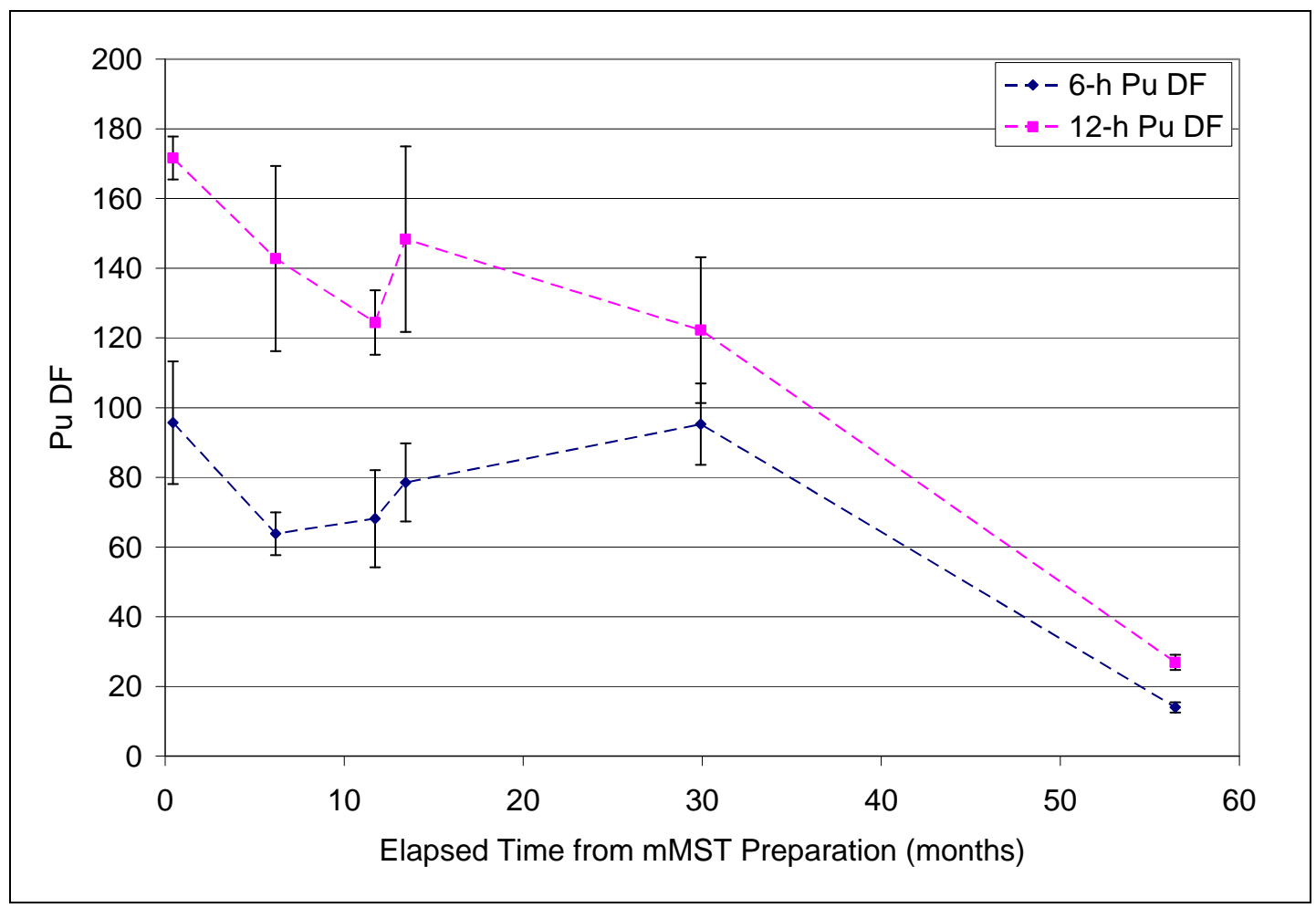

Figure 19. Pu DF for LS-2 as a function of elapsed time since preparation.

Testing was also performed using a "uranium-only" simulant to determine if mMST begins to absorb uranium as the peroxide is lost with age. Similar testing with "uranium-only" simulant was performed with these same batches of MST (Optima 00-QAB-417) and mMST (Optima 06QAB-0139) 26 months earlier. These earlier results were used for comparison to determine if the loss of peroxide over time caused an increase in uranium uptake by the mMST. Figures 20 and 21 show the uranium decontamination factors (DFs) for the MST and mMST samples, respectively, measured in Oct. 2007 and Dec. 2009. For the MST there is no measurable change in the uranium sorption between the two sets of data. For the mMST, there is an increase in the uranium sorption measured at the 12 hour time point. The decontamination factor measured in 2009 was $1.21 \pm 0.0109$ compared to $1.10 \pm 0.0178$ in 2007 . A plot of the uranium concentration with respect to contact time for both sets of data is provided in the Appendix. 


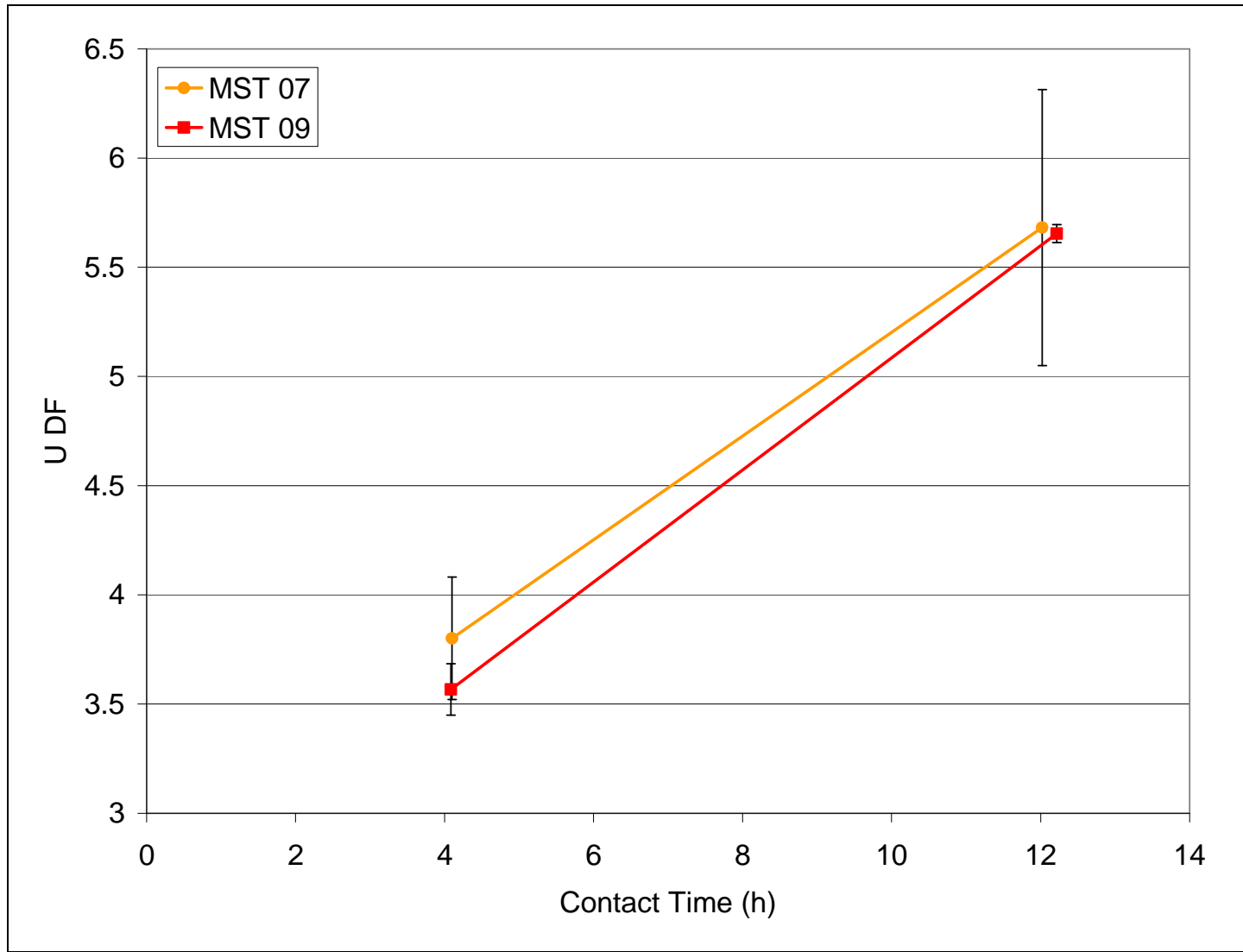

Figure 20. Uranium decontamination factors for MST (Optima 00-QAB-417) measured in October 2007 and in December 2009. 


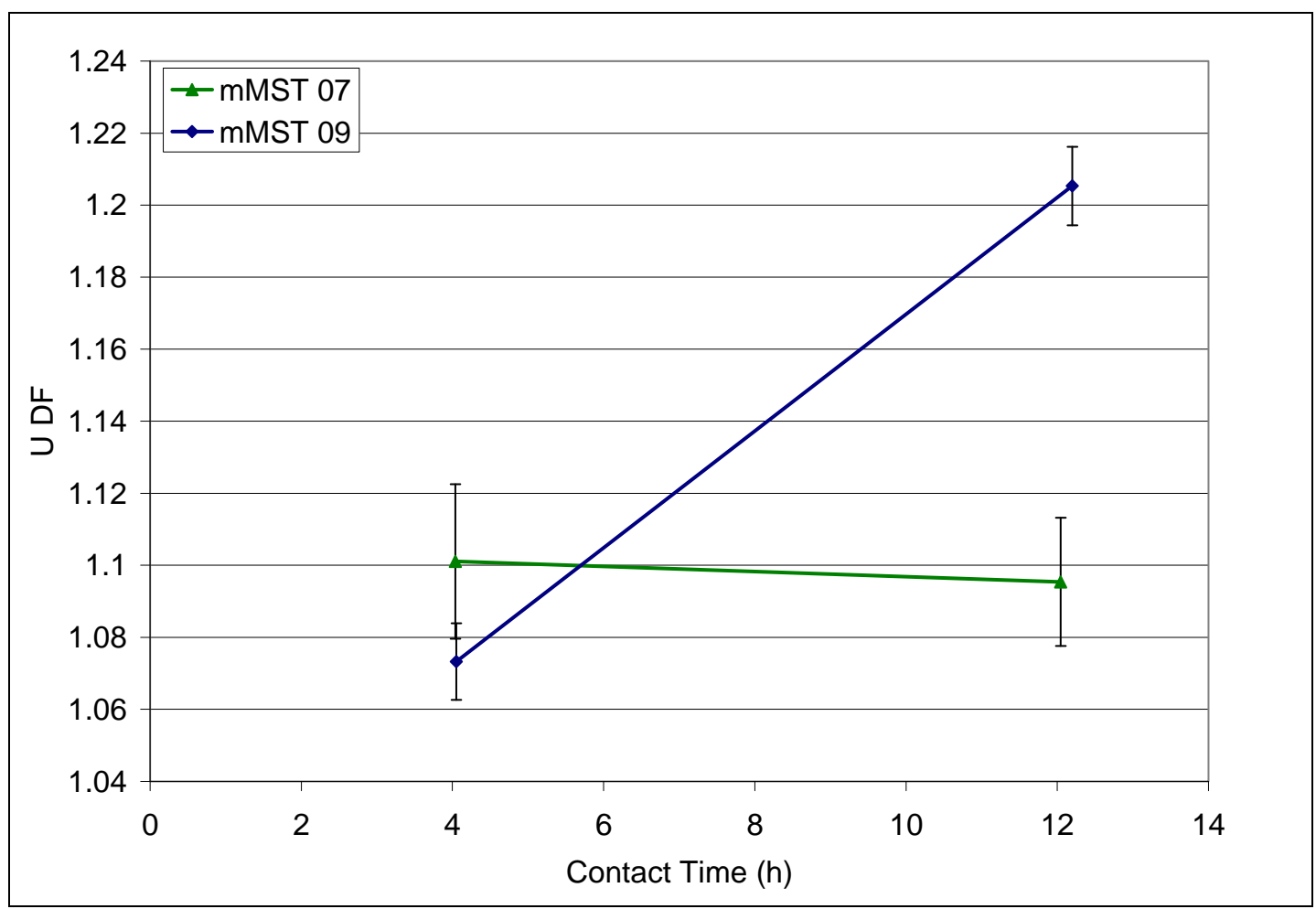

Figure 21. Uranium decontamination factors for mMST (Optima 06-QAB-0139) measured in October 2007 and in December 2009.

\subsection{Conclusions}

Phase III testing of modified MST focused on further characterization of the material including determination of peroxide content, evaluation of the post-synthesis gas release under different conditions, and evaluation of the performance of the material under varying conditions. Several of the characterizations also focused on how the material changes with age. Iodometric titration was used to determine the peroxide content of the mMST samples. Results from these tests indicated a loss of peroxide content with age or extended exposure to elevated temperatures. A logarithmic trend between peroxide added during the synthesis and peroxide present in the resulting materials was also determined using this method. Further testing indicated a loss of peroxide content after exposure of the material to an alkaline salt solution, similar in composition to the simulated waste solutions used for performance testing.

Previous testing established that the mMST releases oxygen gas during the synthesis, and continues to off-gas at a rapidly diminishing rate after synthesis. Several modifications to the work-up of the material were evaluated to determine their effect on gas release after preparation. These modifications included either an acidic or alkaline wash of the material after the synthesis was complete. There appeared to be little effect of these modifications on the post-synthesis gas release rates. The alkaline wash did result in a slight decrease of the initial gas release rate; however after two days the gas release measurements are not statistically different among the different batches of mMST. Because the material may be exposed to elevated temperatures of up to $120^{\circ} \mathrm{F}\left(49^{\circ} \mathrm{C}\right)$ during shipping and storage, an experiment was performed to measure the rate of gas release at this elevated temperature. The gas release rate was found to be consistently higher than the rate measured at room temperature. The quantity of post-synthesis gas released 
from the mMST is sufficient under all conditions tested to require vented containers for the shipment and storage of large quantities of material.

A desorption test was designed to determine if any desorption of $\mathrm{Sr}, \mathrm{Pu}$, or $\mathrm{Np}$ occurred under conditions used to wash the mMST prior to transfer to the DWPF. Several dilutions of decontaminated salt solution were prepared. No loss of $\mathrm{Sr}, \mathrm{Np}$, or $\mathrm{Pu}$ was observed over the concentration range tested.

To determine the effect of radiation on the performance of the material, a performance test was completed using material that had been irradiated at a dose similar to what would be received during the ARP processing. Results from this testing indicated no adverse effects of irradiation on the performance of the material.

Performance tests were also completed with samples of varying age to determine if the loss of peroxide effects the $\mathrm{Sr}$ and actinide removal efficiency of the material. Testing did indicate some loss of $\mathrm{Pu}$ and $\mathrm{Sr}$ removal in the oldest sample tested (4.7 yrs). Previous testing with this sample indicated no loss in Pu removal up to an age of 30 months. The age of the sample did not appear to reduce the $\mathrm{Np}$ removal efficiency, and no measurable uptake of uranium was observed at this sorbent loading $(0.2 \mathrm{~g} / \mathrm{L})$. An additional test was performed using a uranium only simulant and increased sorbent loadings $(3.0 \mathrm{~g} / \mathrm{L})$ to determine if the loss of peroxide with age results in uptake of uranium by mMST. Results for one sample measured at age 1.44 years and 3.64 years were compared, and a slight increase of uranium uptake was observed in the older sample (DF of 1.10 vs. 1.21).

\subsection{Recommendations, Path Forward or Future Work}

Based on the results of the Phase III testing as well as that from earlier studies (Phases I and II), SRNL researchers recommend adopting the use of the mMST material for the removal of strontium and actinides from the SRS HLW supernatant liquids in the Actinide Removal Process and Salt Waste Processing Facility. Given the decrease in $\mathrm{Sr}$ and $\mathrm{Pu}$ removal performance for the mMST having an age of 4.7 years, we recommend that mMST be used within 30 months of production. Furthermore we recommend that DOE provide funding to conduct pilot-scale testing of the mixing and settling characteristics of the mMST and impact, if any, on the generation of hydrogen during processing in the DWPF.

\subsection{References}

1. Lynch, R. W.; Dosch, R. G.; Kenna, B. T.; Johnstone, J. K.; Nowak, E. J. Sandia Solidification Process: A Broad Range Aqueous Waste Solidification Method. In Management of Radioactive Wastes from theNuclear Fuel Cycle, Vol., IAEA Symposium on the Management of Radioactive Waste, Vienna, Austria,March 22, 1976, IAEA, Vienna, 1976, p 360-372.

2. Lynch, R. W. Sandia Solidification Process - Cumulative Report July 1974 - January 1976; Technical Report Sandia National Laboratory, SAND-76-0105, Albuquerque, NM, January 1976.

3. Walker, D. D.; Schmitz, M. A. "Technical Data Summary In-Tank Precipitation Processing of Soluble High-Level Waste,” DPSTD-84-103, May 1984.

4. Record of Decision: Savannah River Site Salt Processing Alternatives (Salt Processing SEIS, DOE/EIS-0082-S2), Federal Register, Vol. 66, No. 201, October 17, 2001. 
5. "Actinide Removal Process Alternative Study and Selection (U)," G-ADS-G-00007, Rev. 0, January 2002.

6. Harris, J. B. "Specification for Procurement of Monosodium Titanate," Specification No. ZSPP-H-00001, Rev. 2, May 1992.

7. Lorier, T. H.; Jantzen, C. M. "Evaluation of the TiO2 Limit for DWPF Glass", WSRC-TR2003-00396, Revision 0, October 30, 2003.

8. Hobbs, D. T.; Nyman, M.; Clearfield, A. "Tailoring Inorganic Sorbents for SRS Strontium and Actinide Separations: Optimized Monosodium Titanate and Pharmacosiderite," Volume 1 - Technical Proposal, WSRC-SRTC-PR-02-21-02, February 7, 2003.

9. Hobbs, D. T.; Nyman, M. D.; Poirier, M. R.; Barnes, M. J.; Thompson, M. E.; "Tailoring Inorganic Sorbents for SRS Strontium and Actinide Separations: Optimized Monosodium Titanate Phase II Interim Report for External Release,” WSRC-STI-2006-00072, Rev. 0, August 2006.

10. Hobbs, D. T.; Nyman, M. D.; Peters, T. B.; Poirier, M. R.; Barnes, M. J.; Thompson, M. E.; "Tailoring Inorganic Sorbents for SRS Strontium and Actinide Separations: Optimized Monosodium Titanate Phase II Final Report,” WSRC-STI-2007-00082, Rev. 0, June 2007.

11. Hobbs, D. T., "Improved Strontium and Actinide Separations Modified Monosodium Titanate Final Report of FY2008 Testing Activities," SRNL-STI-2008-00390, Rev. 0, December 2008.

12. Hobbs, D. T., Barnes, M. J., Pulmano, R. L., Marshall, K. M., Edwards, T. B., Bronikowski, M. G., Fink, S. D. (2005) Strontium and Actinide Separations from High Level Nuclear Waste Solutions Using Monosodium Titanate 1. Simulant Testing. Separation Science and Technology, 40 (15): 3093.

13. Nyman, M.; Hobbs, D. T. (2006) A Family of Peroxo-titanate Materials Tailored for Optimal Strontium and Actinide Sorption. Chem. Mater. 18 (26): 6425.

14. Missimer, D.; Jurgensen, A.; Rutherford, R. "High Temperature X-ray Diffraction Analyses of Monosodium Titanate \& Sodium Peroxotitanate”, SRNL-L4200-2009-00024, June 8, 2009.

15. Dinnebier, R. E. "Material Phase Transitions/Melting Point Temperature", http://www.mpistuttgart.mpg.de/xray/html/temperature_calibration.html.

16. "Calibration Standards", http://www.chemistry.ohio-state.edu/ gallaghe/ta/calib_stand.htm.

17. Poirier, M. R.; Fink, S. D., "MST Settling Rates in the Actinide Removal Process," WSRCSTI-2007-00410, Rev. 0, August 2007. 
SRNL-STI-2010-00383

Rev 0

Appendix A 


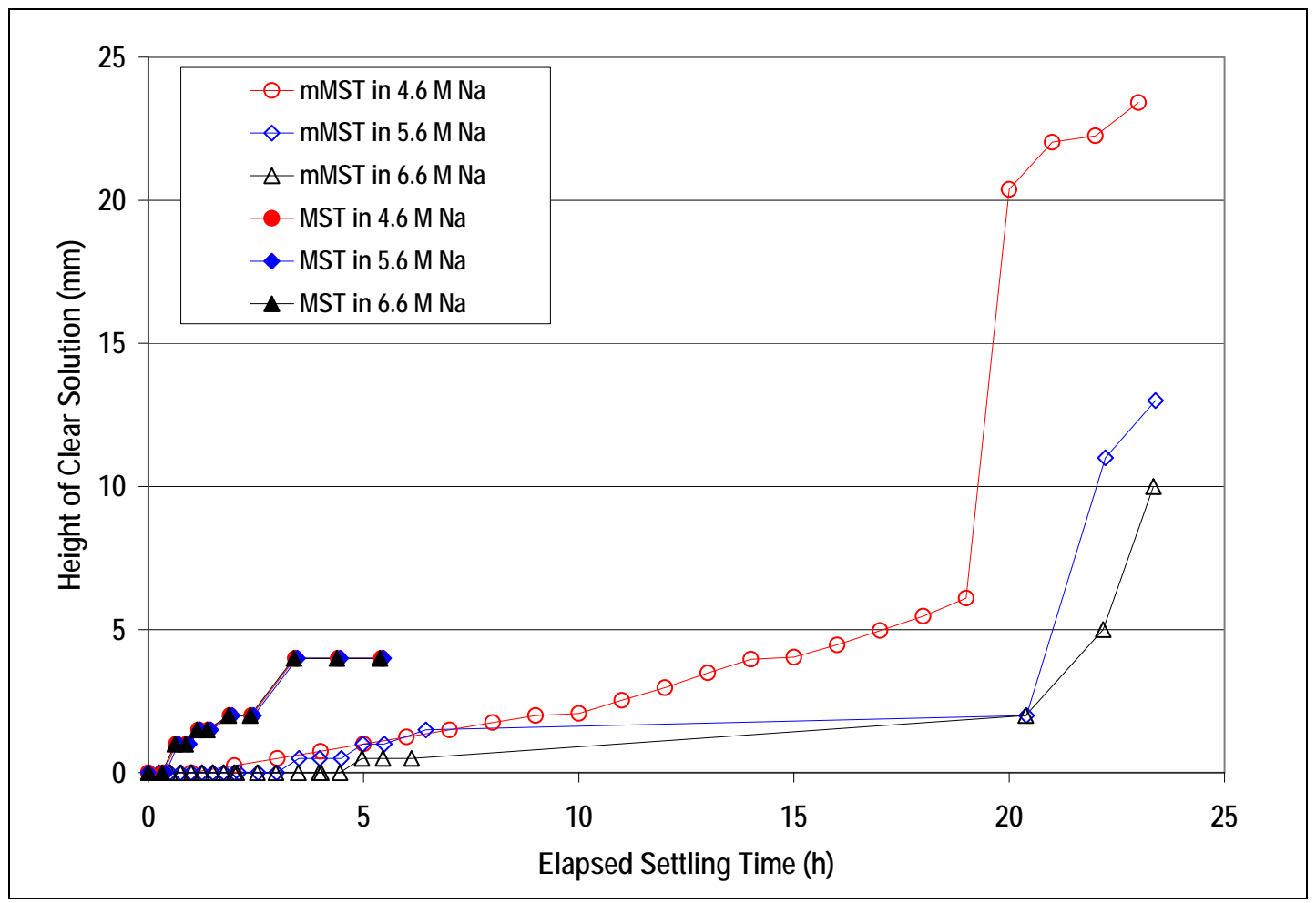

Figure A-1. Height of clear solution at top of settling test versus elapsed time for mMST and MST samples in solutions of varying ionic strength.

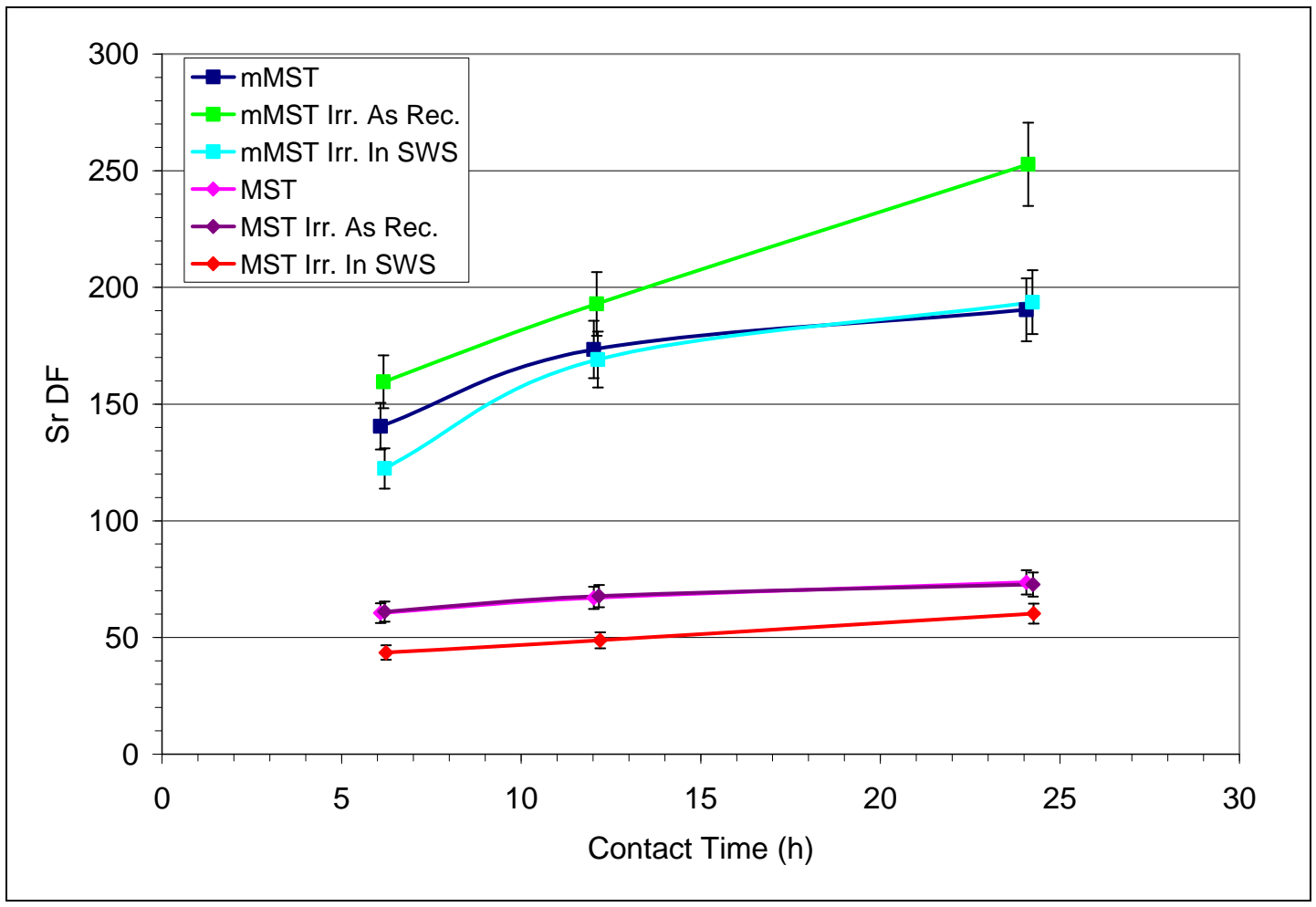

Figure A-2. Sr DF vs. contact time, calculated from gamma scan results. Error bars indicate 1 sigma uncertainty. 


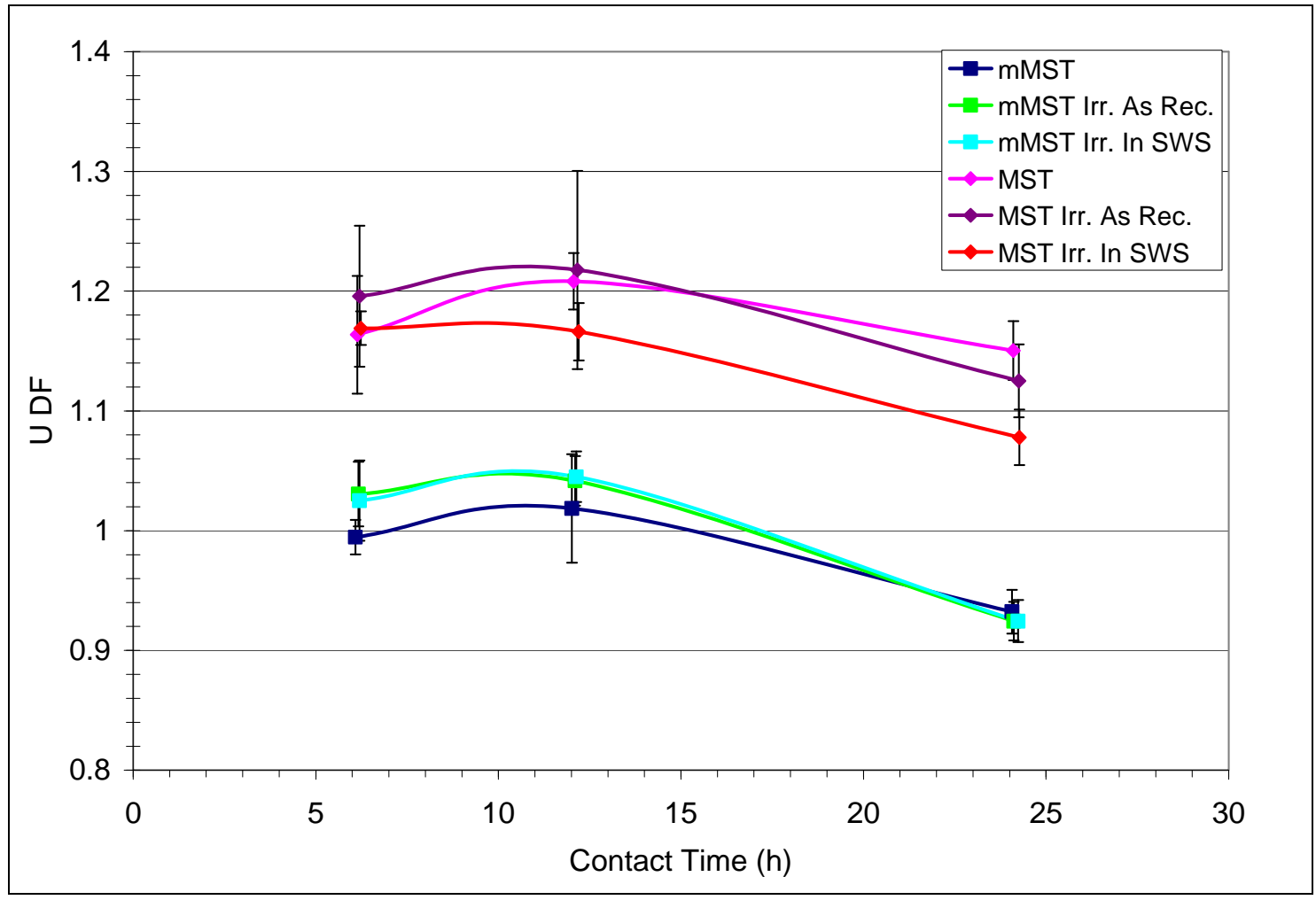

Figure A-3. U DF vs. contact time, calculated from ICP-MS results. Error bars indicate 1 sigma uncertainty.

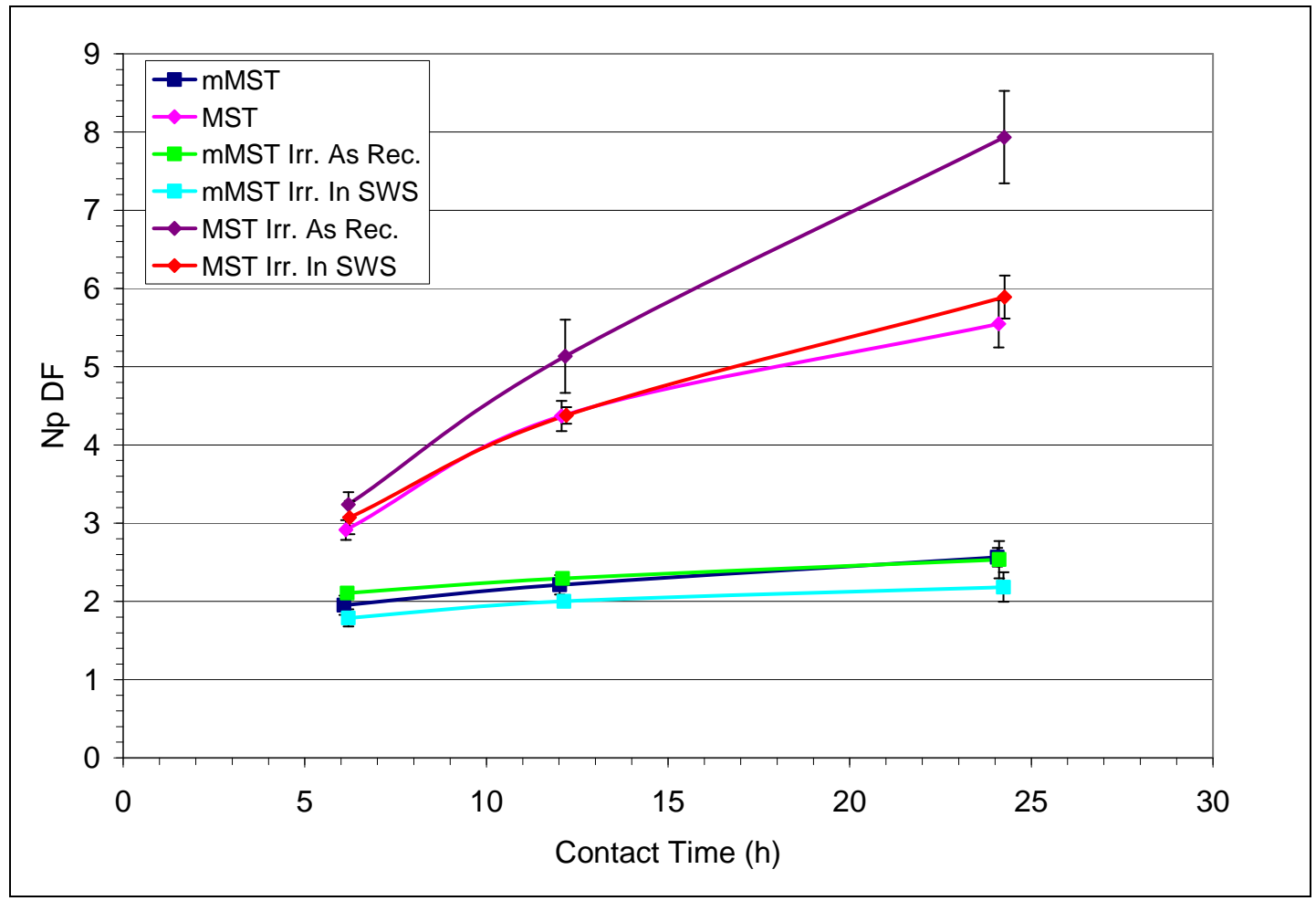

Figure A-4. Np DF vs. contact time, calculated from ICP-MS results. Error bars indicate 1 sigma uncertainty. 


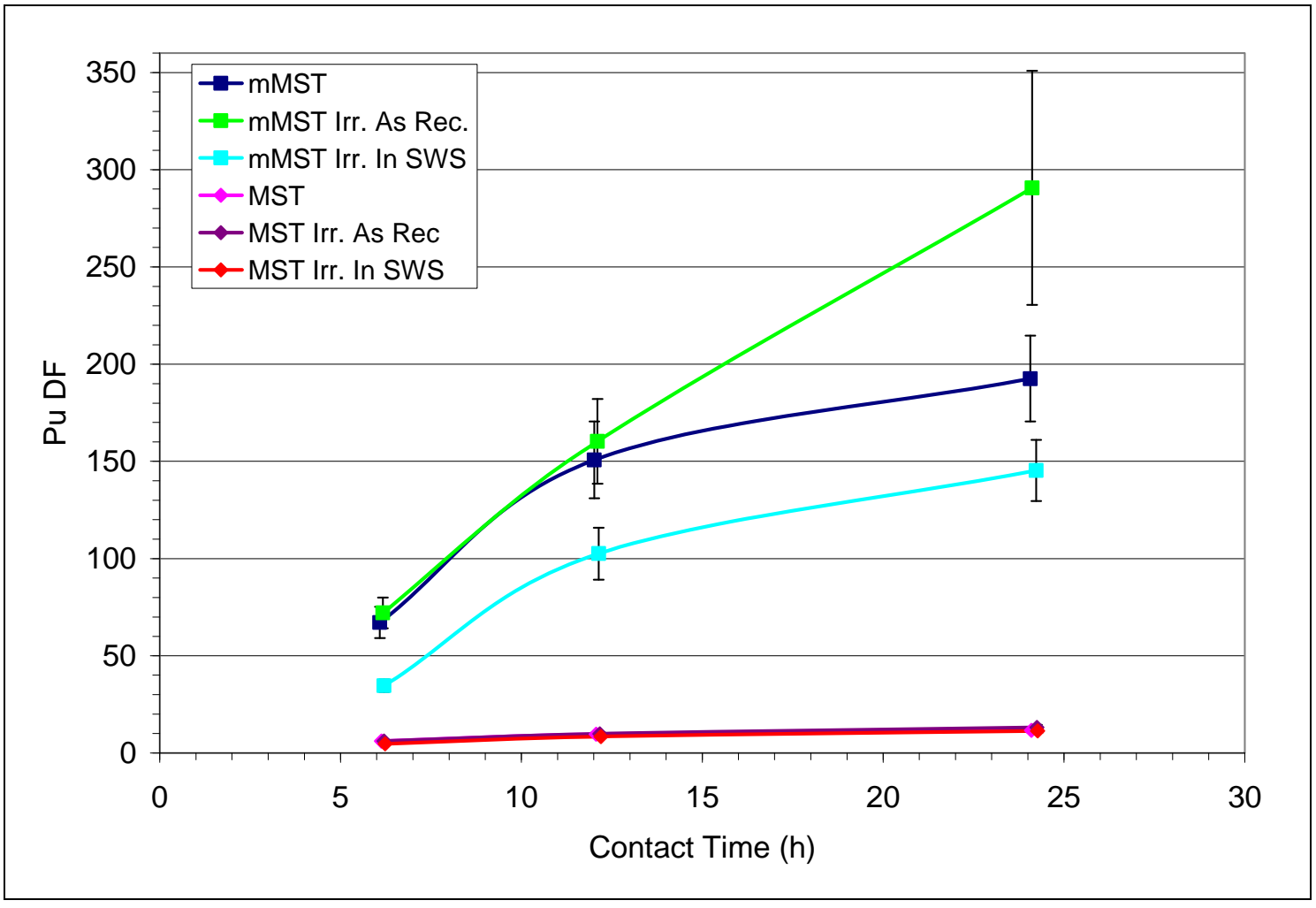

Figure A-5. Pu DF vs. contact time, calculated from PuTTA results. Error bars indicate 1 sigma uncertainty.

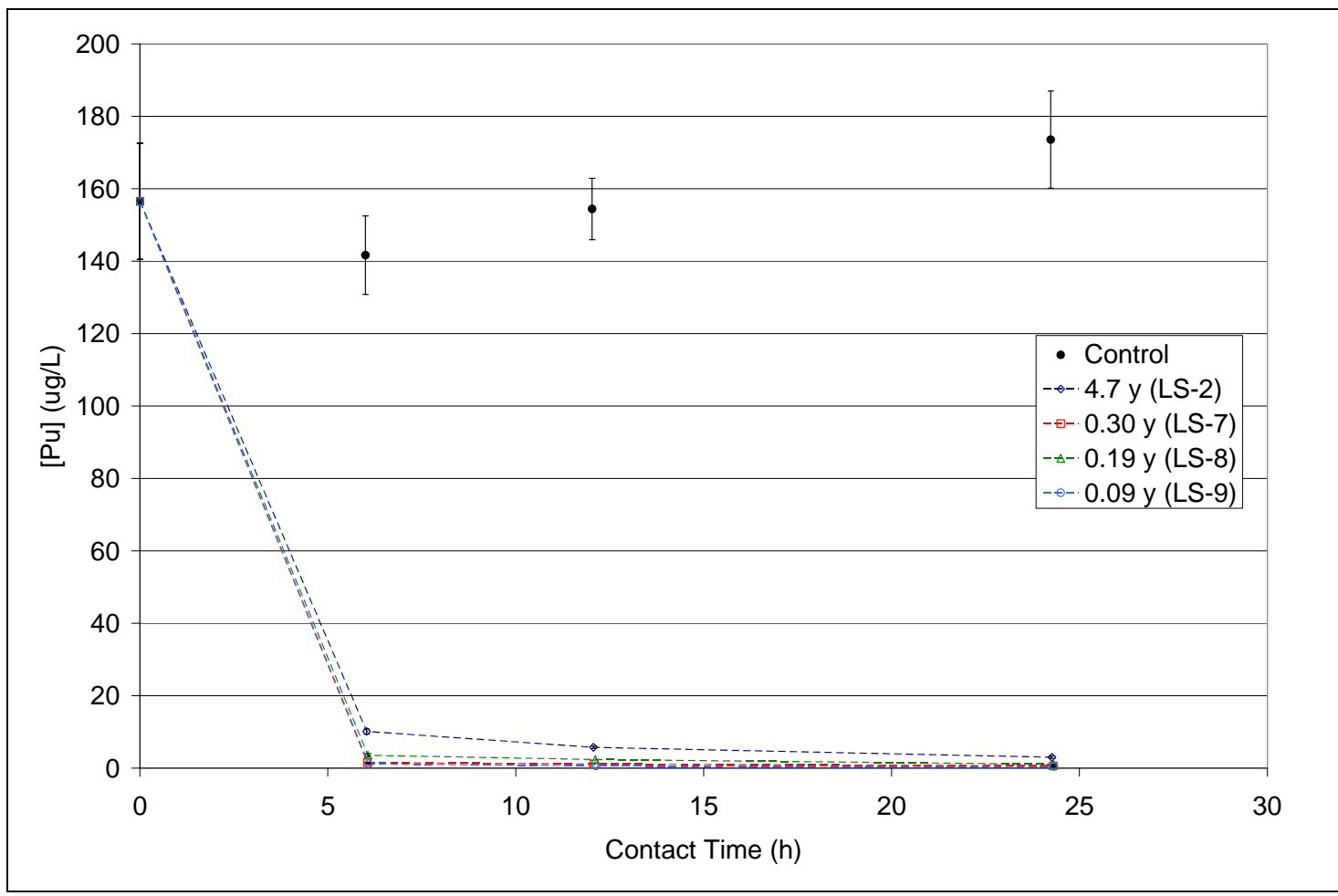

Figure A-6. Pu concentration versus contact time for mMST samples of increasing storage age. 


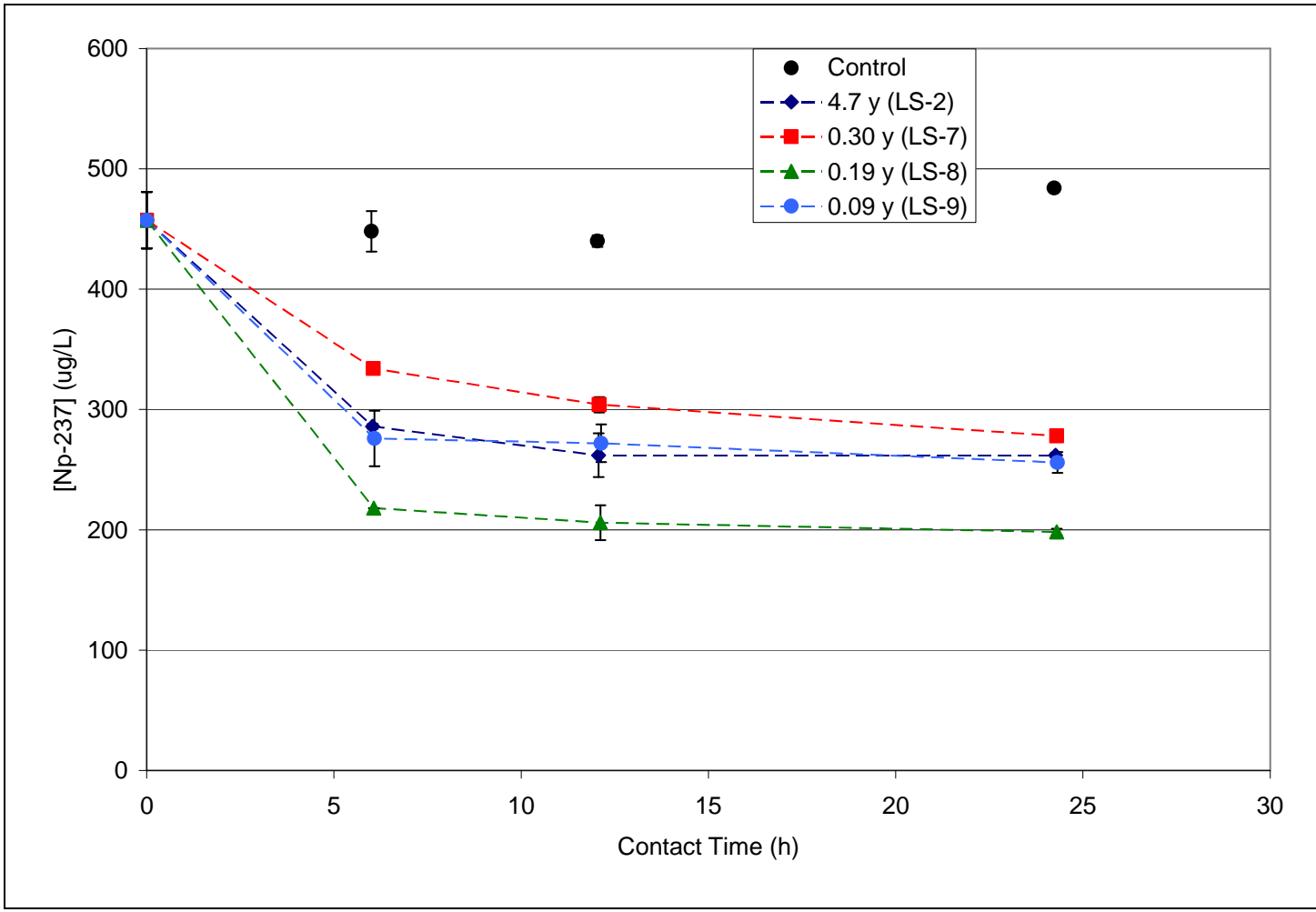

Figure A-7. ${ }^{237} \mathrm{~Np}$ concentration versus contact time for mMST samples of increasing storage age.

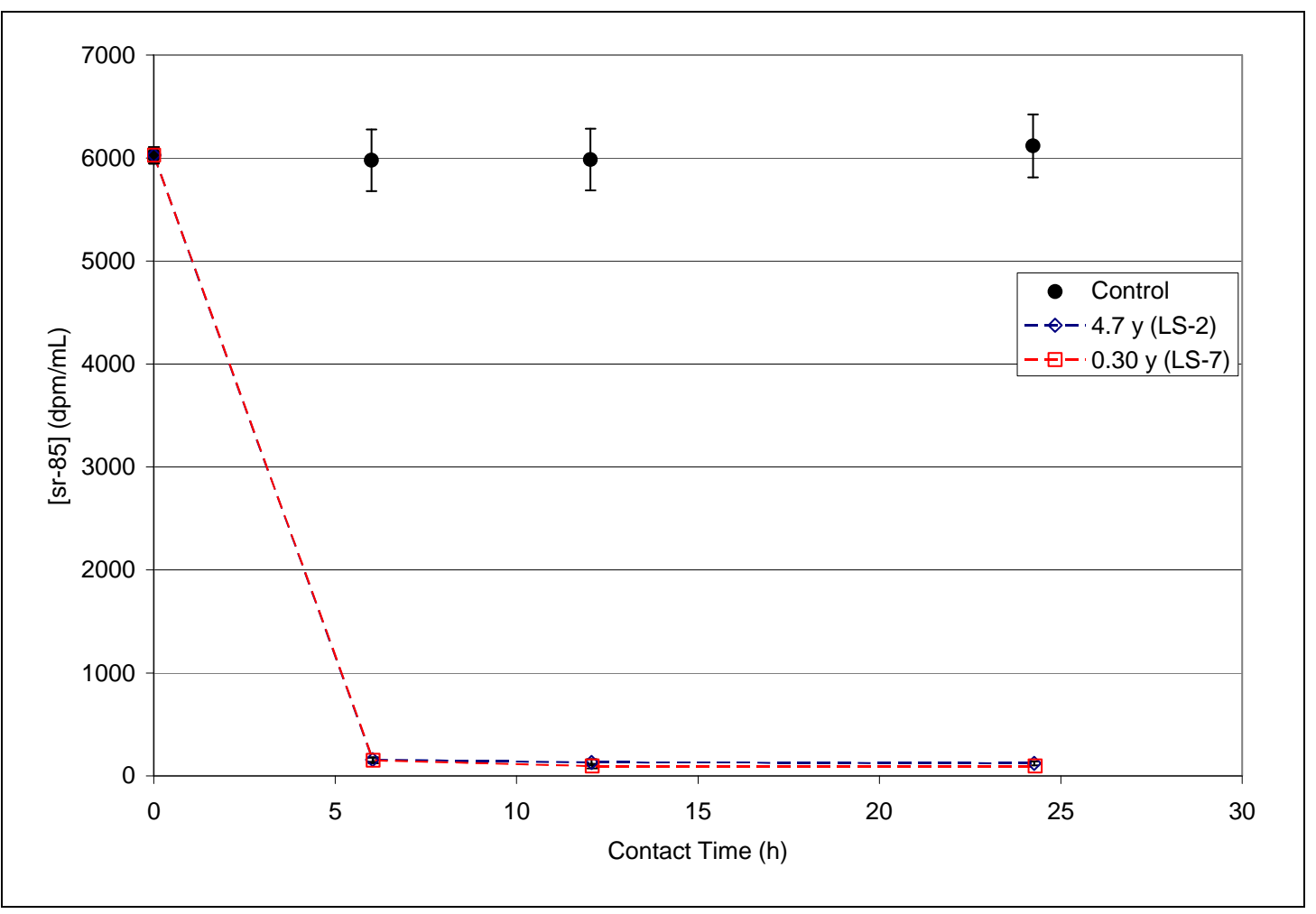

Figure A-8. ${ }^{85} \mathrm{Sr}$ activity versus contact time for mMST samples of increasing storage age. All values for LS-8 (0.19 y) and LS-9 (0.09 y) were below the method detection limit. 


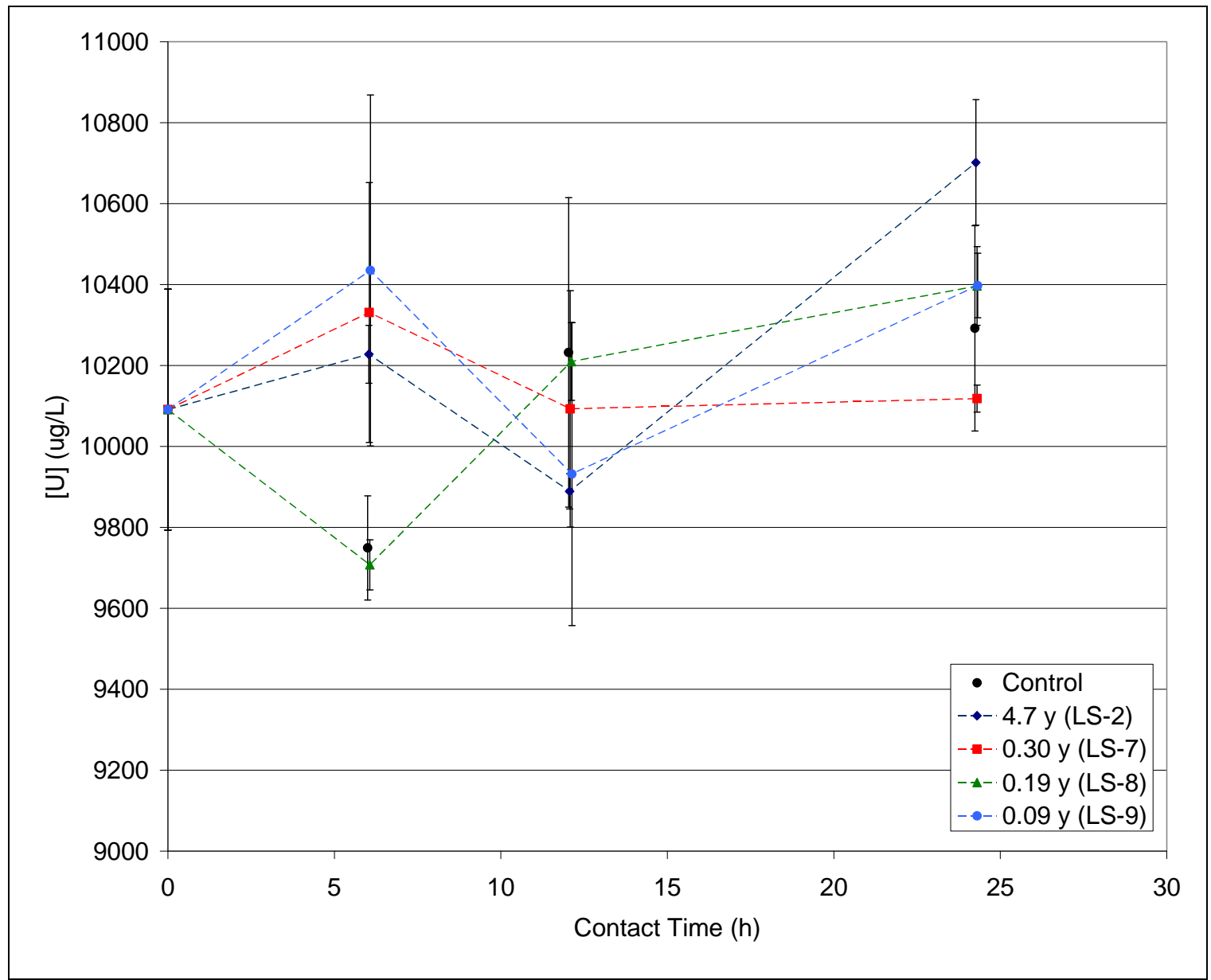

Figure A-9. U concentration versus contact time for mMST samples of increasing storage age. 


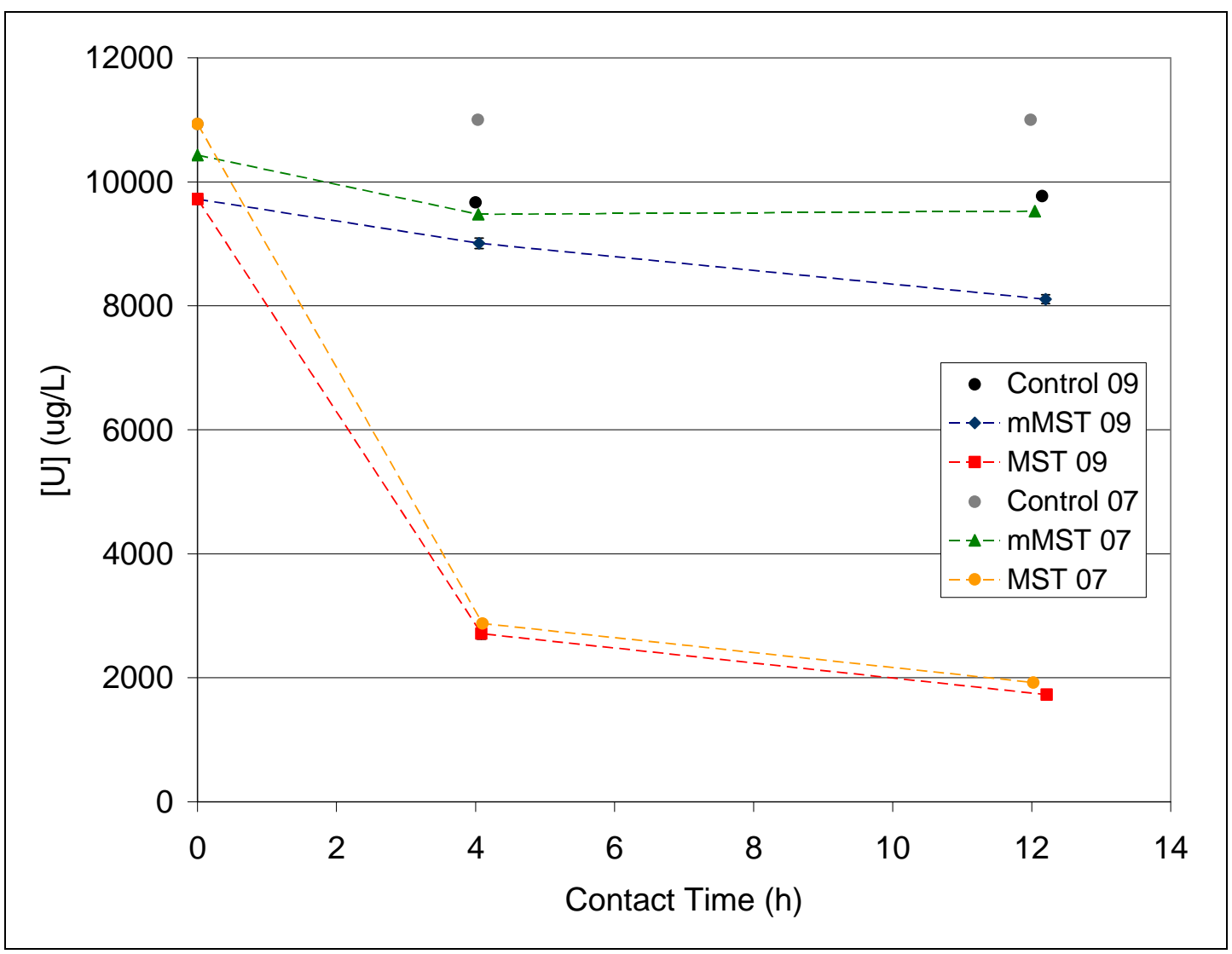

Figure A-10. Uranium concentration versus contact time for mMST and MST measured in December 2009 and October 2007. 


\section{Distribution:}

S. L. Marra, 773-A

A. B. Barnes, 999-W

D. A. Crowley, 773-43A

S. D. Fink, 773-A

J. H. Scogin, 773-A

B. J. Giddings, 786-5A

C. C. Herman, 999-W

F. M. Pennebaker, 773-42A

N. P. Machara, DOE-HQ (Germantown)

W. R. Wilmarth, 773-A

T. B. Peters, $773-42 \mathrm{~A}$

R. O. Voegtlen, 704-71F

R. T. McNew, 704-27S

D. J. Martin, 241-152H

E. J. Freed, 704-56H

S. J. Brown, 241-152H

M. A. Rios-Armstrong, 766-H

T. H. Huff, 766-H

W. B. Brasel, 992-2W

M. R. Norton, Parsons Corp - Silver Bluff Office

R. K. Leugemors, 992-5W 